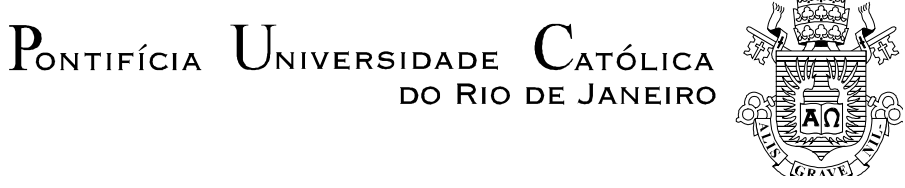

Paulo Guilherme Oliveira de Oliveira

Estudo de Confiabilidade de Sistemas de Controle de Dispositivos de Segurança de Sub-superfície em Poços de Petróleo

Dissertação de Mestrado

Dissertação apresentada como requisito parcial para obtenção do grau de Mestre pelo Programa de Pósgraduação em Engenharia Mecânica do departamento de Engenharia Mecânica da PUC-Rio.

Orientador: Prof. Arthur Martins Barbosa Braga 


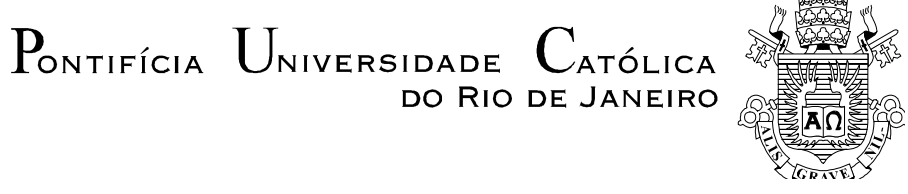

Paulo Guilherme Oliveira de Oliveira

\title{
Estudo de Confiabilidade de Sistemas de Controle de Dispositivos de Segurança de Sub-superfície em Poços de Petróleo
}

Dissertação apresentada como requisito parcial para obtenção do grau de Mestre pelo Programa de PósGraduação em Engenharia Mecânica do Centro Técnico Científico da PUC-Rio. Aprovada pela Comissão Examinadora abaixo assinada.

\author{
Prof. Arthur Martins Barbosa Braga \\ Orientador \\ Departamento de Engenharia Mecânica - PUC-Rio \\ Prof. Wellington Campos \\ Departamento de Engenharia Mecânica - PUC-Rio
}

Dr. Eduardo dos Santos Radespiel

Petrobras

Dr. Manoel Feliciano da Silva Junior CENPES/Petrobras

Prof. Márcio da Silveira Carvalho Coordenador Setorial do Centro Técnico Científico - PUC-Rio

Rio de Janeiro, 29 de Janeiro de 2016 
Todos os direitos reservados. É proibida a reprodução total ou parcial do trabalho sem autorização do autor, do orientador e da universidade.

\section{Paulo Guilherme Oliveira de Oliveira}

Graduou-se em Engenharia Mecânica na UFRJ (Universidade Federal do Rio de Janeiro) em 2004. Fez pós-graduação latu sensu em sistemas offshore (MSO) na COPPE-UFRJ em 2005. Trabalhou como engenheiro mecânico durante três anos na Technip Engenharia. Trabalha como engenheiro de Petróleo na Petrobras desde 2007, atua na coordenação de projetos de implementação de novas tecnologias na área de completação de poços, também participou de grupos de trabalho para revisão de procedimentos de gestão e operacionais da engenharia de poços.

Ficha Catalográfica

Oliveira, Paulo Guilherme Oliveira de

Estudo de confiabilidade de sistemas de controle de dispositivos de segurança de sub-superfície em poços de petróleo / Paulo Guilherme Oliveira de Oliveira ; orientador: Arthur Martins Barbosa Braga. - 2016.

$141 \mathrm{f}$; $30 \mathrm{~cm}$

Dissertação (mestrado)-Pontifícia Universidade Católica do Rio de Janeiro, Departamento de Engenharia Mecânica, 2016. Inclui bibliografia

1. Engenharia mecânica - Teses. 2. Poços. 3. Petróleo. 4. Confiabilidade. 5. Dispositivo de segurança de sub-superfície. 6. Processos de markov. I. Braga, Arthur Martins Barbosa. II. Pontifícia Universidade Católica do Rio de Janeiro. Departamento de Engenharia Mecânica. III. Título. 
À minha mãe Maria das Graças, pela motivação constante.

À minha esposa Ariane, pelo seu apoio e dedicação. 


\section{Agradecimentos}

Aos meus pais, que sempre acompanharam meus estudos com confiança e carinho.

Ao meu orientador Arthur Braga, pelo auxílio nas horas mais difíceis desse período.

À PUC-Rio e, principalmente, ao departamento de Engenharia Mecânica, que permitiu a realização desta dissertação, sempre fornecendo todo suporte necessário.

À Petrobras, pelo apoio e suporte prestado.

Ao professor Pauli Adriano, o qual sem seus ensinamentos eu não seria capaz de realizar este trabalho.

Aos amigos da engenharia de completação, que me incentivaram nessa etapa da vida, incluindo as discussões técnicas, o aprendizado dentro e fora das salas de aula, além do ótimo convívio. Um agradecimento em especial a Wellington Campos, pelos seus ensinamentos, pelas discussões filosóficas, e principalmente pela sua confiança e motivação na reta final deste trabalho.

Aos familiares e amigos, que ajudaram, de forma direta ou indireta, na conclusão deste trabalho.

À minha esposa Ariane, pelo amor, amizade, paciência e auxílio em todos os momentos. 


\section{Resumo}

Oliveira, Paulo Guilherme Oliveira de; Braga, Arthur Martins Barbosa. Estudo de Confiabilidade de Sistemas de Controle de Dispositivos de Segurança de Sub-superfície em Poços de Petróleo. Rio de Janeiro, 2016. 141p. Dissertação de Mestrado - Departamento de Engenharia Mecânica, Pontifícia Universidade Católica do Rio de Janeiro.

Os desafios na construção de poços de petróleo vêm aumentando ao longo do tempo, seja pelo aumento das dificuldades técnicas devido à maior complexidade das áreas a serem desenvolvidas, sejam pelas melhorias nas regras dos órgãos reguladores visando aumentar a segurança. Existem dois pilares que devem nortear um projeto de um poço de petróleo: segurança e produtividade. $\mathrm{O}$ equipamento denominado dispositivo de segurança de sub-superfície e seu sistema de controle podem ser considerados importantes para os dois, pois caso o sistema falhe, obtendo-se um fechamento prematuro do poço, afetará diretamente a produção. Por outro lado, caso a falha ocorra em uma tentativa de fechamento, poderá influenciar nas consequências de um desastre, o que afetaria tanto pessoas como o meio ambiente. $\mathrm{O}$ objetivo deste estudo e comparar a confiabilidade de alguns modelos de sistemas de controle do dispositivo de segurança de sub-superfície, levando em consideração as disposições dos equipamentos ao longo do sistema e suas respectivas taxas de falha. Além disso, a maioria dos estudos de confiabilidade realizados nesta área tem como foco principal a segurança, porém este estudo visa obter um foco de eficiência de produção, e as análises serão baseadas em comparações entre algumas configurações disponíveis do sistema, entre componentes em série e em paralelo, utilizando o modelo de análise de confiabilidade markoviano.

\section{Palavras-chave}

Poços; petróleo; confiabilidade; dispositivo de segurança de sub-superfície; processos de markov. 


\section{Abstract}

Oliveira, Paulo Guilherme Oliveira de; Braga, Arthur Martins Barbosa (Advisor). Reliability Study of Subsurface Safety Valve Control System in Oil Wells. Rio de Janeiro, 2016. 141p. MSc. Dissertation - Departamento de Engenharia Mecânica, Pontifícia Universidade Católica do Rio de Janeiro.

The challenges in well construction have been increasing over time, sometimes by increasing the technical difficulties due to the greater complexity of the areas to be developed, sometimes by the improvements in the rules of regulatory agencies to increase security. There are two pillars that should guide the project of a petroleum well: safety and productivity. The equipment called Subsurface Safety Valve and its control system can be considered important for both pillars, because if the system fails resulting in a premature well closure, it will directly affect the production. On the other hand, if the failure occurs in an attempt to closing it, may influence the consequence of a disaster, which would affect both people and the environment. The objective of this study is to compare the reliability of some control systems models taking into account the equipment positions throughout the system and their failure rates. Furthermore, most reliable studies conducted in this area has mainly focused on safety, but this study has a focus on production efficiency, and the analysis will be based on comparisons between some configurations available for subsurface safety valves control system, including serial and parallel components, using the model of Markov reliability analysis.

\section{Keywords}

Well; oil; reliability; Subsurface safety valve; Markov processes. 


\section{Sumário}

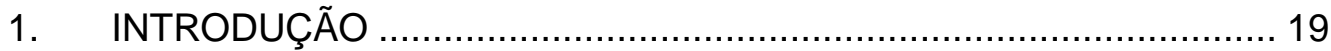

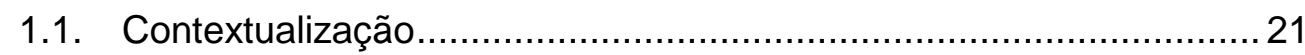

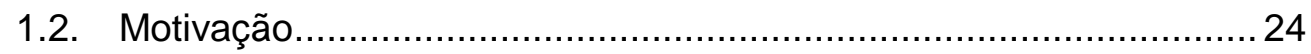

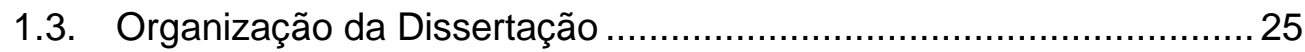

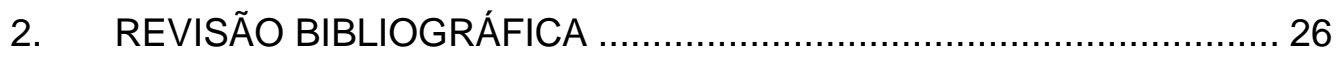

3. ENGENHARIA DE POÇOS DE PETRÓLEO SUBMARINO ….............. 35

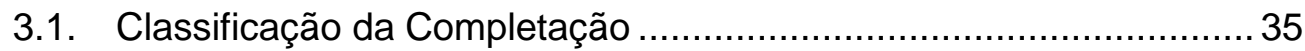

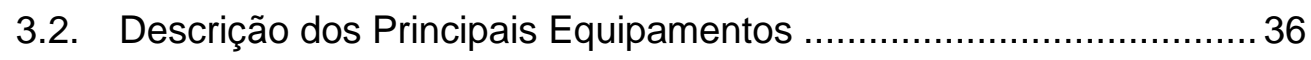

3.2.1. Árvore de NatalvMolhada 36

$\begin{array}{ll}\text { 3.2.2. Suspensor de Coluna } & 37\end{array}$

3.2.3. Umbilical e linhas de controle 38

3.2.4. Dispositivo de segurança de sub-superfície (DSSS) 39

3.3. Sistema de Controle do DSSS ....................................................... 44

4. ENGENHARIA DE CONFIABILIDADE........................................... 47

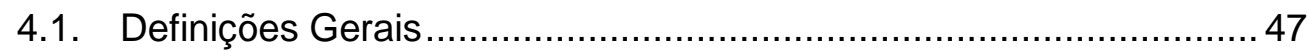

4.2. O Conceito de Falha …………………………..............................

4.2.1. Natureza das falhas 52

4.2.2. Falhas Relacionadas à Idade 56

4.2.3. Falhas Aleatórias - Componentes Complexos 56

4.2.4. O Conceito de Falha para o Trabalho 56

4.3. Distribuições Estatísticas ................................................................ 58

4.3.1. Distribuição exponencial 58

4.3.2. Distribuição de Weibull 59

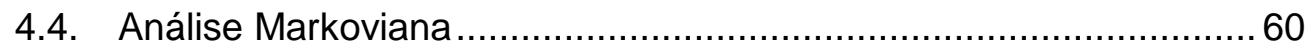

4.4.1. Processos de Markov 61

4.4.2. Análise de 1 componente 62

4.4.3. Dois componentes em paralelo 63

4.4.4. Três componentes (A e B em paralelo, $C$ em série) 65 
4.4.5. Sistemas dois componentes - Equipamentos ativos independentes 68

4.4.6. Sistema em série 69

4.4.7. Sistema em paralelo ativo - cargas independentes 70

4.4.8. Sistemas dois componentes paralelo ativo - cargas compartilhadas $\quad 71$

4.4.9. Sistema paralelo em espera (Standby System) 74

$\begin{array}{ll}\text { 4.4.9.1. Sistema ideal } & 74\end{array}$

4.4.9.2. Falha da unidade "em espera" 77

4.4.9.3. Falha no equipamento de acionamento do sistema em espera 79

4.4.9.4. Efeitos combinados 81

4.4.10. Sistemas com mais de dois componentes 81

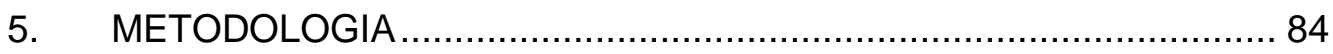

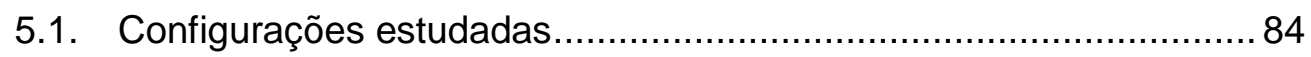

5.1.1. Sistemas tipo A (hidráulico-direto) 85

5.1.2. Sistemas tipo B (eletro-hidráulico multiplexado) 90

5.1.3. Sistema Tipo C - Elétrico 92

5.2. Software Utilizado ................................................................ 95

5.3. Dados Utilizados ................................................................. 97

5.3.1. Estimador da taxa de falha 98

5.3.2. Intervalo de confiança da taxa de falha 100

$\begin{array}{ll}\text { 5.3.3. Propagação das incertezas } & 101\end{array}$

6. ANÁLISE DOS RESULTADOS .................................................... 103

6.1. Caso A1 - Sistema HD sem redundância ................................... 103

6.2. Caso A2 - Sistema HD com redundância no umbilical.................. 105

6.3. Caso A3 - Sistema HD com duas redundâncias no umbilical ........ 108

6.4. Caso A4 - Sistema HD com redundância na linha de controle....... 111

6.5. Caso A5 - Sistema HD com redundância na linha de controle e no umbilical 
6.6. Caso A6 - Sistema HD com redundância na LC e no UC e falha no acionamento

6.7. Caso B1 - Sistema EH - ANM Multiplexada .................................119

6.1. Caso B2 - Sistema EH - ANM Multiplexada com redundância na LC 123

6.2. Caso C1 - Sistema "elétrico direto" sem redundância.................... 126

6.3. Caso C2 - Sistema multiplexado com controle elétrico .................. 129

6.4. Comparação dos Resultados .................................................... 131

7. CONCLUSÕES E RECOMENDAÇÕES …................................... 135

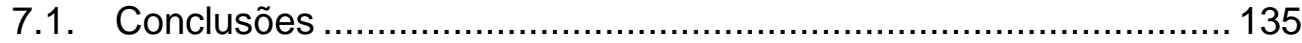

7.2. Recomendações para Próximos Trabalhos ................................. 137

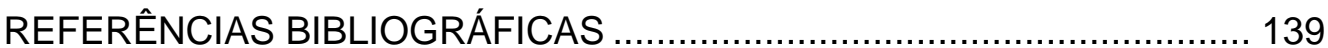




\section{Lista de figuras}

Figura 1-1 - Ciclo de vida de um poço de petróleo .........................................20

Figura 1-2 - Erupção de um poço de petróleo .................................................21

Figura 1-3 Lagoa de óleo nas proximidades de um poço de petróleo .................22

Figura 1-4 - Exemplo de duas barreiras de segurança - Fonte: NORSOK-D10.23

Figura 3-1 - Comparação entre árvore de natal seca e molhada ........................36

Figura 3-2 - Árvore de Natal Molhada (ANM) ................................................ 37

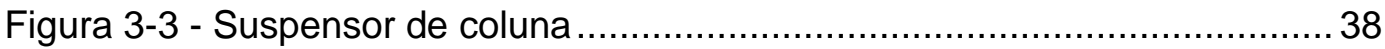

Figura 3-4 - Umbilical de Controle.............................................................. 38

Figura 3-5 - Dispositivo de Segurança de Sub-Superfície (DSSS) ....................41

Figura 3-6 - DSSS Auto equalizável............................................................. 43

Figura 3-7 - Esquemático do sistema de controle do DSSS.............................44

Figura 4-1 Esquemático - Curva da Banheira ............................................... 48

Figura 4-2 Tipos de probabilidades condicionais de falhas .............................53

Figura 4-3 - Estudo da probabilidade condicional de falhas ao longo do tempo.54

Figura 4-4 - Diagrama de blocos - 1 componente ........................................62 62

Figura 4-5 - Diagrama de transição - 1 componente ....................................... 63

Figura 4-6 - Diagrama de blocos - 2 componentes em paralelo ........................ 64

Figura 4-7 - Diagrama de transição - dois componentes em paralelo .................64

Figura 4-8 - Diagrama de blocos - três componentes....................................65

Figura 4-9 - Diagrama de transição - três componentes ..................................66

Figura 4-10 - Diagrama de transição - equipamentos ativos independentes ......68

Figura 4-11 - Diagrama de transição - sistema em série .................................. 70

Figura 4-12 - Diagrama de transição - sistema paralelo ativo - cargas

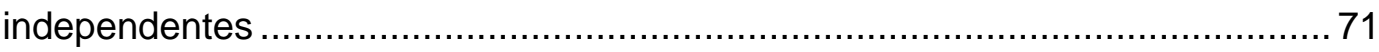

Figura 4-13 - Diagrama de transição - sistema paralelo ativo - cargas

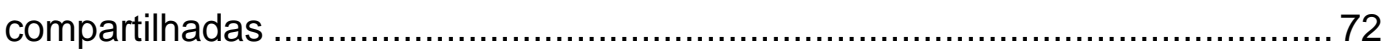

Figura 4-14 - Influencia do incremento da carga na confiabilidade.................... 74 
Figura 4-15 - Diagrama de transição - sistema paralelo em espera 75

Figura 4-16 - Comparação de R(t): sist. paralelo ativo x sist. paralelo standby .. 77

Figura 4-17 - Diagrama de transição - falha da unidade "em espera" 77

Figura 4-18 Influencia da falha da unidade de backup na confiabilidade do sistema

Figura 4-19 - Diagrama de transição - falha no equip. de acionamento do sist.

espera 80

Figura 4-20 - Três componentes em paralelo ............................................... 82

Figura 4-21 - Diagrama de transição - três componentes em paralelo ................83

Figura 5-1 - Sistema A1 - HD sem Redundância............................................. 86

Figura 5-2 - Sistema A2 - HD com Redundância no Umbilical ..........................8 87

Figura 5-3 - Sistema A3 - HD com duas redundâncias do Umbilical ...................88

Figura 5-4 - Sistema A4 - HD com Redundância na Linha Hidráulica .................88

Figura 5-5 - Sistema A5 - HD com redundância na LC e no UC ....................... 89

Figura 5-6 - Sistema A6 - HD com redundância no UC e LC e falha no acionamento

Figura 5-7 - Sistema B1 - Hidráulico - ANM Multiplexada sem redundância na LC

Figura 5-8 - Sistema B2 - Hidráulico - ANM Multiplexada com redundância na LC

Figura 5-9 - Sistema C1 - Sistema Elétrico sem Redundância...........................94

Figura 5-10 - Sistema C2 - Sistema Elétrico Multiplexado ...............................99

Figura 5-11 - Visualização dos estados de Markov ...........................................95

Figura 5-12 - Editor de propriedades - Detalhamento do diagrama...................96

Figura 5-13 - Editor de propriedades - Detalhamento do nó...............................96

Figura 6-1 - Simplificação do sistema A1 ................................................... 103

Figura 6-2 - Estados possíveis do sistema A1 ........................................... 104

Figura 6-3 - Confiabilidade x Tempo - Sistema HD equipamentos em série .... 105

Figura 6-4 - Simplificação de sistema A2 106 
Figura 6-5 - Diagrama de transição de estados para sistema A2 107

Figura 6-6 - Confiabilidade x Tempo - Sistema HD com redundância no UC ... 108 Figura 6-7 - Simplificação do sistema A3 ............................................... 108

Figura 6-8 - Diagrama de transição de estados para sistema A3 .................... 109

Figura 6-9 - Confiabilidade x Tempo - Sistema HD com duas redundâncias no UC 110

Figura 6-10 - Simplificação do sistema A5 111

Figura 6-11 - Diagrama de transição de estados para sistema A4 112

Figura 6-12 - Confiabilidade x Tempo - Sistema HD com redundância na LC.. 113

Figura 6-13 - Simplificação do sistema A5

Figura 6-14 - Diagrama de transição de estados para sistema A5

Figura 6-15 - Confiabilidade x Tempo - Sistema HD com redundância no

UC e na LC

Figura 6-16 - Simplificação do sistema A6 116

Figura 6-17 - Descrição dos estados do sistema A6 116

Figura 6-18 - Diagrama de transição de estados para sistema A6

Figura 6-19-R(t) $\times T$ - Sist HD redundância na LC e UC e falha no acionamento

Figura 6-20 - Simplificação do sistema B1 120

Figura 6-21 - Diagrama de transição de estados para sistema B1 121

Figura 6-22 - Confiabilidade x Tempo - Sistema multiplexado 122

Figura 6-23 - Simplificação do sistema B2 123

Figura 6-24 - Diagrama de transição de estados para sistema B2 125

Figura 6-25 - Confiabilidade x Tempo - Sistema multiplex com redundância na LC. 126

Figura 6-26 - Simplificação do sistema C1 127

Figura 6-27 - Diagrama de transição de estados para sistema C1 127

Figura 6-28 - Confiabilidade x Tempo - Sistema elétrico direto sem redundância 128 
Figura 6-29 - Simplicação do sistema C2.

Figura 6-30 - Diagrama de transição de estados para sistema C2. 130

Figura 6-31 - Confiabilidade x Tempo - Sistema multiplex com acionamento elétrico.

Figura 6-32 - Gráfico de comparação de Confiabilidade x Tempo - Todos os sistemas 


\section{Lista de Tabelas}

Tabela 2-1 - Graus de validação - API 14A 12th edição....................................30

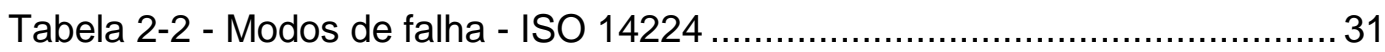

Tabela 2-3 - Definição de falha para o sistema DSSS. Fonte: Molnes ............... 32

Tabela 4-1 - Classificação dos Processos de Markov ......................................62

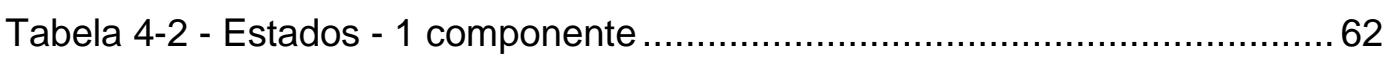

Tabela 4-3 - Tabela de estados - dois componentes ....................................64

Tabela 4-4 - Tabela de estados - três componentes .......................................65

Tabela 4-5 - Tabela de estados - Equipamentos em série ..............................70

Tabela 4-6 - Tabela de estados - Sistema paralelo ativo - cargas

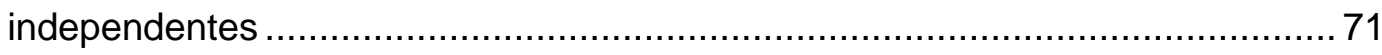

Tabela 4-7 - Tabela de descrição dos estados - Sistema paralelo em espera ...75

Tabela 4-8 - Tabela de estados - três componentes ........................................ 82

Tabela 5-1 - Vantagens e desvantagens dos sistemas hidráulico e elétrico ......93

Tabela 5-2 - Informações de taxa de falha utilizadas para o estudo...................98

Tabela 6-1 - Descrição dos estados do sistema A1 ................................... 104

Tabela 6-2 - Taxas de falha dos equipamentos - Sistema A1 ....................... 104

Tabela 6-3 - Descrição dos estados do sistema A2 …................................... 106

Tabela 6-4 - Taxas de falha dos equipamentos - Sistema A2 ...................... 107

Tabela 6-5 - Descrição dos estados do sistema A3 ..................................... 109

Tabela 6-6 - Taxas de falha dos equipamentos - Sistema A3 ....................... 110

Tabela 6-7 - Descrição dos estados do sistema A4 .................................... 111

Tabela 6-8 - Taxas de falha dos equipamentos - Sistema A4 ....................... 112

Tabela 6-9 - Descrição dos estados do sistema A5 …................................... 114

Tabela 6-10 - Taxas de falha dos equipamentos - Sistema A5 ...................... 115

Tabela 6-11 - Taxas de falha dos equipamentos - Sistema A6 ..................... 118

Tabela 6-12 - Descrição dos estados do sistema B1 ................................... 121

Tabela 6-13 - Taxas de falha dos equipamentos - Sistema B1 ...................... 122 
Tabela 6-14 - Descrição dos estados do sistema B2 124

Tabela 6-15 - - Taxas de falha dos equipamentos - Sistema B2 125

Tabela 6-16 - Descrição dos estados do sistema C1 127

Tabela 6-17 - Taxas de falha dos equipamentos - Sistema C1 128

Tabela 6-18 - Descrição dos estados do sistema C2 129

Tabela 6-19 - Taxas de falha dos equipamentos - Sistema C2 130

Tabela 6-20 - Descrição dos sistemas - Tabela resumo 132

Tabela 6-21 - Comparação das métricas 133 


\section{Lista de Abreviações}

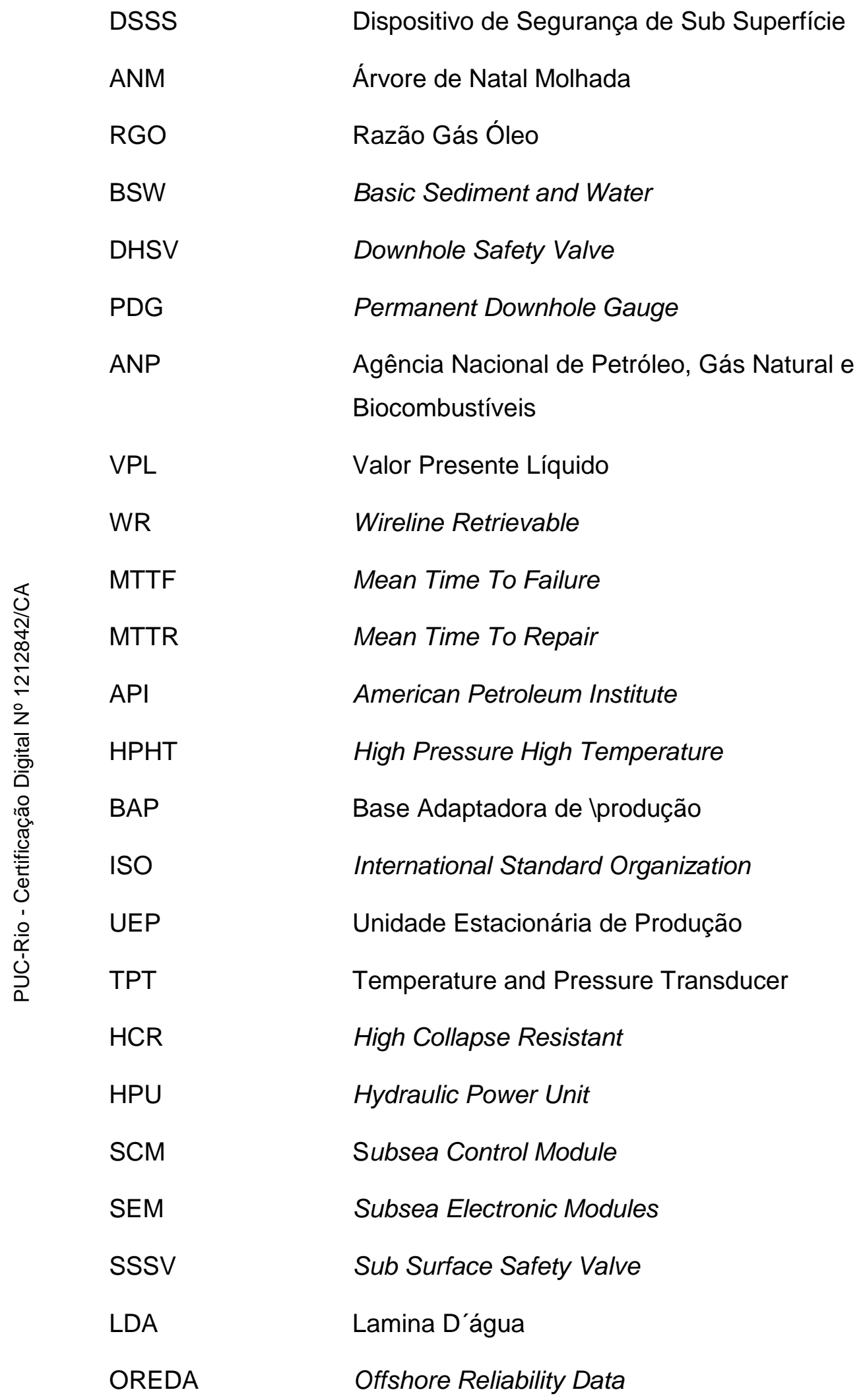




\section{Lista de Símbolos}

$\lambda$

$\mu$

$\alpha$

$\beta$

t

$\eta$

$\theta$

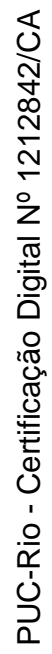

Taxa de falha

Taxa de reparo

Parâmetro de escala da distribuição de Weibull

Parâmetro de forma da distribuição de Weibull

Tempo

Número de falhas observadas no intervalo de tempo $t$

Taxa de falha média

Desvio padrão 


\section{INTRODUÇÃO}

A dificuldade de produzir hidrocarbonetos vem crescendo ao longo do tempo, pois a cada ano que passa as reservas encontradas estão cada vez mais em lugares inóspitos e de difícil extração, como no pré-sal.

Os dois pilares para que se possa desenvolver um projeto de engenharia, principalmente na área construção de poços de petróleo, são a segurança e o retorno do investimento, onde este segundo item pode ser dividido em produtividade e custo.

Em um poço de petróleo, existem vários sistemas de segurança para que a produção seja feita de forma sempre segura e controlada, sendo alguns deles instalados durante a fase de perfuração do poço e, outros, instalados e testados durante a completação do poço (ANM, colunas de produção, obturadores (packers), DSSS etc).

A figura 1.1 representa o ciclo de vida de um poço de petróleo, desde a sua fase de projeto até seu abandono definitivo. Uma vez definido pela área de reservatório que um poço será perfurado, inicia-se o seu projeto de construção. Então o poço é perfurado e, na sequência, completado, ficando assim disponível para a produção (ou injeção, no caso de um poço injetor).

Porém, ao longo da vida produtiva do campo, o declínio da produção de hidrocarbonetos (óleo e/ou gás) é algo inevitável, e novas intervenções em poços ou até mesmo novos projetos de poços são demandados, a fim de se manter a produção da unidade de operação do campo pelo maior tempo possível. Paralelamente ao declínio de produção, a ocorrência de aumento de BSW (água produzida) e RGO (produção de gás) também podem demandar intervenções em poços a fim de se isolar zonas do poço, entre outros objetivos. Problemas de integridade também podem aparecer, e tais problemas necessariamente demandam intervenções para se reestabelecer as condições de integridade conforme especificadas no projeto original do poço. Uma vez que o poço se encontra fechado com a necessidade de intervenção, é realizado um estudo de viabilidade técnico-econômica. Uma vez avaliada positivamente, uma sonda é planejada para reentrar no poço e realizar a intervenção para reestabelecer a produção. O poço fica neste "ciclo" até que a análise econômica de intervenção não seja mais positiva. Neste ponto de sua vida produtiva, é planejada e realizada a intervenção de abandono definitivo do poço. 


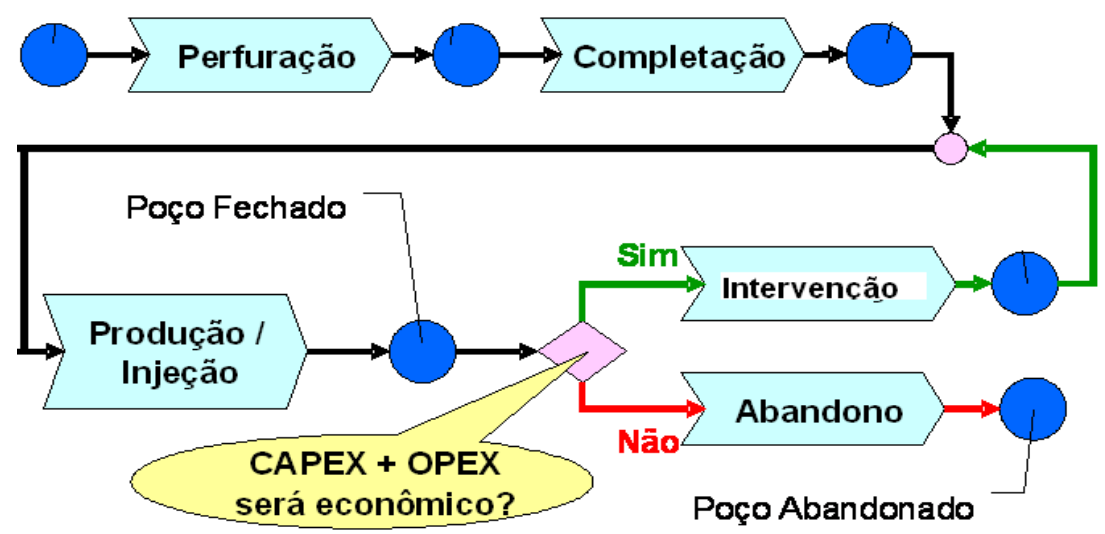

Figura 1-1 - Ciclo de vida de um poço de petróleo

Diferente da maioria dos estudos já realizados, os quais focam sua confiabilidade visando a segurança, este trabalho pretende obter um foco de eficiência de produção, estudando um dos sistemas de segurança de um poço de petróleo, o dispositivo de segurança de sub-superfície (DSSS), mais conhecido como DHSV (Downhole Safety Valve) e seu sistema de controle. Esta análise será baseada em comparações entre algumas configurações disponíveis do sistema de controle do DSSS, entre componentes em série e em paralelo, baseado no modelo de análise de confiabilidade markoviano.

Dentre os métodos utilizados no cálculo de atributos de confiabilidade, o markoviano é um dos mais poderosos. Ele modela o sistema em evidência por intermédio dos estados intermediários que o sistema pode assumir e as respectivas transições entre eles. Em confiabilidade, um estado representa uma combinação de componentes, cada um dos quais em um estado de falha ou funcionamento. Assim, um sistema de n componentes terá um espaço com, no máximo, $\mathrm{N}=2^{n}$ estados. Com o passar do tempo, o sistema deverá evoluir caminhando entre estes estados e as falhas e reparos que os componentes sofrem com o passar do tempo são os mecanismos de mudança de um estado para outro.

O conceito de confiabilidade está diretamente relacionado com a credibilidade que se tem em um produto, equipamento ou sistema. A análise de confiabilidade se caracteriza principalmente por uma avaliação probabilística da falha de um sistema / produto em fase de projeto, e a qualidade da manutenção e operação dos equipamentos são essenciais para que a confiabilidade de projeto seja mantida. 


\subsection{Contextualização}

Posto de maneira bem simples, a completação nada mais é do que a conexão do reservatório à unidade de produção na superfície, através da qual os fluidos produzidos são conduzidos de maneira segura e eficiente até a superfície. Uma definição mais abrangente seria:

A de transformação do esforço de perfuração em uma unidade produtiva completamente equipada e com os requisitos de segurança atendidos, pronta para produzir óleo e gás, gerando receitas.

Nos primeiros dias da indústria de petróleo, poucas eram as atividades definidas nos dias de hoje como completação de poços. Um poço era perfurado e dava o ar de sua graça através de erupções, como o mostrado na Figura 1-2.

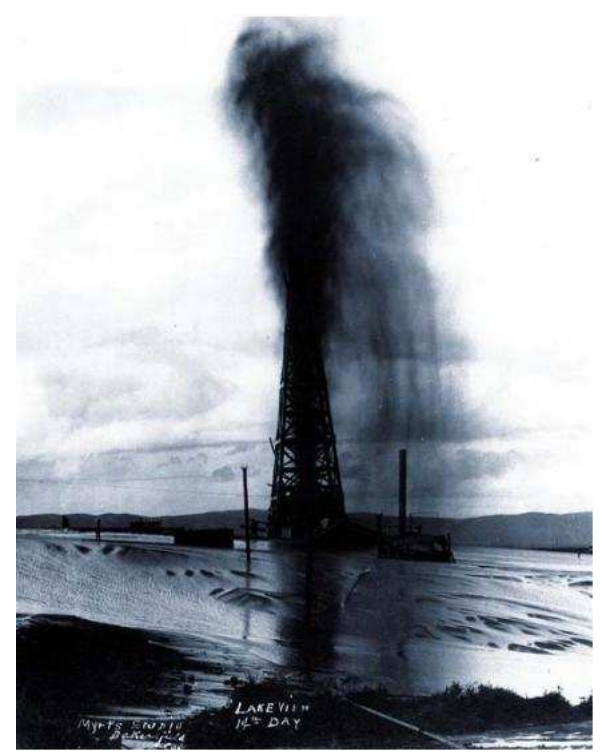

Figura 1-2 - Erupção de um poço de petróleo

O blow-out (erupção) do poço era extinto através de cargas de explosivos, que também ajudavam a estimular o poço, no sentido que as cargas promoviam o fraturamento e pulverização da rocha do intervalo produtor, de forma a aumentar a produtividade do poço. 


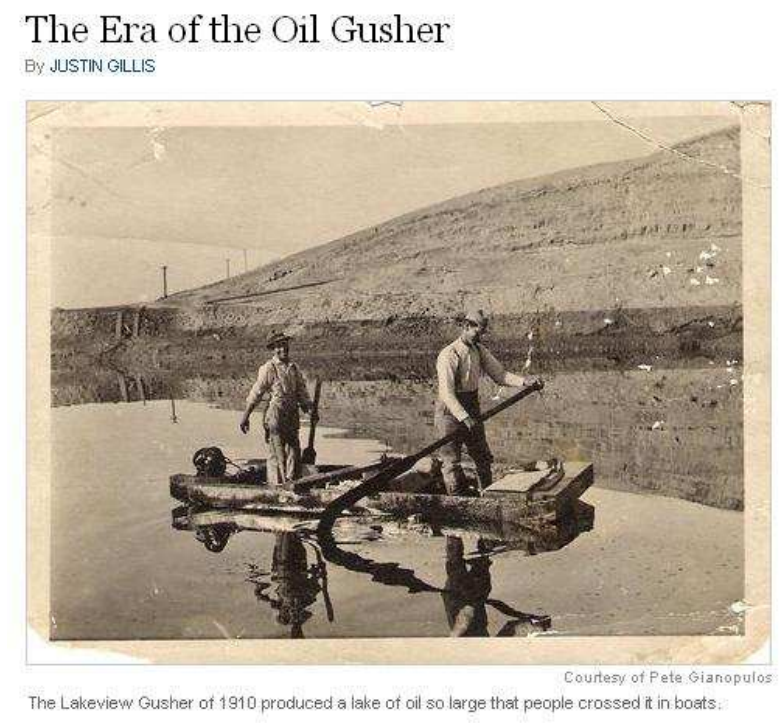

Figura 1-3 Lagoa de óleo nas proximidades de um poço de petróleo

Como é observado na figura acima, o poço produzia para verdadeiras "lagoas de óleo" formadas nas redondezas do poço, algo inconcebível em termos de proteção ambiental. Além disso, cabe ressaltar a ineficiência operacional que eventualmente pode representar a produção do poço com a vazão baseada no potencial máximo do mesmo. Relembrando estes fatos históricos, e reconhecendo a evolução da regulamentação da indústria de petróleo, tanto do ponto de vista de segurança e meio-ambiente como puramente do ponto de vista de eficiência de projeto, nos auxilia a entender como as atividades de completação foram sendo desenvolvidas através de demandas tecnológicas básicas ao longo destes mais 150 anos de história.

A preocupação com a integridade do poço é dominante em um projeto de completação. O conceito mundialmente adotado na indústria de petróleo da necessidade de duas barreiras de segurança durante toda a vida do poço (perfuração, completação, produção e eventuais intervenções para manutenção, ou workovers) pressupõe a existência de dois envelopes de contenção de eventual vazamento de fluido do reservatório até o ambiente, seja a terra ou o fundo do mar, ou seja, qualquer caminho que o fluido produzido "tomaria" até o meio ambiente, ele "teria que atravessar" dois conjuntos de componentes chamados de barreiras de segurança - que funcionam bloqueando sua passagem. Tais envelopes contém dispositivos de segurança, que são barreiras de segurança operadas remotamente, ou seja, a qualquer momento elas podem ser fechadas. Por exemplo: a coluna de produção e a válvula de segurança de sub-superfície, instalada abaixo da árvore de natal, formam o envelope primário. Externamente 
ao envelope primário, o espaço anular entre a coluna de produção e o revestimento de produção, contando com as válvulas da árvore de natal e o packer de produção, formam o envelope secundário de barreiras de segurança.

A norma NORSOK D-010 define integridade de poço como: "Aplicação de soluções técnicas operacionais e organizacionais para reduzir o risco de descargas não controladas de fluidos do reservatório ao longo do ciclo de vida do poço" (tradução livre.). A Figura 1-4 ilustra os dois envelopes de barreiras de segurança (NORSOK D-10, 2013, p.21):

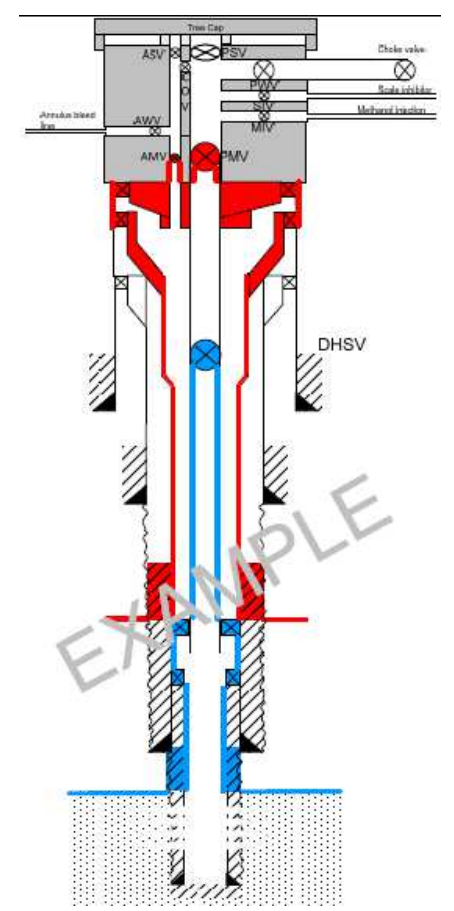

Figura 1-4 - Exemplo de duas barreiras de segurança - Fonte: NORSOK-D10

Segundo Fonseca (2012, p. 12), podemos definir "segurança operacional" como "estado no qual os riscos de lesão às pessoas, dano às instalações, impacto à sociedade ou a degradação do meio ambiente são reduzidos e mantidos em um nível aceitável ou abaixo do mesmo".

Além disso, qualquer projeto de completação tem por premissa básica a eficiência operacional ao longo de toda a vida do poço. O diâmetro da coluna de produção, por exemplo, deve ser escolhido de modo que maximize a vazão de óleo dentro de um envelope operacional pré-determinado (faixas de pressão e vazão nas quais o poço deve operar). Em resumo, a completação de poços objetiva equipar o poço perfurado para a produção, da forma mais eficiente 
possível, garantindo que o poço esteja íntegro a qualquer momento de sua vida produtiva.

Logo, a integridade de poço e a confiabilidade dos equipamentos e materiais utilizados são fundamentais para que intervenções para manutenção / correção futuras sejam minimizadas e até mesmo evitadas. Porém, o declínio da produção de hidrocarbonetos (óleo e/ou gás) é algo inevitável ao longo da vida produtiva do campo, e com este declínio da produção, novas intervenções ou até mesmo novos projetos de poços são demandadas a fim de se manter a produção da unidade de operação do campo pelo maior tempo possível. Paralelamente ao declínio de produção, a ocorrência de aumento de BSW (água produzida) e RGO (produção de gás) também podem demandar intervenções em poços a fim de se isolar zonas do poço etc. Problemas de integridade também podem aparecer (por exemplo, ANM com válvula não operacional), e tais problemas necessariamente demandam intervenções no poço para se reestabelecer as condições de integridade conforme especificadas no projeto original do poço. Por isso faz muito sentido a seguinte regra "quanto mais cara é a intervenção (poço submarino, por exemplo), mais confiáveis devem ser os equipamentos instalados no poço". Ou seja: em geral, maiores custos de intervenção com sonda requerem projetos mais robustos.

\subsection{Motivação}

O presente estudo foi originado pela necessidade de se avaliar com detalhes e estabelecer uma metodologia de análise da confiabilidade do sistema de controle de um dispositivo de segurança de sub-superfície.

Nos últimos anos, a utilização deste sistema de segurança na fase de produção do poço de petróleo no Brasil foi limitada, graças a vários estudos realizados por empresas internacionais, mostrando que existia certa característica de poços chamados poços isolados - em que estariam mais seguros sem a utilização deste sistema, visto o grande número de falhas ocorridas no sistema, causando assim intervenções para a correção destes problemas (MOREIRA; JORGE, 2004; MOLNES, 2004).

Porém, após o acidente de Macondo em 2010, no Golfo do México, a Agência Nacional de Petróleo, Gás Natural e Biocombustíveis (ANP), vem reavaliando a necessidade de utilização deste sistema e o resultado é que todos os poços 
marítimos construídos atualmente estão deverão ter uma DSSS em sua completação.

O objetivo do estudo é poder avaliar a atual configuração do sistema e comparar com algumas possibilidades de otimização desta configuração, do ponto de vista de disponibilidade, utilizando dados históricos da indústria como um todo, em conjunto com análises estatística de confiabilidade de sistemas.

\subsection{Organização da Dissertação}

Este trabalho está dividido em 7 capítulos. O capítulo 2 apresenta uma revisão bibliográfica, no capítulo 3 a engenharia de poço é detalhada, com o intuito de descrever os principais equipamentos de um poço de petróleo que influencia no estudo em questão.

No capítulo 4 é abordado o tema da engenharia de confiabilidade, com algumas definições gerais, um detalhamento sobre sistemas redundantes, além de uma explanação sobre o conceito de falha e o processo de Markov.

Nos capítulos 5 e 6 são apresentadas a metodologia utilizada neste trabalho, assim como a análise dos resultados obtidos, e o capítulo 7 encerra 0 trabalho com conclusões e algumas recomendações para trabalhos futuros. 


\section{REVISÃO BIBLIOGRÁFICA}

A Integridade de um poço de petróleo já foi assunto para vários trabalhos acadêmicos ao longo dos anos. Porém, a grande maioria destes trabalhos contém uma visão de segurança operacional, e não de manutenção da produtividade do poço.

As previsões de produção de um campo de petróleo devem levar em consideração vários fatores, como incertezas geológicas, econômicas, estratégias de produção, incertezas no modelo de reservatório e da confiabilidade dos sistemas de produção, entre outros. Carvalho (2011) verificou a importância e a influência de um estudo da análise da confiabilidade dos sistemas de produção integrada com a simulação do reservatório, a fim de verificar o impacto sobre a produção de óleo e sobre o valor presente líquido. O trabalho aplicou conceitos de engenharia de confiabilidade a poços injetores e produtores e sistemas de produção, construindo um algoritmo computacional para manipular o arquivo base do simulador de reservatório para representar, de forma mais próxima do real, a operação de um sistema de produção de petróleo.

O estudo mostrou que o principal efeito de incluir as informações de confiabilidade de poços injetores e produtores em um simulador de fluxo é o atraso da produção, pois a produção acumulada final de óleo apresentou uma queda de $2 \%$ para um cenário de óleo leve e um valor menor ainda para um cenário de óleo pesado. Porém, foi observada uma diferença significativa no VPL dos dois cenários: entre $7 \%$ e $17 \%$ no cenário de óleo leve e entre $12 \%$ e $50 \%$ no cenário de óleo pesado, o que demostra a importância de se considerar dados de confiabilidade dos sistemas na concepção do projeto para que os retornos financeiros não fiquem superestimados.

Uma das primeiras referências para análise de projetos de completação no Brasil é o trabalho de Takashina (1987), que propôs a utilização de fundamentos da Teoria de Confiabilidade para se tomar ações preventivas relativas à garantia de qualidade e quantificar a segurança de projetos de completação de poços. Ele propôs a utilização dos conceitos de taxas de falhas e árvores de falhas para quantificar os riscos de vazamento a partir de um poço de petróleo, e foi um dos pioneiros a extrapolar os conceitos de barreiras de segurança de um poço. Uma das conclusões do trabalho é que "Através da confiabilidade pode-se avaliar de forma precisa a utilização de redundância ou "stand-by", pois a aplicação 
inadequada da redundância pode trazer em muitos casos aumento de peso, elevação de custo inicial e de custo de manutenção, aumento de controles, aumento de dimensões e interferências indesejáveis em outros componentes do sistema" e recomenda, entre outras ações, "implantar e manter o banco de dados de falhas para estudos da confiabilidade dos componentes da barreira de segurança".

Medley (1978) fala sobre as experiências de 92 válvulas de segurança de subsuperfície, todas wireline retrievable (WR), contendo três modelos distintos: válvulas do tipo "by-pass", esfera e flapper. São válvulas de três campos do mar do Norte, todas de plataforma fixa (isto é, possuíam fácil acesso à manutenção e testes), de diâmetros 4 11/2" e 5 1/2", testadas mensalmente. As taxas de falha foram calculadas como o número de falhas pelo número de testes realizados, utilizando os registros de testes e falhas de um período de oito anos, demostrando que já existia um procedimento de registros de falhas para este tipo de equipamento de segurança.

O estudo realizado por Moreira (1993) teve como premissa que os DSSSs eram o principal motivo para a realização de workovers, vista sua alta taxa de falha. O estudo foi realizado utilizando o conceito de árvore de falhas e apontou um decréscimo de $1,8 \%$ da confiabilidade do poço com a retirada do DSSS. Uma das conclusões do estudo foi que a probabilidade de se ter um vazamento de óleo significativo durante a produção é bem pequena quando comparado com a probabilidade durante workovers, e então que dada a importância do DSSS na frequência de workovers, deve-se trabalhar para melhorar sua confiabilidade (foi calculado um MTTF de 5.3 anos).

Accioly (1995) desenvolveu um estudo com o objetivo de realizar a análise exploratória dos dados de falhas de bombas centrífugas submersas, de modo a esclarecer os fatores que influenciam no seu desempenho e tempo de vida, através do ajuste de um modelo de falhas, além da obtenção de estimativas dos tempos medianos de vida destes equipamentos. Neste estudo, o modelo de taxas proporcionais de Weibull se mostrou inadequado, sendo o modelo de envelhecimento acelerado, representado pelo "modelo gama generalizado", foi o que melhor se adaptou.

Frota (2003) propõe uma metodologia para auxiliar a tarefa de planejamento da manutenção de poços, baseado na análise de dados reais. Observa-se, após 
toda análise dos dados, que a falha da válvula de segurança de sub-superfície não era a principal razão para a realização de intervenções em poços na época, havendo outras causas com um histórico mais desfavorável. Duas informações importantes relacionadas a este resultado é que o conceito de poço submarino isolado, isto é, poço que não necessita de válvula de segurança de sub-superfície, era largamente utilizado na Petrobras nesta época e, assim, não havia pontos para sustentar uma análise mais apurada do cenário.

Outra conclusão foi que, apesar de o ajuste de distribuição de Weibull se mostrar o mais adequado para a modelagem de falhas em poços, os valores do parâmetro $\beta$ da distribuição de Weibull para as falhas referentes ao sistema DSSS está muito próximo de 1 , isto é, no limiar do estado de falha constante, característica utilizada como premissa neste trabalho.

O trabalho apresentado por Garcia et al. (2006) utilizou um algoritmo genérico multi-objetivo (MOGA) para preparar um planejamento otimizado de teste do sistema DSSS ao longo da vida produtiva do poço, visando diminuir os custos e otimizando a disponibilidade do sistema. O trabalho comparou os custos associados a várias disponibilidades do sistema, que é dependente da frequência de testes periódicos.

A dissertação de André Luiz Alves (2012) desenvolveu uma metodologia de análise da probabilidade de erupção de um poço submarino durante a fase de produção. Apesar de o trabalho possuir um foco nas árvores de natal molhadas, ele abrange outros equipamentos ligados à segurança, como o DSSS. Uma conclusão interessante é que a probabilidade de erupção de um poço é maior quando este está fechado ou produzindo por elevação natural do que quando está produzindo por gas lift, que é o caso mais comum atualmente no Brasil.

Outra conclusão é que dentre os componentes não reparáveis, a confiabilidade da válvula de gas lift é a que mais influencia na probabilidade de erupção, e não - DSSS. Além disso, a redução do intervalo de inspeção visual para detecção de vazamentos na cabeça do poço se mostrou mais eficaz para a diminuição da probabilidade de erupção do que o intervalo de testes do DSSS.

A norma internacional API RP 14A (2005) descreve os requisitos mínimos para as válvulas de segurança de sub-superfície. A norma contempla todos os componentes da válvula e estabelece tolerâncias e folgas que possam afetar o desempenho da válvula. Descreve como deve ser especificada uma válvula, suas 
características funcionais, os parâmetros de operação e compatibilidade com o ambiente a ser instalado, os critérios de projeto, testes funcionais, requisitos mínimos dos fabricantes controle de qualidade na fabricação, entre outros tópicos.

A $12^{\underline{a}}$ edição desta norma sofreu mudanças significativas com relação à $11^{\text {a }}$ edição. Esta nova edição foi publicada em janeiro de 2015 e as modificações serão cobradas a partir de janeiro de 2016. As principais modificações são:

- Inclusão de novos "graus de validação";

- Inclusão de diretrizes sobre válvulas de segurança de sub-superfície específicas para poços injetores;

- Inclusão de considerações relacionadas às válvulas insertáveis;

- Inclusão de análise e metodologia de projeto (análise de elementos finitos, CFC);

- Inclusão de requisitos de validação para válvulas a serem utilizadas em ambiente HPHT (high pressure / high temperatute).

A inclusão dos graus de validação foi a modificação mais relevante nesta nova edição da norma. $\mathrm{Na} 11^{\underline{a}}$ edição, as válvulas eram enquadradas em classes de serviço, e dependendo da classe existiam vários parâmetros de construção e testes em que a válvula deveria ser submetida. As classes eram:

- Classe 1: Serviços padrões

- Classe 2: Serviços com produção de areia

- Classe 3: Serviços com possibilidade de trinca sob tensão (stress cracking)

- Classe 4: Serviços com alto potencial de corrosão

$\mathrm{Na} 12^{\mathrm{a}}$ edição, as classes de serviço foram substituídas pelos graus de validação (V4-1, V4-2, V3, V2, V1 e V1-H). A tabela abaixo apresenta um resumo das diferenças entre os testes de validação das duas edições: 


\begin{tabular}{|c|c|c|}
\hline Grau de & Classe de Serviço & Testes Adicionais API 14A 12a \\
\hline Validação & Equivalente & Ed \\
\hline V4-1 & Classe 1 & $\mathrm{~N} / \mathrm{A}$ \\
\hline V4-2 & Classe 2 & $\mathrm{~N} / \mathrm{A}$ \\
\hline V3 & Sem equivalência & Vazão com água; Anexo D \\
\hline V2 & Sem equivalência & $\begin{array}{l}\text { Vazão com água; Vazão com } \\
\text { areia; Anexo D. }\end{array}$ \\
\hline V1 & Sem equivalência & $\begin{array}{l}\text { Vazão com água; Vazão com } \\
\text { areia; Anexos D e G. }\end{array}$ \\
\hline V1-H & Sem equivalência & $\begin{array}{l}\text { Vazão com água; Vazão com } \\
\text { areia; Anexos D, G, J e L. }\end{array}$ \\
\hline
\end{tabular}

A $12^{\text {a }}$ Edição não fornece requisitos para as classes 3 e 4 . Requisitos de seleção de material para todas os DSSSs estão definidas nas seções 4 e 5 da norma.

A norma internacional API RP 14B (2012) fornece os requisitos de instalação, operação, testes e manutenção das válvulas de segurança de sub-superfície, além de guias para sua correta seleção e manuseio. Além disso, fornece requisitos básicos do sistema como um todo relacionado ao sistema de controle (linhas de controle, passagens no tubing hanger, fluido de controle, conexões, etc).

Os requisitos de aceitação de testes são para vazamento da flapper (ou do elemento de vedação do poço) são:

a) $0,43 \mathrm{Sm}^{3} / \mathrm{min}\left(25,5 \mathrm{Sm}^{3} / \mathrm{hr}\right)(900 \mathrm{sct} / \mathrm{hr})$ para gás;

b) $0,4 \mathrm{l} / \mathrm{min}(6,3 \mathrm{gal} / \mathrm{h})$ para líquido.

A norma internacional ISO 14224 (2006) fornece uma base para o registro de dados para análises de confiabilidade em um formato padrão para equipamentos em todas as instalações e operações dentro da indústria de petróleo durante o ciclo de vida operacional dos equipamentos. Ela descreve os princípios de coleta de dados e termos e definições associadas que constituem uma "linguagem de 
confiabilidade", que pode ser útil para comunicar a experiência operacional. Esta norma também descreve práticas de controle e garantia de qualidade de dados para fornecer orientação para o usuário.

Com relação ao sistema do DSSS, a norma possui uma tabela com os modos de falha, considerando não somente a válvula em si, mas sua interface com as linhas de controle:

Tabela 2-2 - Modos de falha - ISO 14224

Modos de Falha

\begin{tabular}{|c|c|c|}
\hline Código & Descrição & Exemplo \\
\hline FTO & Falha ao abrir & Válvula não abrir quando solicitada \\
\hline FTC & Falha ao fechar & Válvula não fechar quando solicitada \\
\hline LCP & $\begin{array}{l}\text { Vazamento na } \\
\text { posição fechada }\end{array}$ & $\begin{array}{l}\text { Vazamento pela válvula excedendo } \\
\text { os critérios de aceitação }\end{array}$ \\
\hline WCL & $\begin{array}{c}\text { Comunicação } \\
\text { poço-linha de controle }\end{array}$ & $\begin{array}{l}\text { Influxo de fluido do poço para a linha } \\
\text { de controle }\end{array}$ \\
\hline CLW & $\begin{array}{l}\text { Comunicação linha } \\
\text { de controle-poço }\end{array}$ & $\begin{array}{l}\text { Perda de fluido hidráulico para o } \\
\text { poço }\end{array}$ \\
\hline PCL & $\begin{array}{l}\text { Fechamento } \\
\text { prematuro }\end{array}$ & Fechamento espúrio da válvula \\
\hline OTH & Outros & $\begin{array}{l}\text { Modos de falha não cobertos pelos } \\
\text { códigos acima }\end{array}$ \\
\hline UNK & Desconhecido & $\begin{array}{l}\text { Pouca informação para definir o } \\
\text { modo de falha }\end{array}$ \\
\hline
\end{tabular}

Molnes (1989) separa os modos de falha para o sistema DSSS entre as funções principais e secundárias do sistema. É descrito como funções principais: Enquanto a válvula estiver aberta, fechar o poço quando requerido, na profundidade em que está instalada, impedindo fluxo se óleo/gás/condensado de acordo com os 
requisitos da norma API 14B. Na posição fechada, a válvula deve manter o poço sem fluxo, dentro dos requisitos da norma API 14B, até o comando de abrir for dado. Neste momento, a válvula deve abrir completamente, sem nenhuma restrição ao fluxo.

As funções secundárias têm como objetivo transferir a válvula para um estado onde as funções principais são reestabelecidas. Bloqueios temporários e permanentes e realizar comunicação da linha de controle com uma válvula insertável são exemplos de funções secundárias.

Abaixo está a definição de falha, para o sistema DSSS, segundo Molnes (1989):

Tabela 2-3 - Definicão de falha para o sistema DSSS. Fonte: Molnes

\begin{tabular}{|c|c|c|}
\hline Tipo da Função & Posição da Válvula & Modo de Falha \\
\hline \multirow{8}{*}{ Função Primária } & \multirow{4}{*}{ Válvula Aberta } & $\begin{array}{l}\text { Falha em fechar, quando solicitada } \\
\text { (FTC) }\end{array}$ \\
\hline & & Fechamento prematuro (PCL) \\
\hline & & $\begin{array}{l}\text { Comunicação linha de controle }=>\text { poço } \\
\text { (CLW) }\end{array}$ \\
\hline & & Falha em assentar no nipple (FSN) \\
\hline & \multirow{4}{*}{ Válvula Fechada } & Vazamento (LCP) \\
\hline & & Falha em abrir, quando solicitada (FTO) \\
\hline & & $\begin{array}{l}\text { Comunicação poço => linha de controle } \\
\text { (WCL) }\end{array}$ \\
\hline & & Falha em "ficar" no nipple (FTH) \\
\hline \multirow{9}{*}{ Função secundária } & \multirow{9}{*}{$\begin{array}{l}\text { Válvula aberta ou } \\
\text { fechada }\end{array}$} & Falha em deslocar o tubo de fluxo \\
\hline & & $\begin{array}{l}\text { Tubo de fluxo deslocado } \\
\text { prematuramente }\end{array}$ \\
\hline & & $\begin{array}{l}\text { Ativação inadvertida da válvula } \\
\text { temporariamente bloqueada }\end{array}$ \\
\hline & & Bloqueio permanente inadvertido \\
\hline & & Falha em ativar a válvula remotamente \\
\hline & & Falha em ativar a válvula via wireline \\
\hline & & Falha em travar a válvula remotamente \\
\hline & & Falha em travar a válvula via wireline \\
\hline & & Falha em remover o travamento \\
\hline
\end{tabular}

Molnes (1989) também inclui definições dos modos de falha relacionado à função primária do sistema DSSS. A falha de vazamento na posição fechada 
(LCP) se aplica sempre que a taxa de vazamento exceder o limite da API 14B. Este tipo de falha pode ser detectado através de testes do DSSS ou sempre que o poço for fechado na válvula por outro motivo.

A falha em fechar quando solicitada (FTC), em alguns casos, pode ser difícil de ser detectada e ser confundida com a falha anterior (LCP). Sempre que o vazamento for muito grande, a ponto de se tornar claro que a válvula está longe da posição fechada, a falha deverá ser reportada como FTC. Molnes (1989) sugere um vazamento "muito grande" quando este exceder $5 \%$ da vazão antes do fechamento.

A falha de fechamento prematuro (PCL) deve ser aplicada quando uma válvula fecha sem ser comandada e o nível de vazamento, após fechada, está de acordo com a API 14B. Porém, se o vazamento através da válvula - após fechada - for maior que os limites da API 14B, a falha deverá ser registrada como LCP e a falha PCL deve ser reportada como falha secundária. Além disso, se for percebido um vazamento do poço para a linha de controle na sequência de um PCL, esta falha também deve ser reportada, para uma melhor análise no intuito de se chegar na causa da falha.

A falha em abrir quando solicitada (FTO) deve ser aplicada em situações onde a linha de controle é pressurizada, uma vez estando despressurizada. FTO deveria ser utilizada para descrever casos onde a válvula falha em responder quando é fornecido pressão à linha de controle. Isto pode ser causado por obstrução entre as partes móveis, linha de controle plugueada, etc.

A falha comunicação poço => linha de controle $(\mathrm{WCL})$ pode ser separada para válvulas tubing mounted e wireline retrievable. Para válvulas tubing mounted, o modo de falha WCL pode ocorrer depois da pressão da linha de controle ser drenada, com a válvula na posição fechada. Mesmo com a flapper fechada e vedando, uma porção dos fluidos que ficam acima da flapper pode entrar na linha de controle, o que pode acontecer por vazamento nos selos estáticos ou dinâmicos da câmara hidráulica, dependendo do projeto da válvula. Outros pontos de vazamento podem ser as conexões roscadas, as soldas, selos estáticos, discos de ruptura, etc.

A falha comunicação linha de controle $=>$ poço (CLW) é válida somente com a válvula na posição aberta, e é aplicada quando o fluido de controle começa a vazar, seja para dentro da coluna de completação ou para o anular. Esta falha 
pode acontecer pela falha dos selos estáticos ou dinâmicos, falha nas conexões da linha de controle, etc. Este modo de falha deve ser utilizado somente em casos onde a válvula é retirada antes do sistema entrar no modo de falha PCL, isto é, o sistema de bombeio do fluido de controle ser capaz de manter a pressão necessária, mesmo com o vazamento.

A definição de barreira de poço, segundo a norma norueguesa NORSOK D-10 (NORSOK D-10, 2013, p.15) é "um envelope de um ou mais elementos de barreira dependentes, capaz de prevenir fluxo não intencional de uma formação para outra ou para a superfície".

A norma menciona que pelo menos duas barreiras devem estar disponíveis durante toda as atividades de poço, onde exista um diferencial de pressão que possa causar fluxo do poço para o ambiente externo. Além disso, diz que "as barreiras primária e secundária devem sempre que possível ser independentes uma em relação a outra, sem elementos de barreira comuns".

A norma ainda informa que "Um DSSS deve ser instalado na coluna de completação em todos os poços que penetram um reservatório com incidência de hidrocarboneto ou poços com pressão do reservatório suficiente para levantar fluidos de superfície ou para o fundo do mar.", e este deve fazer parte do sistema de emergência da plataforma. Deve ser instalada no mínimo a 50 metros abaixo do fundo do mar e a profundidade de assentamento deve levar em consideração a formação de hidratos e a deposição de parafinas e incrustações. 


\section{ENGENHARIA DE POÇOS DE PETRÓLEO SUBMARINO}

Como já foi descrito no capítulo 1, a completação de um poço de petróleo tem como finalidade transformar o esforço da perfuração em uma unidade produtiva, realizando, entre outras operações, a instalação de equipamentos de controle e segurança de poço. Neste capítulo iremos descrever um pouco como podemos classificar os poços com relação à sua completação, assim como descrever alguns dos seus principais equipamentos, que estão diretamente relacionados com o sistema de estudo desta dissertação - o dispositivo de segurança de subsuperfície.

\subsection{Classificação da Completação}

Quanto ao tipo de completação utilizada, várias classificações são possíveis. A completação normalmente é dividida em completação inferior (isto é, em frente ao reservatório), a completação superior e os equipamentos de cabeça de poço. A completação em frente ao reservatório pode ser considerada a conexão entre o reservatório e o poço, enquanto a completação superior é a ligação entre a completação em frente ao reservatório e as facilidades de superfície.

Quanto ao posicionamento da cabeça, os poços podem ser classificados como completação seca ou completação molhada. A completação seca é caracterizada pelo posicionamento da árvore de natal onde o ser humano tem acesso, e com isto são percebidas várias características construtivas referentes a esta configuração, como por exemplo, menores dimensões do conjunto, válvulas flangeadas, etc. Esta completação é utilizada em poços terrestres e poços marítimos instalados em plataformas fixas.

Por outro lado, a completação molhada tem como principal característica a instalação da árvore de natal no solo marinho, no fundo do mar. Como, na grande maioria das vezes, não é possível a atuação humana nas profundidades onde a árvore de natal é instalada, não há como ter equipamentos flangeados, o que torna necessário a utilização de outros sistemas de conexão, todos sem a necessidade da ação humana. Outra característica deste sistema são as grandes dimensões dos equipamentos, além de funis nas extremidades dos equipamentos para facilitar sua conexão. 

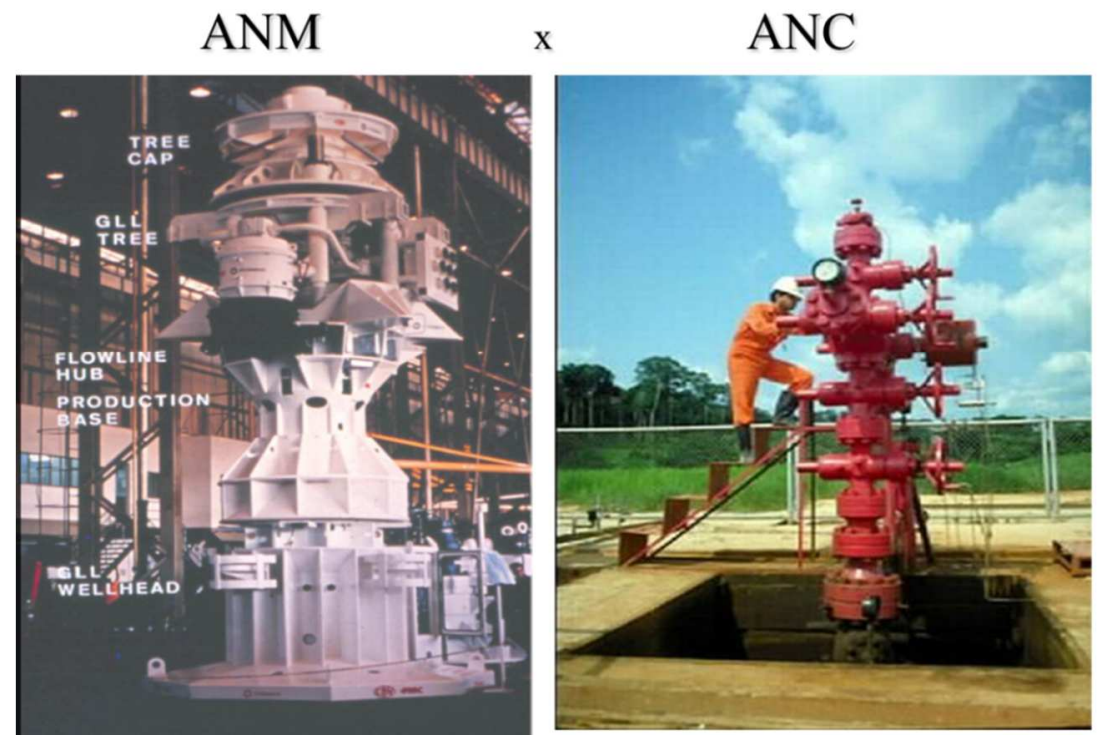

Figura 3-1 - Comparação entre árvore de natal seca e molhada

\subsection{Descrição dos Principais Equipamentos}

\subsection{1. Árvore de Natal Molhada}

Árvore de Natal Molhada pode ser definida como:

Equipamento submarino composto por um conjunto de válvulas operadas remotamente por acionadores hidráulicos, sensores de pressão e de temperatura. É instalado na cabeça do poço de completação molhada, no leito marinho. Embora seja mais complexa, conceitualmente é muito similar à árvore de natal seca. Uma árvore de natal molhada (ANM) pode ser do tipo vertical ou horizontal; o tipo vertical também é chamado no Brasil de 'convencional', enquanto que a de tipo horizontal, com sigla ANMH, permite a retirada da coluna de produção sem a retirada da ANM. O método de instalação de uma ANM iniciou-se com o uso de cabos-guia, mas a instalação em águas mais profundas atualmente é realizada sem cabos-guia (guidelineless). A parte superior da ANM é chamada de 'capa da árvore' (tree cap) e realiza diversas funções, incluindo o controle das linhas hidráulicas das válvulas fail-safe-close. A ANM conecta-se às linhas de exportação do fluido produzido e de acesso ao anular, e com o umbilical de controle, responsável pelo controle do equipamento, realizado remotamente a partir da unidade estacionária de produção. Tem como principal função permitir que o escoamento dos fluidos de um poço seja enviado sob controle para uma unidade estacionária de produção*. (FERNÁNDEZ y FERNÁNDEZ; PEDROSA JUNIOR; PINHO, 2009). 


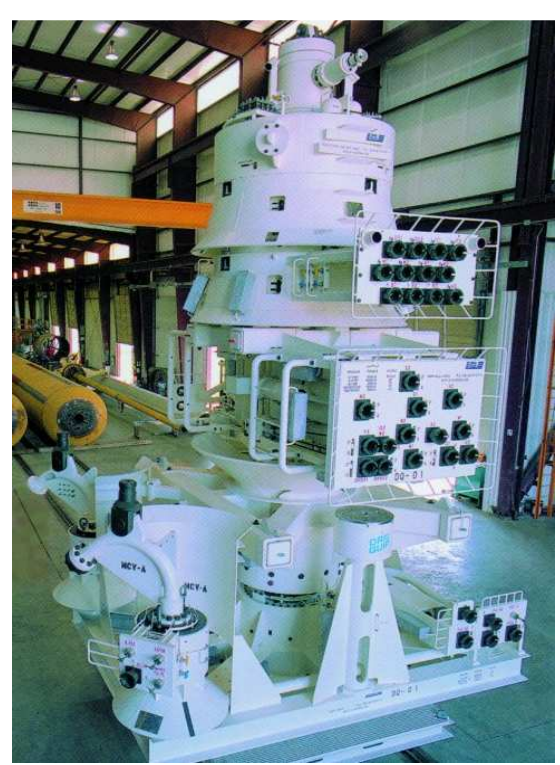

Figura 3-2 - Árvore de Natal Molhada (ANM)

\subsubsection{Suspensor de Coluna}

O suspensor de coluna, ou tubing hanger, é um equipamento instalado junto com a coluna de produção, e tem como principais funções suportar a coluna de produção, promover estanqueidade entre a coluna e o espaço anular colunarevestimento e fornecer o caminho para controle do DSSS, injeção química e monitoramentos de dentro do poço.

É a interface entre o poço e a ANM, e isto é feito através de bores, a saber:

- Bore de produção: permite o acesso à coluna de produção;

- Bores das linhas de DSSS: permitem o acesso às linhas hidráulicas do DSSS e possuem, internamente, um coletor de detritos para evitar contaminação do fluido hidráulico;

- Bore do conector do PDG (permanent downhole gauge: temperatura e pressão de fundo do poço): permite a instalação do conector elétrico de PDG. 

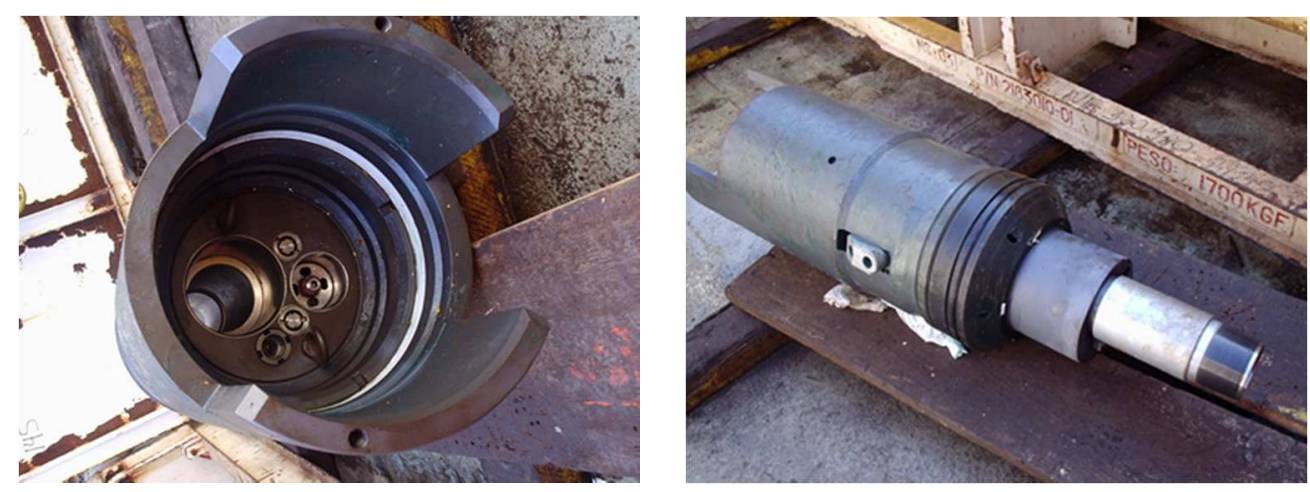

Figura 3-3 - Suspensor de coluna

Outra funcionalidade deste equipamento é permitir a comunicação hidráulica entre o fluido contido na linha de controle dentro do poço para a parte superior, fora do poço.

\subsubsection{Umbilical e linhas de controle}

Para poços produtores que estão interligados diretamente à unidade estacionária de produção - UEP (poços satélites) e que utilizam gas lift como método de elevação artificial, a ligação ANM-UEP é realizada, basicamente, através de 3 linhas: uma linha de produção, uma linha de gas lift e um umbilical de controle. Neste caso, as ANMs são controladas individualmente através do umbilical de controle.

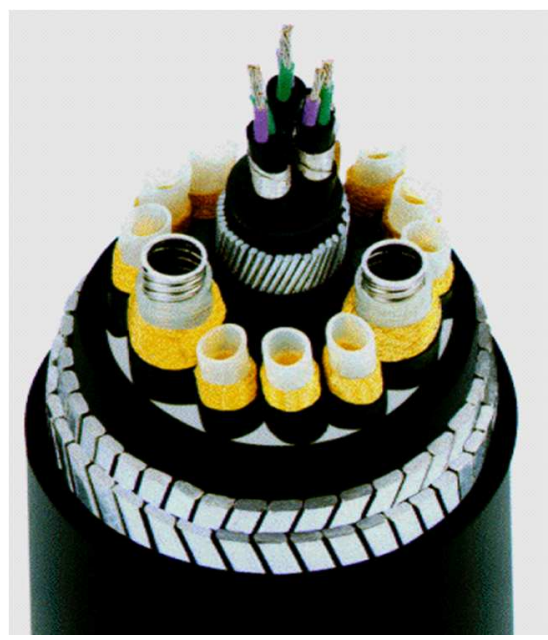

Figura 3-4 - Umbilical de Controle

O umbilical de controle é constituído, tipicamente, por nove linhas hidráulicas de diâmetro (ID) 3/8" para controlar as válvulas da ANM e DSSS, três linhas para injeção de etanol e outros produtos químicos, além de cabos elétricos para receber os sinais do TPT (Temperature and Pressure Transducer) e PDG. As nove linhas 
hidráulicas estão sempre cheias de fluido de controle e não precisam ser resistentes ao colapso. No entanto, as linhas de injeção de produtos químicos podem ficar ocasionalmente vazias e precisam ser resistentes ao colapso. Os umbilicais possuem também camada estrutural de aço carbono para resistir aos esforços de lançamento.

Quando se deseja abrir uma válvula (por exemplo o DSSS), basta pressurizar a mangueira do umbilical submarino correspondente a essa válvula, ocorrendo, portanto, a abertura da mesma. Caso a pressão seja cortada, em função de uma operação de rotina ou emergência, ocorrerá o fechamento da válvula.

As três mangueiras HCR (High Collapse Resistant) de ID 1/2" destinam-se ao transporte de etanol e outros produtos químicos para injeção na ANM. O cabo elétrico de 3 pares $\left(2,5 \mathrm{~mm}^{2}\right)$ são os cabos destinados a transmitir os sinais elétricos portadores das informações referentes às variáveis físicas de produção obtidas dos equipamentos de medição instalados no fundo (PDG) e na ANM (TPT - instalado na via de produção; PT - Pressure Transducer - instalado na via de anular).

As linhas de controle do DSSS ficam localizadas no anular coluna de produçãorevestimento de produção e são responsável por realizar a interligação da válvula com a cabeça do poço. Na maioria das vezes, as linhas de controle tem um comprimento pequeno, porém em algumas situações estas linhas podem ter centenas de metros, pois é necessário realizar a instalação mais profunda da válvula.

Além disso, não é possível haver uma conexão hidráulica ou elétrica da UEP até as válvulas ou sensores da ANM sem emendas, ou seja, sem conectores hidráulicos e elétricos. Esses conectores estão localizados na interface entre o umbilical e a BAP (Base Adaptadora de Produção), na interface entre a BAP e a ANM, na interface entre a Tree Cap (Capa da Árvore) e a ANM, e na interface entre a ANM e o suspensor de coluna.

\subsubsection{Dispositivo de segurança de sub-superfície (DSSS)}

Pode ser definido como um dispositivo de segurança, posicionada na coluna de produção, que possibilita um fechamento praticamente instantâneo da coluna de produção, cessando o fluxo de óleo e/ou gás, caso algum problema sério venha 
ocorrer com os equipamentos de superfície. Também é chamado de SSSV (Sub Surface Safety Valve), o dispositivo é considerado a primeira barreira de segurança no caminho de fluxo pela coluna de produção, durante a fase de produção do poço. Sua função é evitar erupções ou fluxos descontrolados do poço (também chamados de blow-outs).

Outra característica desta válvula é que ela é classificada como válvula "normalmente fechada" (fail-safe-close), isto é, caso ela ou seu sistema falhe, a válvula se fecha. Ou seja, é necessário a pressurização da linha hidráulica de controle para sua abertura. Despressurizando esta linha de controle, o DSSS automaticamente será fechado. Para produzir o poço, o DSSS deve ficar na posição aberta, o que é obtido através da pressurização das linhas de controle desde a Unidade Estacionária de Produção (UEP), passando pelo manifold (quando existente) e pela ANM, nas completações molhadas, ou entrando diretamente na árvore de natal convencional (ANC), nas completações secas.

O DSSS serve para impedir o vazamento de hidrocarbonetos para o meio ambiente no caso de uma das seguintes causas de acidentes catastróficos na cabeça do poço:

- Furacão;

- Explosão próximo da árvore de natal;

- Impacto (batida de caminhão, avião ou trem, no caso de poços terrestres - arraste de linhas de ancoragem, queda de equipamentos sobre a ANM, no caso de poços submarinos, etc);

- Ato terrorista;

- Etc

Todos estes eventos, com exceção de colisão em poços submarinos, já ocorreram. Poços de plataformas e surgentes são candidatos, portanto, à utilização de DSSSs. Princípio de funcionamento:

- Ao se pressurizar a linha de controle, a pressão aplicada através do painel hidráulico atua sobre o pistão interno de acionamento, deslocando o tubo de fluxo para baixo a ele solidário, provocando a abertura da flapper e ao 
mesmo tempo, comprimindo uma mola. Assim, enquanto houver pressão suficiente na linha de controle (LC), a flapper se manterá aberta.

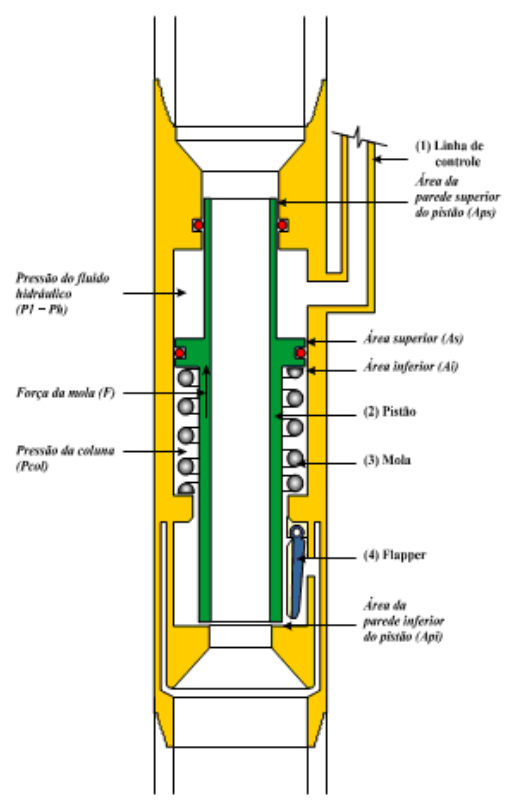

Figura 3-5 - Dispositivo de Segurança de Sub-Superfície (DSSS)

Em uma situação de sinistro em que a LC for despressurizada, a mola provocará o deslocamento do tubo de fluxo para cima, fechando a flapper e consequentemente o fluxo do poço.

Normalmente a válvula fica instalado 1 tubo abaixo do suspensor de coluna, porém existem alguns motivos para que esta instalação mais profunda ocorra. Em poços marítimos de completação seca, onde as cabeças dos poços ficam localizadas nas plataformas fixas, existe a possibilidade de um poço já estar completamente completado e consequentemente, produzindo, enquanto o poço ao lado (já que, neste caso, as cabeças dos poços ficam dispostas em cluster) ainda está iniciando a perfuração. Nestes casos, o início da perfuração de todos os poços em cluster são em paralelo, e após uma certa profundidade - chamada de kickoff point - os poços são desviados e se afastam. Porém, no trecho onde as perfurações ocorrem em paralelo, existe a possibilidade de colisão, e se um destes poços já se encontra em produção, o dano desta colisão seria muito maior. Nestes casos, o DSSS é instalado abaixo do kickoff point, para evitar maiores danos caso haja um erro deste tipo.

Outro caso onde a válvula é instada a centenas de metros abaixo do suspensor de coluna é quando há possibilidade, em poços marítimos de completação submarina, da formação de hidrato. Hidrato é um sólido que é formado na 
presença de água, gás, baixa temperatura e altas pressões. É um sólido semelhante ao gelo no aspecto visual, porém apresenta propriedades bem diferentes (solidifica acima em temperaturas acima de zero graus, por exemplo). Portanto, em alguns casos a área logo abaixo do suspensor de coluna pode estar sujeita à formação de hidratos, já que é uma zona do poço de altas pressões e baixas temperaturas, e propício a ter gás e água em caso de fechamento do poço. Assim, a solução é realizar a instalação do DSSS em uma posição mais profunda, oois a temperatura é maior e fora do envelope de hidrato. A norma internacional API 14B (AMERICAN PETROLEUM INSTITUTE, 2012) cita a possibilidade de formação de hidrato como um insumo que deve ser considerado no momento da escolha da profundidade de instalação da válvula.

Antes de sua abertura deve-se ter o cuidado de equalizar as pressões acima e abaixo da flapper. Em caso de emergência operacional (Ex: vazamento na superfície) é possível amortecer o poço pelo bombeio direto (pela coluna de produção) de fluido de completação, recalcando o óleo para a formação, pois a válvula permite o fluxo de cima para baixo, e serve principalmente como válvula de segurança impedindo a produção do poço para o fundo do Mar caso ocorra acidentalmente o arrasamento da ANM.

Quanto ao modo de instalação na coluna de produção, passou-se a adotar os DSSSs enroscadas diretamente na coluna (tubing mounted), que, a despeito de exigir retirada da coluna para reparo, apresenta vida útil e custo final vantajosos em relação aos DSSSs instalados com Unidade de Arame (wireline retrievable).

Os DSSSs tubing mounted apresentam as seguintes vantagens em relação aos DSSSs wireline retrievable:

I. menor restrição ao fluxo;

II. maior vida útil;

III. possibilidade de utilização em lâmina d'água profunda (DSSS com câmara de nitrogênio)

As válvulas conhecidas como storm choke são válvulas calibradas na superfície para fechamento em determinadas condições de fluxo (vazão e densidade do fluido produzido) e pressão. Como estas condições variam durante a vida produtiva do poço, depois de determinado tempo, as storm choke acabam por apresentar problemas funcionais (fechamentos indevidos, dificuldades de 
reabertura ou mesmo não fechamento ou fechamento definitivo), necessitando serem retiradas, via operação com unidade de arame, para recalibração.

DSSS auto-equalizável: A flapper dispõe de dispositivo para equalização, esta se dá no início da descida do tubo de fluxo ao se pressionar a LC pelo painel hidráulico.
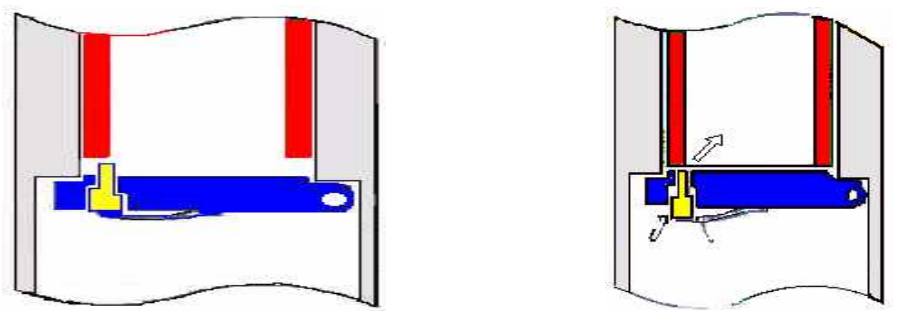

Figura 3-6 - DSSS Auto equalizável

DSSS não auto-equalizável: a flapper não tem o dispositivo de equalização, esta deverá ser feita com injeção de fluido pelo interior da coluna até atingir a pressão de shut in.

Os DSSSs podem ser sensitivos e não sensitivos. Nos DSSSs sensitivos, a pressão no interior da coluna influência as pressões de abertura e fechamento da válvula. Deste modo, quando de um fechamento indevido do DSSS, passa a ser de suma importância não apenas a equalização das pressões acima e abaixo do DSSS, mas também o acréscimo desta pressão à pressão de acionamento (abertura) do DSSS.

Já nos DSSSs não sensitivos, a pressão no interior da coluna não influencia diretamente na pressão de abertura e fechamento da válvula. Portanto, quando do fechamento do DSSS em que tenha ocorrido trapeamento de pressão abaixo da flapper, efetuada a equalização das pressões acima e abaixo da flapper, não será necessário o acréscimo desta pressão à pressão de abertura do DSSS.

Bane e Peoples (2009) descreve as diferenças técnicas entre uma válvula de segurança de sub-superfície e seu sistema de controle utilizada em águas profundas e as válvulas de completação seca, sejam para poços terrestres ou para poços marítimos de completação seca (plataforma fixa). Também lista e detalha as três tecnologias utilizadas atualmente em lamina d'água profunda, que são as válvulas de super molas (Heavy Sprung system), sistema balanceado de linhas de controle (Balanced Line system) e sistema de câmara de nitrogênio (gas charged system). Além disso, é apresentada uma nova tecnologia - uma válvula 
com as mesmas características de fechamento das válvulas de tecnologia "heavy sprung" (utilização de molas com capacidade alta de compressão), porém com uma câmera atmosférica no lado oposto do pistão fazendo que a válvula seja insensitiva à pressão do poço, reduzindo drasticamente sua pressão de abertura, principalmente em casos extremos, como poços HPHT.

\subsection{Sistema de Controle do DSSS}

O sistema de controle do DSSS não compreende somente da válvula propriamente dita, mas sim de um sistema que compreende os seguintes componentes, listados abaixo:

- Linha de Controle

- Suspensor de Coluna

- Árvore de Natal

- Umbilical de Controle

- HPU (Hydraulic Power Unit) e Painel de Controle

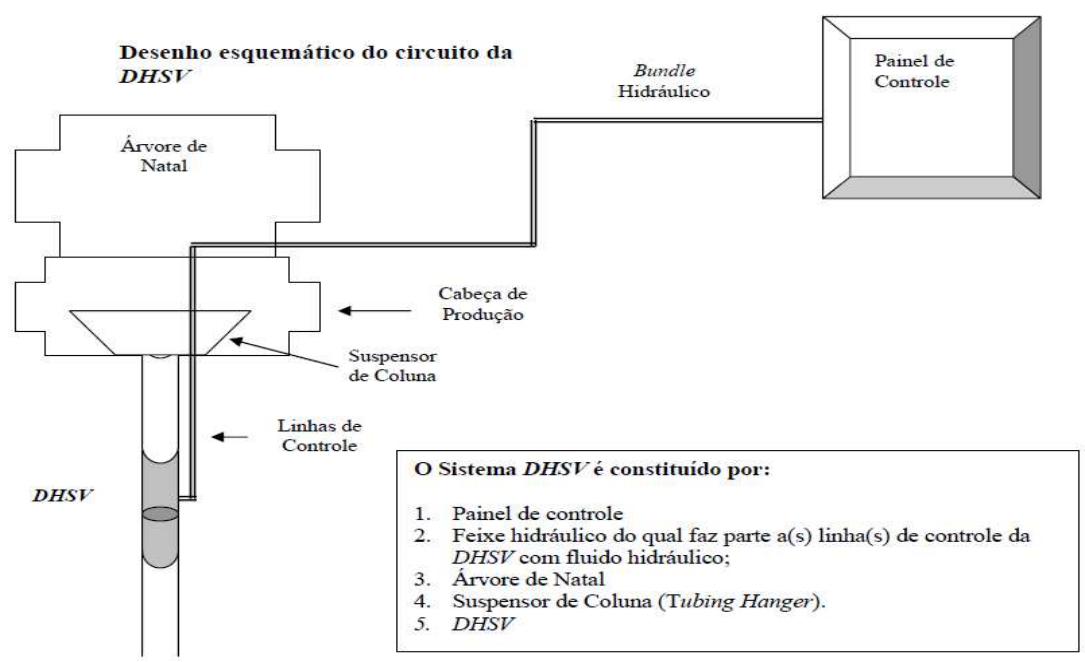

Figura 3-7 - Esquemático do sistema de controle do DSSS

O sistema de controle pode ser basicamente de três formas: Hidráulico direto, eletro-hidráulico multiplexado ou inteiramente elétrico.

No sistema de controle hidráulico direto, o atuador de uma válvula da ANM é pressurizado e despressurizado diretamente pela mesma linha de controle desde 
a plataforma. É o sistema de controle mais simples para equipamentos submarinos, porém necessita de uma linha de potência hidráulica para cada válvula.

Para as válvulas com a característica fail safe close, o vazamento de fluido hidráulico em sua linha de controle provavelmente resulta em um fechamento espúrio da válvula. Se o vazamento for bem pequeno, a unidade de potência hidráulica, ou HPU (Hydraulic Power Unit), instalada na plataforma, consegue suprir continuamente esta perda de fluido, sem permitir que a pressão caia ao ponto de ocasionar a fechamento prematuro da válvula.

Uma característica deste tipo de sistema de controle é que para grandes comprimentos de umbilical, o tempo de resposta no acionamento de válvulas pode ser lento. O sistema de controle hidráulico direto deve ter seu tempo máximo de atuação e o fechamento total da válvula de 10 minutos, o que, na prática, limita o comprimento do umbilical em, aproximadamente $10 \mathrm{Km}$.

No sistema de controle multiplexado, sinais elétricos são enviados a partir da plataforma até um módulo de controle submarino, ou SCM (subsea control module). Neste módulo, encontram-se a eletrônica submarina e as válvulas solenoides, e desta forma, com um par de cabos elétricos, junto com uma linha de suprimento hidráulico, pode-se atuar um grande número de válvulas. Quando o sinal de abertura de uma determinada válvula é enviado pela plataforma, a eletrônica submarina recebe e codifica este sinal e aciona a válvula solenoide correspondente, permitindo a pressurização do atuador da válvula que se quer abrir.

Uma característica deste tipo de controle são os requisitos mais restritivos sobre a classe de limpeza do fluido hidráulico. Isto se deve às pequenas passagens existentes nas válvulas solenóides instaladas no SCM, que pode ser instalado tanto na ANM como em um manifold submarino. Este último equipamento pode reunir a produção de diversos poços, permitindo a coleta através de um único duto entre ele e a plataforma. O sistema de controle eletrohidráulico multiplexado tem sua limitação de comprimento de umbilical em, aproximadamente $150 \mathrm{Km}$.

O sistema de controle totalmente elétrico pode ser considerado concorrente do sistema multiplexado para todos os cenários onde este último pode ser utilizado. Para a escolha do sistema de controle elétrico, deve-se levar em consideração a 
vantagem de eliminação de toda a infraestrutura hidráulica (HPU, linhas nos umbilicais, etc.) necessária para o sistema multiplexado. Porém, a aplicação de sistemas de controle inteiramente elétricos em equipamentos submarinos de produção é considerada ainda emergente do ponto de vista de maturidade tecnológica, pois apresenta como premissa o uso de atuadores elétricos para abertura e fechamento de válvulas submarinas.

Algumas características devem ser avaliadas na hora da escolha de qual sistema de controle utilizar. Abaixo seguem algumas:

- Distâncias entre os equipamentos interligados entre si e entre os equipamentos interligados a UEP;

- Número de funções de controle de cada equipamento do sistema submarino;

- Avaliação da necessidade de interface para equipamentos de completação inteligente. 


\section{ENGENHARIA DE CONFIABILIDADE}

\subsection{Definições Gerais}

A confiabilidade pode ser definida como a probabilidade de que um componente ou sistema, funcionando dentro dos limites especificados de projeto, não falhe durante o período de tempo previsto para a sua vida, dentro das condições de agressividade do meio. Já a disponibilidade é descrita como a probabilidade de que um sistema esteja em condição operacional no instante $t$ (LAFRAIA, 2001).

"Os conceitos de confiabilidade e de taxa de falha estão entre as mais importantes ferramentas necessárias para um estudo profundo dos "modelos de falhas" (FROTA, 2003, p.23).

O tempo esperado pode ser entendido como tempo ou período determinado, e está relacionado com posições ou restrições gerenciais, como tempo permitido de operação. Outros aspectos importantes são as condições de operação, que estão associadas a condições de carga, capacidade, ou mesmo a condições ambientais que, eventualmente, possam influenciar os resultados.

O inverso da confiabilidade seria a probabilidade de o componente ou sistema falhar, ou a impossibilidade de um sistema ou componente cumprir com sua função no nível especificado ou requerido. A taxa de falhas pode ser definida como:

" a frequência com que as falhas ocorrem em um intervalo de tempo, medida

Uma pelo número de falhas para cada hora de operação ou pelo número de operações do sistema ou componentes"

Sendo a confiabilidade, para um período $T$, representada por $R(T)$, a probabilidade de falha $Q(T)$ é dada por:

$$
Q(T)=1-R(T)
$$

As fases da vida de um componente ou sistema podem ser descritas pela curva da banheira, que serve para explicar as várias fases pelas quais o equipamento ou sistema passa durante sua vida útil. São identificados três períodos de vida característicos: mortalidade infantil, período de vida útil e período de desgaste: 


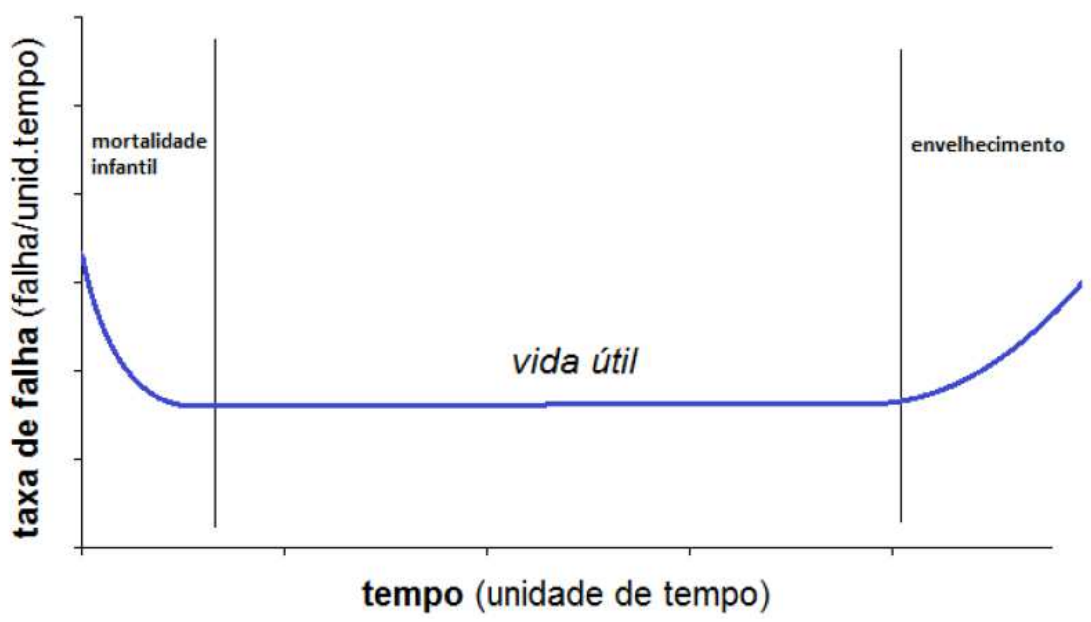

Figura 4-1 Esquemático - Curva da Banheira

O período de mortalidade infantil é caracterizado por falhas prematuras. A taxa de falhas é decrescente e tem sua origem em uma deficiência no processo de fabricação e no controle de qualidade, na mão de obra desqualificada, na préoperação ou no pré-teste mal feitos, nos materiais fora de especificação ou não especificados, não testados, etc.

O período de vida útil é caracterizado por falhas aleatórias e taxa de falhas constante. Exemplos de falhas deste período são, entre outras: interferência indevida, fator de segurança insuficiente, cargas maiores que as esperadas, resistência menor que a esperada, defeitos abaixo do limite de sensibilidade dos ensaios, erros humanos durante o uso, etc.

O período de desgaste inicia-se quando está terminando a vida útil do equipamento, e a taxa de falha por desgaste cresce continuamente. São causas deste período o envelhecimento, desgaste, abrasão, degradação de resistência, fadiga, corrosão, deterioração elétrica, mecânica, química ou hidráulica, entre outros.

Nem todos os tipos de componentes ou sistemas apresentam todas as fases. Os programas de computador são um exemplo típico de sistema que só possui período de mortalidade infantil, pois a medida que os erros de programação são corrigidos, as falhas vão praticamente desaparecendo. Componentes eletrônicos apresentam, normalmente, falhas aleatórias, e para este tipo de falha é comum substituir-se o componente quando este quebra, já que a manutenção preventiva 
muitas vezes é pouco efetiva. Já componentes mecânicos apresentam normalmente as três fases.

A taxa da falha é normalmente representada pela letra $\lambda$ (lambda), e o inverso da taxa de falhas é conhecido como o tempo médio entre falhas, ou MTBF (Mean Time Between Failure):

$$
M T B F=\frac{1}{\lambda}
$$

O valor esperado da variável aleatória contínua, denominada tempo até falha, é definido como o tempo médio até a falha, ou MTTF (Mean Time To Failure). Em muitas situações práticas, o conhecimento do MTTF é suficiente para caracterizar a qualidade e a disponibilidade de um certo item. Analiticamente, o MTTF é dado pela seguinte expressão

$$
M T T F=\int_{0}^{\infty} R(t) d t
$$

A grandeza probabilística que mede a capacidade de se manter ou recolocar um componente, ou unidade, em um estado que permita seu bom desempenho, nas condições de operação determinadas, é a mantenabilidade. Ela pode ser definida como sendo a probabilidade de que um componente, ou sistema, seja reparado e recolocado em funcionamento, dentro de um período de tempo determinado. Este período é representado por T e a mantenabilidade é dada por M(T). Assim como o MTTF depende da confiabilidade, o MTTR (Mean Time to Repair) depende da mantenabilidade, e é expresso por

$$
\operatorname{MTTR}=\int_{0}^{\infty}(1-M(t)) d t
$$

Outro conceito importante é o da Disponibilidade $A(t)$, ou "a probabilidade de que um sistema esteja funcionando satisfatoriamente em t", também conhecida com disponibilidade pontual. Frequentemente, é necessário determinar a disponibilidade de uma missão ou de um intervalo $\left(A^{*}\right)$. Esta disponibilidade é definida como:

$$
A^{*}(t)=\frac{1}{T} \int_{0}^{T} A(t) \cdot d t
$$

Verifica-se que a disponibilidade de intervalo é a média da disponibilidade pontual em relação a um intervalo $T$, que pode ser a vida de projeto ou o tempo necessário para cumprir uma missão. 
Frequentemente observa-se que, após alguns efeitos transientes iniciais, a indisponibilidade pontual assume um valor independente do tempo. Nestes casos, a disponibilidade assintótica ou estacionária é definida por:

$$
A^{*}(\infty)=\lim _{t \rightarrow \infty} \frac{1}{T} \int_{0}^{T} A(t) \cdot d t
$$

Se um sistema ou seus componentes não podem ser reparados, a disponibilidade pontual será igual à sua confiabilidade. A probabilidade de que esteja disponível em t é exatamente igual à probabilidade de que não tenha falhado entre 0 e t, ou seja:

$$
A(t)=R(t)
$$

Logo:

$$
A^{*}(t)=\frac{1}{T} \int_{0}^{T} R(t) \cdot d t
$$

Assim, conforme $T \rightarrow \alpha$, a integral tende para o MTTF, enquanto o denominador tende ao infinito. Logo, $A^{*}(\infty)=0$. Como todo o sistema eventualmente falha, a disponibilidade média sobre um intervalo infinito tende a zero.

A definição de sistema também será importante para um bom entendimento do trabalho apresentado. Sistema pode ser definido como um conjunto de equipamentos, componentes ou subsistemas, e estes componentes podem estar em série ou em paralelo. Também pode ser descrito como uma coleção de componentes ou subsistemas combinados entre si de modo específico para atingir as funções desejadas de desempenho e confiabilidade aceitáveis. Os tipos de componentes, suas quantidades, qualidades e configuração de projeto, quando combinados, tem efeito direto na confiabilidade e disponibilidade do sistema.

As metodologias de cálculo de sistemas podem ser classificadas como métodos combinatórios (por exemplo: Árvore de falhas), processos estocásticos (por exemplo: Markov), e as simulações (por exemplo: Monte Carlo). Os métodos combinatórios são fáceis de construir e compreender, tem uma representação gráfica da lógica funcional do sistema, isto é, como os componentes do sistema estão conectados e como eles se comportam, podem fornecer soluções analíticas para qualquer distribuição, e o comportamento do sistema é representado pelo comportamento dos seus componentes. 


\subsection{O Conceito de Falha}

A definição de falha para este trabalho demanda alguma discussão. O conceito de falha pode ser bastante vasto dependendo dos conceitos e premissas levadas em consideração, e podem ser responsáveis por modificar consideravelmente os resultados das análises.

É fácil ter alguma noção intuitiva do que constitui uma falha. É fácil concordar quando um motor de um carro ou um pneu falha se estes equipamentos deixarem de exercer completamente suas funções mas, as vezes, os itens continuam a funcionar, porém não com a performance esperada. Por exemplo, o motor de um carro pode estar funcionando, porém com um alto consumo de gasolina, ou um pneu conseguir segurar o ar, mas estar careca. Estes equipamentos falharam? Se não, qual seria o limite da má condição para se constituir uma falha? Para tentar cobrir todas estas eventualidades, podemos definir falha como (NOWLAN; HEAP, 1978, p. 18):

\section{"Uma falha é uma condição insatisfatória"}

Em outras palavras, falha pode ser definida como um desvio da condição original na qual se torna insatisfatório para um usuário em particular. Porém, estas definições acima não resolvem totalmente nossos problemas, pois a definição de o que é satisfatório ou insatisfatório depende de vários fatores, como por exemplo, das consequências da falha em um determinado contexto de operação. A divisão exata entre a condição satisfatória e a insatisfatória irá depender não somente da função do equipamento em questão, mas na natureza do equipamento e no contexto da operação no qual o equipamento é utilizado, e a determinação irá variar de empresa para empresa, e os limites entre as condições satisfatórias e insatisfatórias devem ser determinados bem claramente, para os equipamentos de maior importância.

Qualquer equipamento ou sistema encontra seu desempenho ótimo de operação dentro de uma faixa de tolerância especificada pelo fabricante. A operação fora deste intervalo pode induzir queda no desempenho e também em falha do equipamento (ACCIOLY, 1995).

Segundo Lafraia (2001), os equipamentos falham devido a três fatores básicos: falha de projeto, falha na fabricação ou falha na utilização do 
equipamento/sistema. As falhas de projeto ocorrem quando o projetista não consegue identificar claramente as necessidades do cliente ou quando estas não estão adequadamente identificadas e não se consegue aplicar os requisitos de engenharia corretos para a aplicação. Uma vez que o projeto tenha sido adequadamente abordado, a fase de fabricação pode provocar falhas quando os processos de fabricação/montagem são ainda inadequados para o produto sendo processado. O processo inclui pessoal capacitado e equipamentos adequados. Além disso, o uso incorreto do produto, que inclui manutenção inadequada, seja por falta de instrução do fabricante ou de treinamento do cliente, também, pode ser a causa da falha.

Algumas técnicas podem ser adotadas na atividade de análise de falhas, como por exemplo, a investigação de acidentes e incidentes, o estudo e melhoria da confiabilidade do produto/sistema, a realização de um FMEA (análise de modo de falha e efeito), ou uma análise de árvores de falha, onde a escolha de um ou outro método de análise depende de vários fatores, como por exemplo se a falha já aconteceu ou se o produto / sistema está em fase de projeto, se o mais importante é identificar quais falhas são possíveis no sistema ou como uma dada falha poderá ocorrer, etc. Por outro lado, a construção de operações com recursos críticos redundantes, a eliminação dos pontos de falha potenciais na operação e a tentativa de tornar as atividades da operação à prova de falhas são técnicas para eliminar no projeto os pontos de falha potenciais na fase de operação e aumentar a confiabilidade das operações.

Os sistemas que utilizam redundâncias podem tolerar um certo número de falhas internas independentes enquanto continuam a manter uma saída, ou resposta, adequada. Porém, são vulneráveis ao que pode ser chamado de falhas de modo comum. Estas falhas são provocadas por influências no sistema vindas de alguma origem comum a todos os canais redundantes e, como resultado, o sistema apresenta um estado anormal de saída. Portanto as falhas de modo comum são chamadas desta forma, pois são falhas que quando ocorrem, levam o sistema global a falhar.

\subsubsection{Natureza das falhas}

Existe uma ideia usual de que a melhor maneira de se otimizar a disponibilidade de sistemas é através da execução de algum tipo de manutenção preventiva 
periódica, que normalmente tem o objetivo de substituição ou recondicionamento de equipamentos e/ou componentes em intervalos fixos. Esta teoria assume que a maioria dos componentes opera confiavelmente durante um determinado tempo e, após, inicia-se um período de desgaste acelerado. Com uma análise estatística de falhas é possível determinar a vida dos componentes, de forma que os sistemas possam adotar medidas preventivas da manutenção para evitar falhas. Segundo Lafraia (2001), isto é correto para componentes simples e para alguns componentes complexos que apresentam modos de falha dominantes, mas quando há um aumento da complexidade do equipamento / sistema estudado, existe uma mudança considerável na natureza das falhas.

Foi realizado um estudo sobre a probabilidade condicional de falhas ao longo do tempo de operação com aviões civis - que contém uma grande variedade de componentes mecânicos e elétricos, isto é, um sistema altamente complexo, onde o resultado contradiz a suposição de que sempre há uma conexão entre a confiabilidade e o tempo de operação (MOUBRAY, 1997). Esta afirmação leva a ideia de que quanto mais cedo for a intervenção de manutenção, menor será a probabilidade de falha, porém a menos que algum modo de falha predominante e dependente do tempo esteja presente, não há relação alguma entre a idade do equipamento e sua confiabilidade, e manutenções programadas podem, na verdade, aumentar a taxa de falhas, através da introdução de falhas prematuras que não existiam no sistema. Logo, a manutenção corretiva pode ser mais efetiva em caso de falhas sem maiores consequências, e quando estas forem mais graves, a manutenção preventiva assume como a melhor opção.

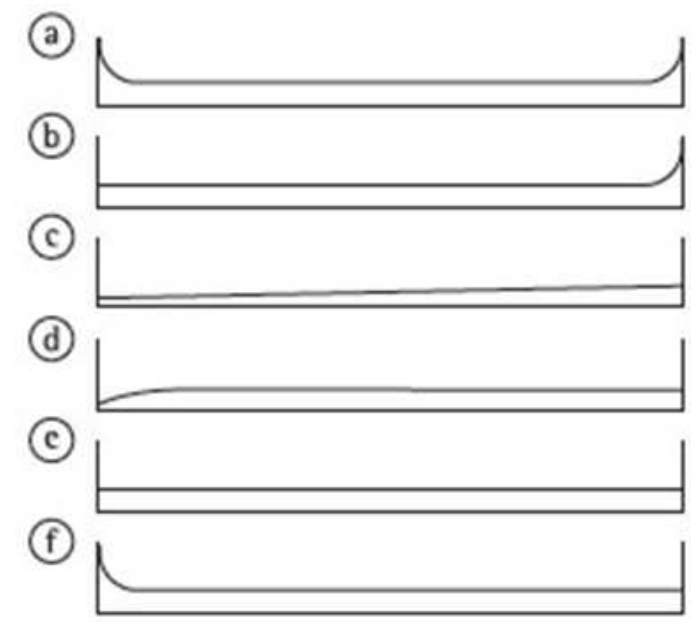

Figura 4-2 Tipos de probabilidades condicionais de falhas 
O modo de falha apresentado na curva "a" (Figura 4-2) é a tradicional curva da banheira, e o modo de falha na curva "b" mostra uma taxa de falha gradualmente crescente e uma zona de desgaste acentuado. O modo de falha apresentado na curva "c" mostra uma taxa de falha levemente crescente, porém sem nenhuma zona de desgaste bem definida. O modo "d" representa uma taxa de falha baixa quando o componente é novo ou recém-saído de fábrica, seguido de um patamar de taxa de falhas constante. O modo "e" apresenta uma taxa de falha constante durante toda a vida do componente. O modo de falha "f" inicia com uma redução rápida da taxa de falha, seguido de um período de taxa de falha constante. No levantamento de dados realizado no estudo, a seguinte distribuição das falhas foi observada:

\section{Percentual de Falhas Observadas}

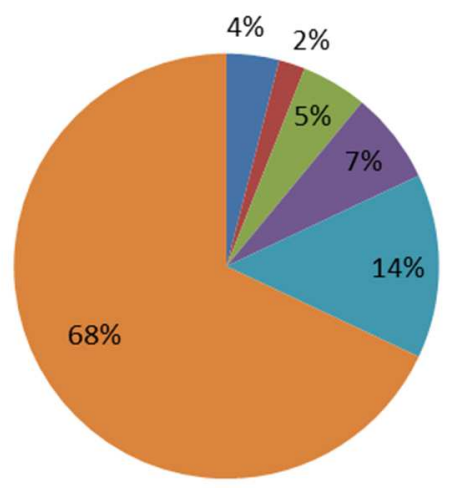

- Curva a

a Curva b

- Curva c

- Curva d

- Curva e

n Curvaf

Figura 4-3 - Estudo da probabilidade condicional de falhas ao longo do tempo

Algumas análises podem ser realizadas a partir deste resultado. Somente uma parte muito pequena - $4 \%$ - dos componentes realmente replicam o conceito tradicional da curva da banheira (curva a); Somente $6 \%$ dos componentes (somatório das curvas a e b) experimentou uma região distinta de envelhecimento durante a vida útil da frota de aviões; Reciprocamente, $89 \%$ dos componentes nunca "viram" nenhum mecanismo de envelhecimento ou desgaste desenvolvido ao longo da vida útil dos componentes das aeronaves (curvas $d$, e e f). Portanto, enquanto a percepção comum tende a acreditar que 9 entre 10 componentes assumem o comportamento da curva da banheira, as análises indicaram que isto não se confirma quando os fatos são conhecidos; $72 \%$ dos componentes (somatórios das curvas a e f) experimentaram o fenômeno de mortalidade infantil e; $68 \%$, isto é, a maior parte do grupo de componentes (curva f), iniciaram 
conforme as características da curva da banheira, mas nunca alcançaram a região de envelhecimento.

Uma observação importante é que na região de taxa de falhas constante, as falhas dos equipamentos são randômicas por natureza - isto é, o "estado da arte" não é desenvolvido para o ponto onde podemos prever qual mecanismo de falha pode estar envolvido, nem saberemos precisamente quando a falha irá ocorrer. Só se sabe que, em uma grande amostra, a taxa de falha é constante. É claro que o trabalho para se ter esta taxa de falha a menor possível sempre acontecerá, e para isso temos que trabalhar em aumentar a confiabilidade dos componentes do sistema. Mas, para Moubray (1997), as regiões de taxa de falhas constante significam que as ações de reparo irão, essencialmente, fazer muito pouco - ou nada - para recuperar o equipamento para a condição de novo. Nesta região, reparos normalmente são perda de dinheiro porque realmente não sabemos o que restaurar, nem o tempo correto para realizar a restauração.

Outro problema em realizar reparos na região de taxa de falhas constante é que estas ações de reparo poderão ser prejudiciais, já que existe a possibilidade de trazer, inadvertidamente, o equipamento para a região da curva da banheira de mortalidade infantil. Se analisarmos o estudo mostrado acima, reparos em $72 \%$ dos componentes (isto é, o somatório das curvas A e F) seriam susceptíveis a esta situação. Outro ponto está relacionado com a periodicidade que deve ser especificada a revisão quando considerado a opção correta. Por exemplo, se um componente segue o comportamento das curvas a ou b, gostaríamos de garantir que o reparo não aconteça muito cedo, ou também estaremos realizando uma perda de recursos. Frequentemente, não sabemos o período correto para realizar o reparo, ou mesmo se uma tarefa é a coisa certa a fazer, pois não temos dados suficientes para amarrar aos padrões de falhas relativa à idade.

Para Frota (2003), onde foram analisadas as falhas em todo o sistema poço, englobando todos os seus componentes, inclusive a linha surgência que o interliga à plataforma de produção, e foi adotado um modo de falha pelo elo mais fraco. Aplicando isto ao conceito de um poço pode-se observar que o mesmo funciona como um conjunto de elementos em série, em que a falha de um dos elementos implica na falha de todo o conjunto. Somente a interrupção total do funcionamento do sistema (poço fechado), devido a falha de um dos seus componentes vitais, que demanda uma sonda de intervenção, é considerada propriamente como falha. 


\subsubsection{Falhas Relacionadas à Idade}

As curvas "a" e "b" da Figura 4-2 ilustram o comportamento da taxa de falhas de componentes que apresentam falhas relacionadas à idade. Nestes casos, a resistência à tensão aplicada diminui com o tempo, e de maneira diferente para equipamentos idênticos, o que torna a previsão da falha extremamente difícil, porém técnicas de vida residual podem dar uma ideia da vida média e da variabilidade da vida esperada.

\subsubsection{Falhas Aleatórias - Componentes Complexos}

Falhas são denominadas aleatórias quando não é possível prever quando elas ocorrerão. Estas falhas podem ocorrer pois a deterioração dos equipamentos / sistemas nem sempre são proporcionais à tensão aplicada, da mesma forma que a tensão nem sempre é aplicada consistentemente. As curvas "c", "d", "e" e "f" da figura 4.2 mostram o comportamento da taxa de falhas de componentes apresentam falhas aleatórias.

Para componentes complexos, os processos de falha tornam-se pouco previsíveis quando comparados com componentes mais simples. $\mathrm{O}$ aumento da complexidade é feito com os objetivos de melhorar o desempenho, seja pela incorporação de novas tecnologias ou pela maior automação, ou para melhorar a segurança, através da incorporação de redundâncias e equipamentos de proteção. As consequências de uma maior complexidade são um aumento do número de componentes que podem falhar, além do número de interfaces e conexões entre os componentes, que aumenta o número e a variedade das possíveis falhas. Isto mostra que componentes complexos estão muito mais sujeitos a falhas aleatórias do que componentes simples, e o período de desgaste geralmente não se aplica nestes casos, fazendo com que substituições programadas para evitar falhas podem não trazer nenhuma efetividade.

\subsubsection{O Conceito de Falha para o Trabalho}

Para este trabalho, a definição de falha pode ser um pouco mais complicada. O sistema controle da válvula de segurança de sub-superfície para águas profundas contém algumas características importantes: 
- O sistema contém equipamentos em série e em paralelo, e é subdividido em sistema principal e sistema reserva;

- Como equipamento de segurança, possui o sistema "fail safe close", isto é, em caso de perda de pressão do sistema, a válvula fecha, interrompendo a produção do poço.

- Atualmente, na maioria dos casos, o sistema "reserva", que fica em paralelo com o sistema principal, não fica pressurizado. Na nomenclatura do processo de Markov, o sistema paralelo atualmente utilizado é um sistema paralelo em espera sem carga. Isso implica no fechamento da válvula caso o sistema principal perca pressão, causando a parada da produção do poço até que o sistema reserva seja acionado e passe a ser pressurizado.

O problema é que, apesar de haver parada da produção pelo fechamento da válvula devido à uma falha do sistema principal, o sistema reserva não apresentou falha neste ponto, e assim que o sistema reserva seja pressurizado, a válvula torna a abrir e a produção é retomada. Assim, o sistema como um todo não pode ser considerado falho, pois foi projetado desta forma.

Por outro lado, este trabalho tem o objetivo de um enfoque de produção, e assim não faz sentido desconsiderar o tempo de parada da produção de um poço que está com seu sistema principal falho e com o sistema reserva despressurizado, o que pode demorar horas, até dias. A pergunta a ser respondida é a seguinte:

Quanto tempo de parada de produção do poço é aceitável, antes de o sistema reserva entrar em operação, para que o sistema como um todo não seja considerado falho?

Analisando os extremos como resposta à pergunta acima, temos:

- Nenhum tempo é aceitável \#1. Isto quer dizer que, caso o sistema principal falhe e o sistema em paralelo se encontre em stand by, uma das opções seria considerar que todo o sistema falhou, e assim não dizer que existe um sistema "em paralelo", e sim um outro sistema totalmente independente que será ativado caso este sistema falhe. Neste caso, podemos levar em consideração que só 
existe um sistema, todo em série, e que existe um "tempo de manutenção" para que todo o sistema retorne à operação.

- Nenhum tempo é aceitável \#2. Caso o sistema principal falhe e o sistema em paralelo se encontre ativo, pode-se assumir todo o sistema como foi projetado e assim a efetividade dos equipamentos em paralelo seria notada e levada em consideração na formulação da solução do problema.

- O tempo não importa, desde que o sistema retorne à operação. Neste caso, assumiremos que o sistema está efetivamente com um sistema paralelo em espera sem carga, e que o tempo de retorno não tem nada a ver com o sistema em si, e sim com problemas de logística e disponibilidade de barcos de operação para realizar a operação de alinhamento e pressurização do sistema reserva.

Neste estudo foi escolhido a resposta "Nenhum tempo é aceitável \#2'.

\subsection{Distribuições Estatísticas}

A engenharia de confiabilidade apresenta várias distribuições que descrevem o comportamento de uma população ou de sistemas com suas probabilidades de falhas. Dois dos principais modelos de distribuições são descritos a seguir.

\subsubsection{Distribuição exponencial}

A distribuição exponencial caracteriza-se por uma taxa de falha constante $\lambda$. É uma distribuição onde o parâmetro principal é a própria taxa de falha $\lambda$. Sua aplicação se dá no período de vida útil do item analisado, e sua função da taxa de falha é a seguinte:

$$
\lambda(\boldsymbol{t})=\lambda
$$

E as funções de confiabilidade e probabilidade de falha podem ser escritas como:

$$
\begin{aligned}
& R(t)=e^{-\lambda t} \\
& Q(t)=1-e^{-\lambda t}
\end{aligned}
$$

Além disso, o MTTF passa a ser um valor constante e igual ao inverso da taxa de falha: 


$$
M T T F=\frac{1}{\lambda}
$$

Uma das mais importantes leis de falhas é aquela cuja duração até falhar é descrita pela distribuição exponencial (MEYER, 1984). A característica de taxa de falha constante implica na ausência de memória, isto é, não importa o tempo de operação do equipamento, este irá falhar sempre pelo seu acaso. Esta característica também pode significar que, após o componente ou sistema estiver em uso, sua probabilidade de falhar não será alterada. Isto quer dizer que enquanto o componente ou sistema estiver funcionando ele será "como se fosse novo".

As aplicações da distribuição exponencial podem ser empregadas nas seguintes situações, segundo Lafraia (2001):

- Falhas de equipamentos com mais de 200 componentes sujeitos a mais de três manutenções corretivas/preventivas;

- Sistemas complexos não redundantes;

- Sistemas complexos com componentes com taxas de falha independentes;

- Sistemas com dados de falha mostrando causas muito heterogêneas;

- Sistemas de vários componentes, com substituições antes de falhas devido a manutenção preventiva.

\subsubsection{Distribuição de Weibull}

$\mathrm{Na}$ distribuição de Weibull, os parâmetros que caracterizam esta distribuição são o parâmetro de escala $\alpha$ e o parâmetro de forma $\beta$, que representa um modelo apropriado para uma lei de falhas, sempre o sistema for composto de vários componentes e a falha seja essencialmente devida à imperfeição "mais grave", dentre um grande número de imperfeições (MEYER, 1984).

Pela distribuição de Weibull podemos obter tanto uma taxa de falhas crescente como uma decrescente, pela simples escolha adequada do parâmetro $\beta$, e caso este parâmetro seja igual a 1, obteremos uma distribuição exponencial. Isto quer dizer que a distribuição exponencial é um caso particular da distribuição de Weibull. Além disso, esta é uma das distribuições mais utilizadas na análise de falhas, e sua função densidade de probabilidade (fdp) tem a seguinte forma: 


$$
f(t)=\frac{\beta}{\alpha}\left(\frac{t}{\alpha}\right)^{\beta-1} E X P\left[-\left(\frac{t}{\alpha}\right)^{\beta}\right], \quad t \geq 0
$$

Onde $\beta \geq 0$ é o fator de forma e $\alpha \geq 0$ é o fator de escala. Para casos em que $\beta$ $=1$, a distribuição de Weibull se transforma em uma exponencial. Quando $\beta<1$, a distribuição apresenta taxa de falha decrescente com o tempo e quando $\beta>1$, a taxa de falha passa a ser crescente.

\subsection{Análise Markoviana}

A análise Markoviana constitui-se em uma poderosa e flexível técnica de modelagem amplamente empregada em análises dinâmicas de confiabilidade e disponibilidade de sistemas. O comportamento da confiabilidade de um sistema é representado usando-se um diagrama de transições entre estados, o qual consiste em um conjunto de estados discretos nos quais o sistema pode se encontrar em um determinado momento, e define as taxas segundo as quais transições entre esses estados podem ocorrer. Desta forma, modelos Markovianos consistem em representações de cadeias de eventos, ou seja, transições dentro do sistema que, no contexto da análise de confiabilidade e disponibilidade, correspondem a sequências de falhas e reparos.

Modelos Markovianos fornecem grande flexibilidade na modelagem do comportamento dinâmico de sistemas. Eles podem ser usados em situações nas quais o emprego de modelos paramétricos simples do tempo de falha como as distribuições Exponencial e de Weibull não são suficientes para descrever as características dinâmicas da confiabilidade e disponibilidade de um sistema, como pode ser o caso de sistemas com redundâncias em standby.

Além disso, descrevem o comportamento dinâmico de um sistema em termos de um conjunto de estados em que o mesmo pode ocupar em um determinado instante, assim como através da possibilidade e velocidade de transições entre esses estados. Estes estados, por sua vez, podem representar condições do sistema como operacional, degradado, em standby, falho, e em manutenção. As transições entre estados são causadas por diversos mecanismos e eventos como inspeções, falhas, reparos, e operações de transferência de controle (switching). Considerando, por exemplo, o caso mais simples de um sistema com dois possíveis estados: operacional (sistema disponível) e falho (sistema indisponível), transições entre os estados poderiam representar os processos de falha e reparo 
aos quais o sistema é submetido. Portanto, o comportamento dinâmico do sistema pode ser considerado como a sequência de estados ocupados pelo sistema à medida que o tempo evolui. Um modelo Markoviano é então a representação de todas as sequências de estados e suas propriedades temporais.

Graficamente, um modelo de Markov é tipicamente representado através de um conjunto de nós e setas, onde os "nós" representam os estados que o sistema pode ocupar e as setas correspondem às transições entre estados.

A análise de modelos de Markov geralmente envolve a determinação da probabilidade de que o sistema estará em um determinado estado em função do tempo. Por exemplo, considerando que no instante $t=00$ sistema se encontra no estado inicial 0 , cálculos são realizados para determinar a probabilidade de que o sistema esteja em um dos outros possíveis estados em um dado instante $t$. Em um dado instante $t$, a soma das probabilidades dos estados dever ser igual a 1 , ou seja, se a probabilidade de o sistema estar em um dado estado decresce de uma quantidade $x$, então a mesma quantidade $x$ deve ser distribuída pelos outros estados do sistema.

\subsubsection{Processos de Markov}

De acordo com lbe (2013), os processos de Markov são classificados de acordo com a natureza do tempo e com a natureza do estado. Com relação ao estado, o processo de Markov pode ser classificado como discreto ou contínuo. O processo de Markov discreto é chamado cadeia de Markov. Com relação ao tempo, um processo de Markov também pode ser classificado como discreto ou contínuo. Então, há quatro tipos básicos do processo de Markov:

a) Cadeia de Markov, discreto no tempo

b) Cadeia de Markov, contínuo no tempo

c) Processo de Markov, discreto no tempo

d) Processo de Markov, contínuo no tempo

A classificação dos processos de Markov estão ilustradas na tabela 4.3 
Tabela 4-1 - Classificação dos Processos de Markov

\begin{tabular}{cccc} 
& & \multicolumn{2}{c}{ Espaço } \\
\cline { 2 - 3 } & Discreto & Discreto & Contínuo \\
\hline \multirow{3}{*}{ Tempo } & Cadeia de Markov, discreto no tempo & $\begin{array}{c}\text { Processo de } \\
\text { Markov, discreto no } \\
\text { tempo }\end{array}$ \\
\cline { 2 - 4 } & Contínuo & Cadeia de Markov, contínuo no tempo & $\begin{array}{c}\text { Processo de } \\
\text { Markov, contínuo no } \\
\text { tempo }\end{array}$ \\
\hline
\end{tabular}

Para este estudo, será utilizado o processo de Markov contínuo no tempo. Abaixo será descrito, com mais detalhes, a ideia da análise pelo processo de Markov, com um, dois e três componentes, para exemplificar o estudo.

\subsubsection{Análise de 1 componente}

O diagrama de blocos para a representação de apenas 1 componente pode ser visto na figura abaixo:

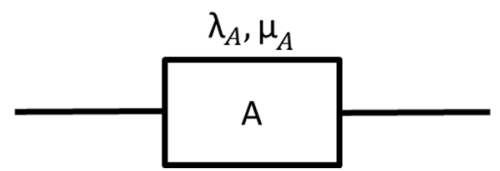

Figura 4-4 - Diagrama de blocos - 1 componente

Onde $\lambda_{\mathrm{A}}$ e $\mu_{\mathrm{A}}$ são as taxas de falha e a de reparo do componente $A$, respectivamente.

Tabela 4-2 - Estados - 1 componente

\begin{tabular}{ccc}
\hline Estado & Componente A & Situação \\
\hline 1 & OK & Disponível \\
\hline 2 & Falho & Indisponível \\
\hline
\end{tabular}

Neste caso, pode-se ter dois estados para este "sistema": disponível ou indisponível, e com as informações acima, pode-se agora montar o diagrama de transição de estados, no caso de 1 componente: 


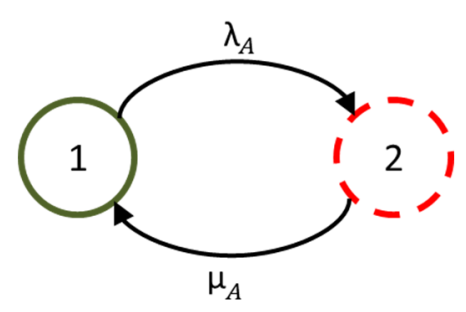

Figura 4-5 - Diagrama de transição - 1 componente

Pode-se estruturar o sistema de equações para o estudo da disponibilidade:

$$
\begin{aligned}
& \mathbf{A}(\mathbf{t}+\Delta \mathbf{t})=\boldsymbol{p}_{1}(\mathbf{t}+\Delta \mathbf{t})=\mathbf{p}_{1}(\mathbf{t})\left[\mathbf{1}-\lambda_{\mathrm{A}} \Delta \mathbf{t}\right]+\mathbf{p}_{2}(\mathbf{t}) \mu_{\mathrm{A}} \Delta \mathbf{t} \\
& \frac{d p_{1}(t)}{d t}=-\lambda_{\mathrm{A}} p_{1}(t)+\mu_{A} p_{2}(t)
\end{aligned}
$$

Onde $p_{1}$ é a probabilidade de o componente estar no estado 1 e $p_{2}$ a probabilidade de o equipamento estar no estado 2 .

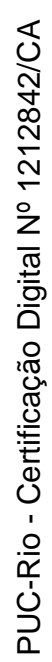

E da indisponibilidade:

$$
\begin{aligned}
& \bar{A}(t+\Delta t)=p_{2}(t+\Delta t)=p_{1}(t) \lambda_{A} \Delta t+p_{2}(t)\left[1-\mu_{A} \Delta t\right] \\
& \frac{d p_{2}(t)}{d t}=\lambda_{A} p_{1}(t)-\mu_{A} p_{2}(t)
\end{aligned}
$$

Assim, tem-se a seguinte matriz de transição

$$
\left|\begin{array}{l}
p_{1}^{\prime} \\
p_{2}^{\prime}
\end{array}\right|=\left|\begin{array}{cc}
-\lambda_{A} & \mu_{A} \\
\lambda_{A} & -\mu_{A}
\end{array}\right|\left|\begin{array}{l}
p_{1} \\
p_{2}
\end{array}\right|
$$

E considerando a condição inicial igual a $p_{1}(0)=1$, temos a seguinte solução:

$$
\begin{aligned}
& \boldsymbol{A}(\boldsymbol{t})=\frac{\mu}{\lambda+\mu}+\frac{\lambda}{\lambda+\mu} e^{-(\lambda+\mu) t} \\
& \overline{\mathrm{A}}(\boldsymbol{t})=\frac{\lambda}{\lambda+\mu}-\frac{\lambda}{\lambda+\mu} e^{-(\lambda+\mu) t}
\end{aligned}
$$

\subsubsection{Dois componentes em paralelo}

Como segundo exemplo, é apresentado abaixo o diagrama de blocos com dois componentes em paralelo: 


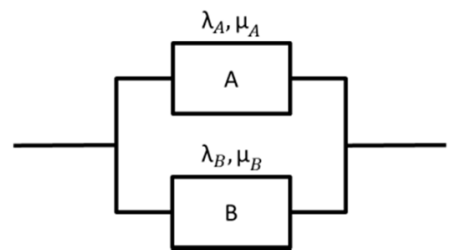

Figura 4-6 - Diagrama de blocos - 2 componentes em paralelo

Agora, ao invés de se ter somente dois estados possíveis passa-se a ter um total de $2^{2}=4$ estados, onde a taxa de falha e taxa de reparo são constantes e iguais a $\lambda$ e $\mu$, respectivamente.

Tabela 4-3 - Tabela de estados - dois componentes

\begin{tabular}{cccc}
\hline Estado & Componente & Componente & Situação \\
& A & B & \\
\hline 1 & OK & OK & Disponível \\
\hline 2 & Falho & OK & Disponível \\
\hline 3 & OK & Falho & Disponível \\
\hline 4 & Falho & Falho & Indisponível \\
\hline
\end{tabular}

Assim como o no primeiro caso, pode-se montar o diagrama de transição de estados:

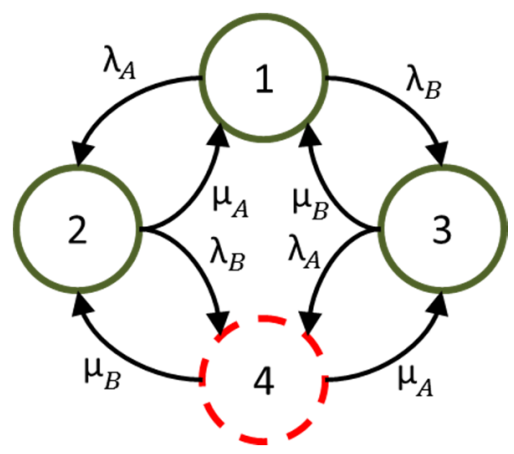

Figura 4-7 - Diagrama de transição - dois componentes em paralelo

Percebe-se que temos três estados onde o sistema se encontra disponível e um estado em que o sistema se encontra indisponível. Pode-se estruturar o sistema de equações para o estudo da disponibilidade:

$$
\begin{aligned}
& \frac{d p_{1}(t)}{d t}=-\left(\lambda_{A}+\lambda_{B}\right) p_{1}(t)+\mu_{A} p_{2}(t)+\mu_{B} p_{3}(t) \\
& \frac{d p_{2}(t)}{d t}=\lambda_{A} p_{1}(t)-\left(\mu_{A}+\lambda_{B}\right) p_{2}(t)+\mu_{B} p_{4}(t)
\end{aligned}
$$




$$
\begin{aligned}
& \frac{d p_{3}(t)}{d t}=\lambda_{\mathrm{B}} p_{1}(t)-\left(\lambda_{A}+\mu_{B}\right) p_{3}(t)+\mu_{A} p_{4}(t) \\
& \frac{d p_{4}(t)}{d t}=\lambda_{\mathrm{B}} p_{2}(t)+\lambda_{A} p_{3}(t)-\left(\mu_{A}+\mu_{B}\right) p_{4}(t)
\end{aligned}
$$

Sendo que a disponibilidade é dada por $A(t)=p_{1}(t)+p_{2}(t)+p_{3}(t)$, e a matriz de transição pode ser escrita como:

$$
\left|\begin{array}{l}
\boldsymbol{p}_{1}^{\prime} \\
\boldsymbol{p}_{2}^{\prime} \\
\boldsymbol{p}_{3}^{\prime} \\
\boldsymbol{p}_{4}^{\prime}
\end{array}\right|=\left|\begin{array}{cccc}
-\left(\lambda_{A}+\lambda_{B}\right) & \mu_{A} & \mu_{B} & \mathbf{0} \\
\lambda_{A} & -\left(\mu_{A}+\lambda_{B}\right) & 0 & \mu_{B} \\
\lambda_{B} & 0 & -\left(\lambda_{A}+\mu_{B}\right) & \mu_{A} \\
0 & \lambda_{B} & \lambda_{A} & -\left(\mu_{A}+\mu_{B}\right)
\end{array}\right|\left|\begin{array}{l}
p_{1} \\
p_{2} \\
p_{3} \\
p_{4}
\end{array}\right|
$$

\subsubsection{Três componentes ( $A$ e $B$ em paralelo, $C$ em série)}

O diagrama de blocos que representa este próximo exemplo é mostrado na figura 4.8. Neste caso, os equipamentos $A$ e $B$ se encontram em paralelo enquanto o equipamento $C$ está em série:

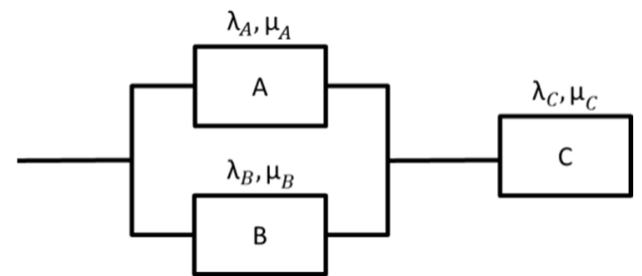

Figura 4-8 - Diagrama de blocos - três componentes

Como temos três equipamentos, um total de $2^{3}=8$ estados serão analisados

Tabela 4-4 - Tabela de estados - três componentes

\begin{tabular}{ccccc}
\hline Estado & Componente & Componente & Componente & Status \\
& A & B & C & \\
\hline 1 & OK & OK & OK & Disponível \\
\hline 2 & Falho & OK & OK & Disponível \\
\hline 3 & OK & Falho & OK & Disponível \\
\hline 4 & OK & OK & Falho & Falho \\
\hline 5 & OK & Falho & Falho & Falho \\
\hline 6 & Falho & Falho & OK & Falho \\
\hline 7 & Falho & OK & Falho & Falho \\
\hline 8 & Falho & Falho & Falho & Falho
\end{tabular}

E, da mesma forma, a taxa de falha e taxa de reparo são constantes e iguais a $\lambda$ e $\mu$, respectivamente. 


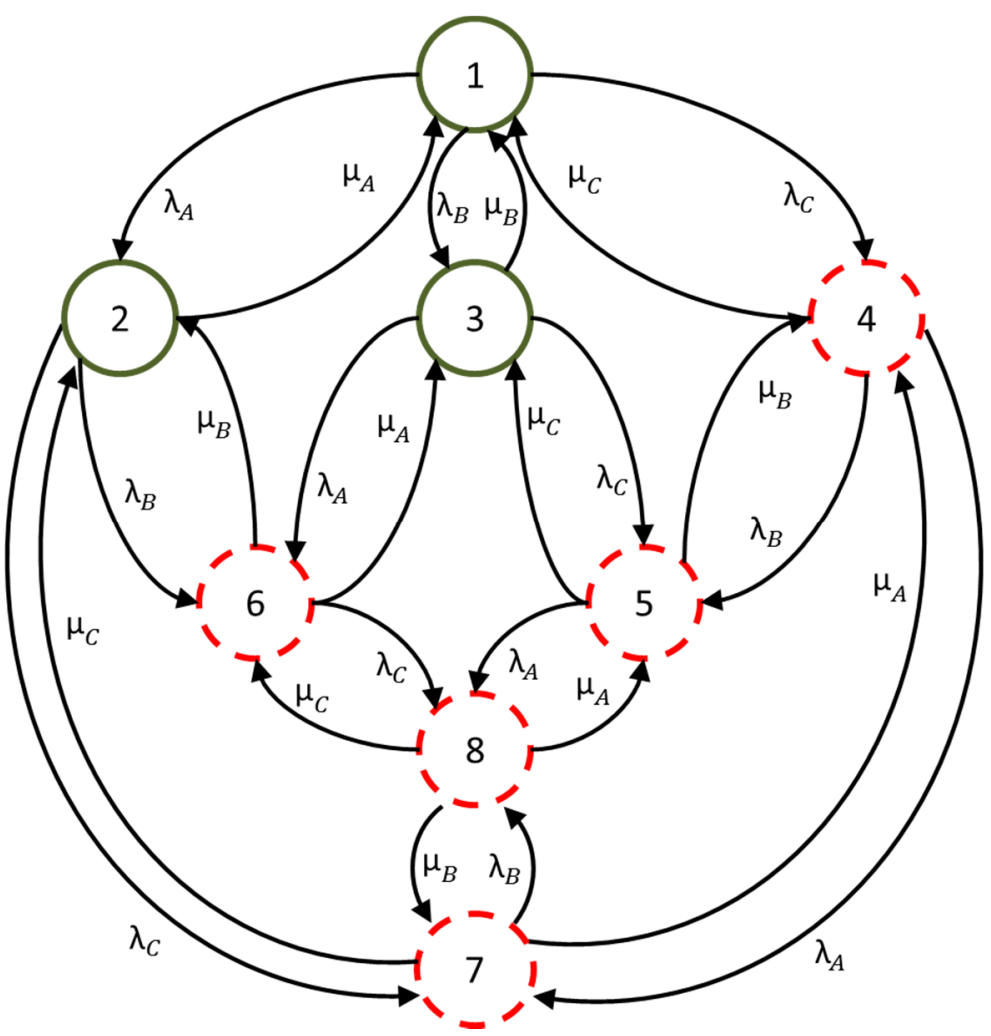

Figura 4-9 - Diagrama de transição - três componentes

Com três componentes no sistema, pode-se notar uma maior complexidade no diagrama de transição de estados, mostrado acima. Este exemplo sugere que, em qualquer estado que se encontre o sistema, existe a possibilidade de reparo dos componentes, e assim o sistema de equações para o estudo da disponibilidade fica:

$$
\begin{aligned}
& \frac{d p_{1}(t)}{d t}=-\left(\lambda_{A}+\lambda_{B}+\lambda_{C}\right) p_{1}(t)+\mu_{A} p_{2}(t)+\mu_{B} p_{3}(t)+\mu_{C} p_{4}(t) \\
& \frac{d p_{2}(t)}{d t}=\lambda_{\mathrm{A}} p_{1}(t)-\left(\mu_{A}+\lambda_{B}+\lambda_{C}\right) p_{2}(t)+\mu_{B} p_{6}(t)+\mu_{C} p_{7}(t) \\
& \frac{d p_{3}(t)}{d t}=\lambda_{\mathrm{B}} p_{1}(t)-\left(\lambda_{A}+\mu_{B}+\lambda_{C}\right) p_{3}(t)+\mu_{C} p_{5}(t)+\mu_{A} p_{6}(t) \\
& \frac{d p_{4}(t)}{d t}=\lambda_{C} p_{1}(t)-\left(\mu_{C}+\lambda_{B}+\lambda_{A}\right) p_{4}(t)+\mu_{B} p_{5}(t)+\mu_{A} p_{7}(t) \\
& \frac{d p_{5}(t)}{d t}=\lambda_{C} p_{3}(t)+\lambda_{B} p_{4}(t)-\left(\mu_{B}+\lambda_{A}+\mu_{C}\right) p_{5}(t)+\mu_{A} p_{8}(t) \\
& \frac{d p_{6}(t)}{d t}=\lambda_{B} p_{2}(t)+\lambda_{A} p_{3}(t)-\left(\mu_{A}+\mu_{B}+\lambda_{C}\right) p_{6}(t)+\mu_{C} p_{8}(t) \\
& \frac{d p_{7}(t)}{d t}=\lambda_{C} p_{2}(t)+\lambda_{A} p_{4}(t)-\left(\mu_{A}+\mu_{C}+\lambda_{B}\right) p_{7}(t)+\mu_{B} p_{8}(t)
\end{aligned}
$$




$$
\frac{d p_{8}(t)}{d t}=\lambda_{\mathrm{A}} p_{5}(t)+\lambda_{C} p_{6}(t)+\lambda_{B} p_{7}(t)-\left(\mu_{A}+\mu_{B}+\mu_{C}\right) p_{8}(t)
$$

Sendo que a disponibilidade é dada por $A(t)=p_{1}(t)+p_{2}(t)+p_{3}(t)$, e a matriz de transição fica:

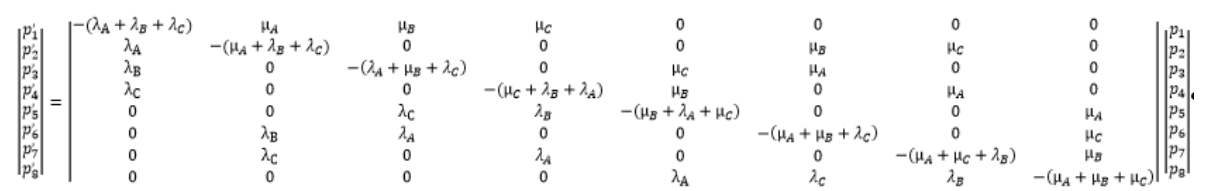

Com os exemplos acima, podemos observar que quanto mais equipamentos tivermos no sistema, teremos mais estados para serem mapeados e com uma maior complexidade para a solução do sistema. Como exemplo, se tivermos 8 componentes, teremos 256 estados para serem mapeados, além da necessidade de termos uma matriz de transição que poderá ser resolvida através de transformada de Laplace.

Porém, os exemplos mostrados até agora não contemplam a vida real, pois normalmente em um sistema mais complexo existe uma interdependência entre as taxas de falha dos equipamentos do sistema, seja pelo posicionamento dos equipamentos, seja pelo modelo de acionamento dos equipamentos em paralelo.

Abaixo serão descritos com mais detalhes os modelos de sistemas que podemos encontrar, onde estas interdependências aparecem:

- Sistemas com dois componentes - equipamentos ativos independentes:

- Sistema em série;

- Sistema em paralelo ativo - cargas independentes;

- Sistema com dois componentes paralelo ativo - cargas compartilhadas;

- Sistema com dois componentes paralelo em espera (Standby System):

- Sistema ideal;

- Considerando falha da unidade "em espera";

- Considerando falha no equipamento de acionamento do sistema em espera;

- Considerando efeitos combinados;

- Sistemas com mais de dois componentes 


\subsubsection{Sistemas dois componentes - Equipamentos ativos independentes}

Um sistema com dois componentes em paralelo poderá ter somente quatro possíveis estados, os quais estão descritos na Tabela 4-3. O diagrama de transição de estados representa a lógica de mudança de estados para este caso particular. As taxas de falhas $\lambda_{A}$ e $\lambda_{B}$ das unidades $A$ e $B$ representam as taxas nas quais as transições são realizadas entre os estados.

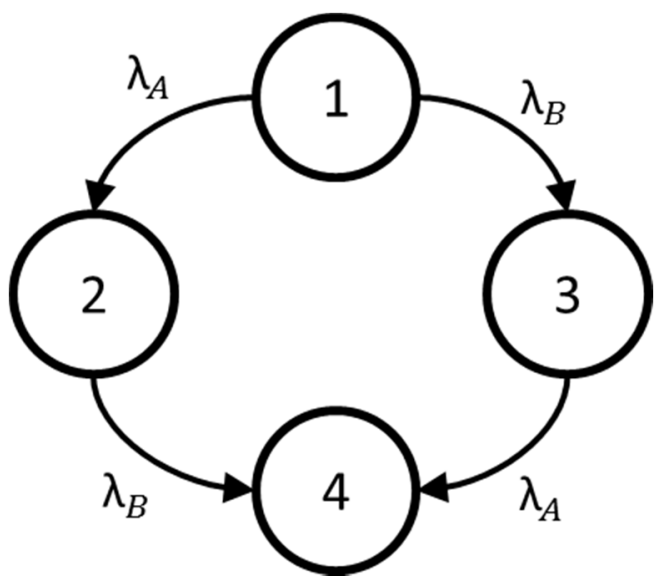

Figura 4-10 - Diagrama de transição - equipamentos ativos independentes

Sendo $\lambda_{A} \Delta t$ a probabilidade do componente A falhar entre os temos t e $t+\Delta t$, e levando em consideração que ele esteja operando em $t$, podemos escrever a rede de mudanças da probabilidade que o sistema tem de estar no estado 1:

$$
p_{1}(t+\Delta t)-p_{1}(t)=-\lambda_{A} \Delta t p_{1}(t)-\lambda_{B} \Delta t p_{1}(t)
$$

ou

$$
\frac{d p_{1}(t)}{d t}=-\lambda_{\mathrm{A}} p_{1}(t)-\lambda_{\mathrm{B}} p_{1}(t)
$$

Para os demais estados, podemos escrever:

$$
\begin{aligned}
\frac{d p_{2}(t)}{d t}= & \lambda_{\mathrm{A}} p_{1}(t)-\lambda_{\mathrm{B}} p_{2}(t) \\
\frac{d p_{3}(t)}{d t}= & \lambda_{\mathrm{B}} p_{1}(t)-\lambda_{\mathrm{A}} p_{3}(t) \\
& \frac{d p_{4}(t)}{d t}=\lambda_{\mathrm{B}} p_{2}(t)+\lambda_{\mathrm{A}} p_{3}(t)
\end{aligned}
$$


Deve-se então resolver as equações diferenciais ordinárias acima para obter as probabilidades dos respectivos estados. Começando pela equação de $\mathrm{p}_{1}(\mathrm{t})$, já que esta não depende de nenhum outro $\mathrm{p}_{\mathrm{i}}(\mathrm{t})$, e utilizando as condições iniciais: $\mathrm{p}_{1}(0)=1$ e $p_{i}(0)=0, \mathrm{i} \neq 1$, obtemos, por substituição:

$$
P_{1}(t)=e^{-\left(\lambda_{A}+\lambda_{B}\right) t}
$$

Para achar $\mathrm{p}_{2}(\mathrm{t})$, substitui-se a equação acima na EDO original:

$$
\frac{d p_{2}(t)}{d t}=\lambda_{A} e^{-\left(\lambda_{A}+\lambda_{B}\right) t}-\lambda_{\mathrm{B}} p_{2}(t)
$$

$E$ assim, a equação também fica somente em função de $p_{2}(t)$. A solução da equação da cima está descrita abaixo:

$$
P_{2}(t)=e^{-\lambda_{B} t}-e^{-\left(\lambda_{A}+\lambda_{B}\right) t}
$$

Realizando o mesmo estudo para $p_{3}(t)$, obtemos a seguinte solução:

$$
P_{3}(t)=e^{-\lambda_{A} t}-e^{-\left(\lambda_{A}+\lambda_{B}\right) t}
$$

E para o cálculo de $\mathrm{p}_{4}(\mathrm{t})$ podemos utilizar:

$$
P_{4}(t)=1-\sum_{i=1}^{3} P_{i}(t)=1-e^{-\lambda_{A} t}-e^{-\lambda_{B} t}+e^{-\left(\lambda_{A}+\lambda_{B}\right) t}
$$

\subsubsection{Sistema em série}

No item anterior, foram analisados dois equipamentos ativos e descritas as probabilidades de que este sistema esteja em cada estado possível, porém não foi identificado se estes dois equipamentos estão em paralelo ou em série. Obviamente, a disposição dos equipamentos faz toda diferença para o cálculo da confiabilidade do sistema, e será analisado o caso onde as duas unidades se encontram em série. Com os equipamentos em série, qualquer falha irá causar a falha do sistema. 
Tabela 4-5 - Tabela de estados - Equipamentos em série

\begin{tabular}{cccc}
\hline Estado & Componente & Componente & Situação \\
& A & B & \\
\hline 1 & OK & OK & Disponível \\
\hline 2 & Falho & OK & Indisponível \\
\hline 3 & OK & Falho & Indisponível \\
\hline 4 & Falho & Falho & Indisponível \\
\hline
\end{tabular}

Da mesma forma, podemos escrever o diagrama de blocos para dois componentes em série:

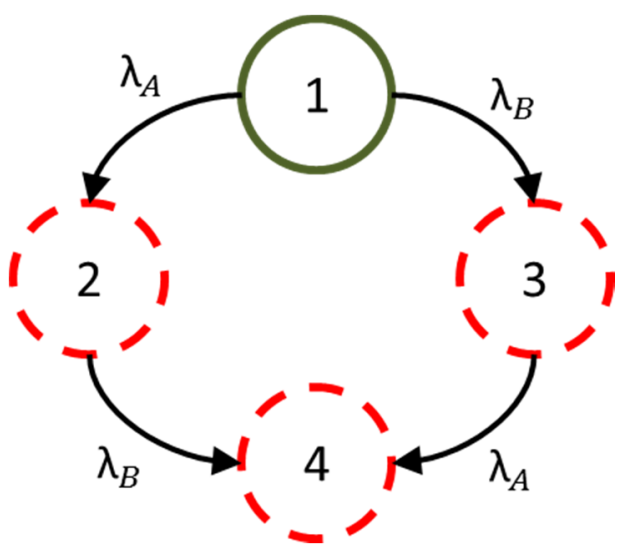

Figura 4-11 - Diagrama de transição - sistema em série

Portanto, a confiabilidade pode ser descrita como:

$$
R(t)=P_{1}(t)=e^{-\left(\lambda_{A}+\lambda_{B}\right) t}
$$

\subsubsection{Sistema em paralelo ativo - cargas independentes}

Em um sistema em paralelo ativo, os dois componentes em paralelo estão exercendo a mesma função em redundância, e as cargas conferidas a cada um deles independe da carga utilizada no componente em paralelo. Neste caso, os dois componentes devem falhar para que haja uma falha do sistema, e podemos escrever tanto a tabela de estados como o diagrama de blocos conforme abaixo: 
Tabela 4-6 - Tabela de estados - Sistema paralelo ativo - cargas independentes

\begin{tabular}{cccc}
\hline Estado & $\begin{array}{c}\text { Componente } \\
\text { A }\end{array}$ & $\begin{array}{c}\text { Componente } \\
\text { B }\end{array}$ & Situação \\
\hline 1 & OK & OK & Disponível \\
\hline 2 & Falho & OK & Disponível \\
\hline 3 & OK & Falho & Disponível \\
\hline 4 & Falho & Falho & Indisponível \\
\hline
\end{tabular}

Da mesma forma, podemos escrever o diagrama de blocos para dois componentes em série:

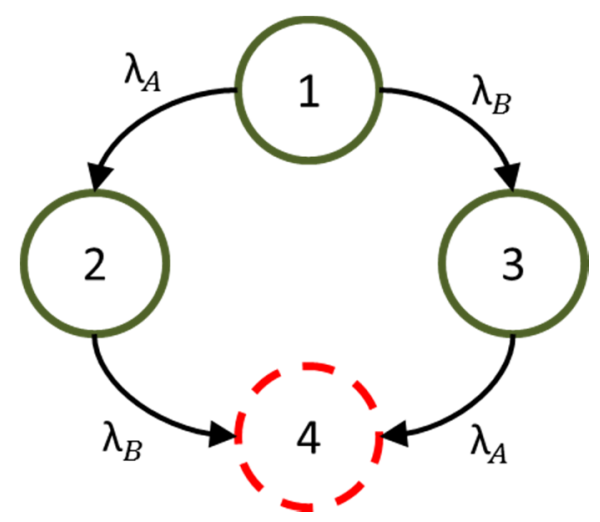

Figura 4-12 - Diagrama de transição - sistema paralelo ativo - cargas independentes

Com isto, podemos escrever a confiabilidade do sistema como:

$$
\begin{aligned}
& R(t)=P_{1}(t)+P_{2}(t)+P_{3}(t)=1-P_{4}(t) \\
& R(t)=e^{-\lambda_{A} t}+e^{-\lambda_{B} t}-e^{-\left(\lambda_{A}+\lambda_{B}\right) t}
\end{aligned}
$$

\subsubsection{Sistemas dois componentes paralelo ativo - cargas compartilhadas}

A análise anterior assume que as taxas de falha de cada componente são independentes do estado do outro componente. Com isto, os estudos de confiabilidade realizados através do processo de Markov demostram os resultados idênticos aos realizados com outras análises para taxas de falha constante. Porém, vários sistemas se comportam de maneira um pouco diferente do apresentado até agora, e uma destas características é o compartilhamento de cargas em um sistema em paralelo. Nestes casos, não podemos mais assumir que as taxas de falha dos componentes são independentes do estado do sistema. 
Como exemplo, imaginemos que dois geradores elétricos dividem a carga elétrica fornecida, sendo que apenas um gerador seria capaz de fornecer esta carga. É de se esperar que, no caso de pane de um gerador, o aumento da carga no segundo gerador irá aumentar sua taxa de falha.

No estudo deste modelo, continuamos com quatro estados possíveis, porém o diagrama de transição possui agora taxas de falha diferenciadas dos equipamentos, uma vez que o outro está falho. As taxas de falha $\lambda_{A}^{*}$ e $\lambda_{B}^{*}$ representam o aumento da taxa de falha advinda do aumento da carga, após a falha do outro componente acontecer.

O diagrama de transição de estados é mostrado na figura abaixo:

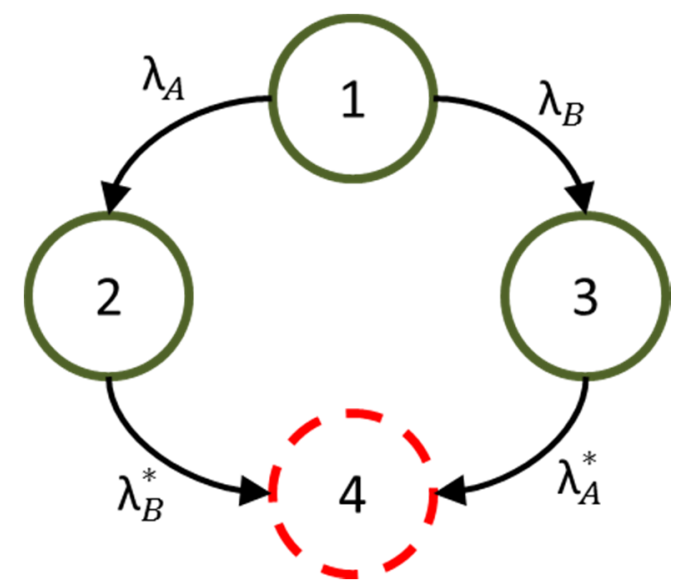

Figura 4-13 - Diagrama de transição - sistema paralelo ativo - cargas compartilhadas

As equações do diagrama de estados do Markov podem ser escritas como:

$$
\begin{aligned}
& \frac{d p_{1}(t)}{d t}=-\lambda_{\mathrm{A}} p_{1}(t)-\lambda_{\mathrm{B}} p_{1}(t) \\
& \frac{d p_{2}(t)}{d t}=\lambda_{\mathrm{A}} p_{1}(t)-\lambda_{B}^{*} p_{2}(t) \\
& \frac{d p_{3}(t)}{d t}=\lambda_{\mathrm{B}} p_{1}(t)-\lambda_{A}^{*} p_{3}(t) \\
& \frac{d p_{4}(t)}{d t}=\lambda_{B}^{*} p_{2}(t)+\lambda_{A}^{*} p_{3}(t)
\end{aligned}
$$

Utilizando as condições iniciais: $p_{1}(0)=1$ e $p_{i}(0)=0$, $i \neq 1$, obtemos os seguintes resultados:

$$
P_{1}(t)=e^{-\left(\lambda_{A}+\lambda_{B}\right) t}
$$




$$
\begin{aligned}
& P_{2}(t)=e^{-\lambda_{B}^{*} t}-e^{-\left(\lambda_{A}+\lambda_{B}^{*}\right) t} \\
& P_{3}(t)=e^{-\lambda_{A}^{*} t}-e^{-\left(\lambda_{A}^{*}+\lambda_{B}\right) t} \\
& P_{4}(t)=1-e^{-\lambda_{A}^{*} t}-e^{-\lambda_{B}^{*} t}-e^{-\left(\lambda_{A}+\lambda_{B}\right) t}+e^{-\left(\lambda_{A}+\lambda_{B}^{*}\right) t}+e^{-\left(\lambda_{A}^{*}+\lambda_{B}\right) t}
\end{aligned}
$$

Também neste sistema, ambos os componentes devem falhar para ocorrer a falha do sistema, e por isso a confiabilidade é escrita como:

$$
\begin{aligned}
& R(t)=P_{1}(t)+P_{2}(t)+P_{3}(t)=1-P_{4}(t) \\
& R(t)=e^{-\lambda_{A}^{*} t}+e^{-\lambda_{B}^{*} t}+e^{-\left(\lambda_{A}+\lambda_{B}\right) t}-e^{-\left(\lambda_{A}+\lambda_{B}^{*}\right) t}-e^{-\left(\lambda_{A}^{*}+\lambda_{B}\right) t}
\end{aligned}
$$

Para analisarmos o efeito do aumento da carga em um sistema redundante de compartilhamento de carga, podem-se considerar dois equipamentos idênticos, isto é, $\lambda_{A}=\lambda_{B}=\lambda$ e $\lambda_{A}^{*}=\lambda_{B}^{*}=\lambda^{*}$, e assim a equação acima pode ser escrita como:

$$
R(t)=2 e^{-\lambda^{*} t}+e^{-2 \lambda t}-2 e^{-\left(\lambda+\lambda^{*}\right) t}
$$

A figura abaixo mostra a confiabilidade $\mathrm{R}(\mathrm{t})$ para um sistema paralelo de dois componentes, variando o aumento da taxa de falha causada pelo incremento da carga no componente funcional. As duas curvas extremas representam os sistemas no qual os dois componentes são independentes $\left(\lambda^{*}=\lambda\right)$, isto é, o sistema em paralelo com taxa de falhas independentes, e o sistema totalmente dependente, no qual a falha de um componente leva automaticamente a falha do outro $\left(\lambda^{*}=\infty\right)$, isto é, o sistema em série. 


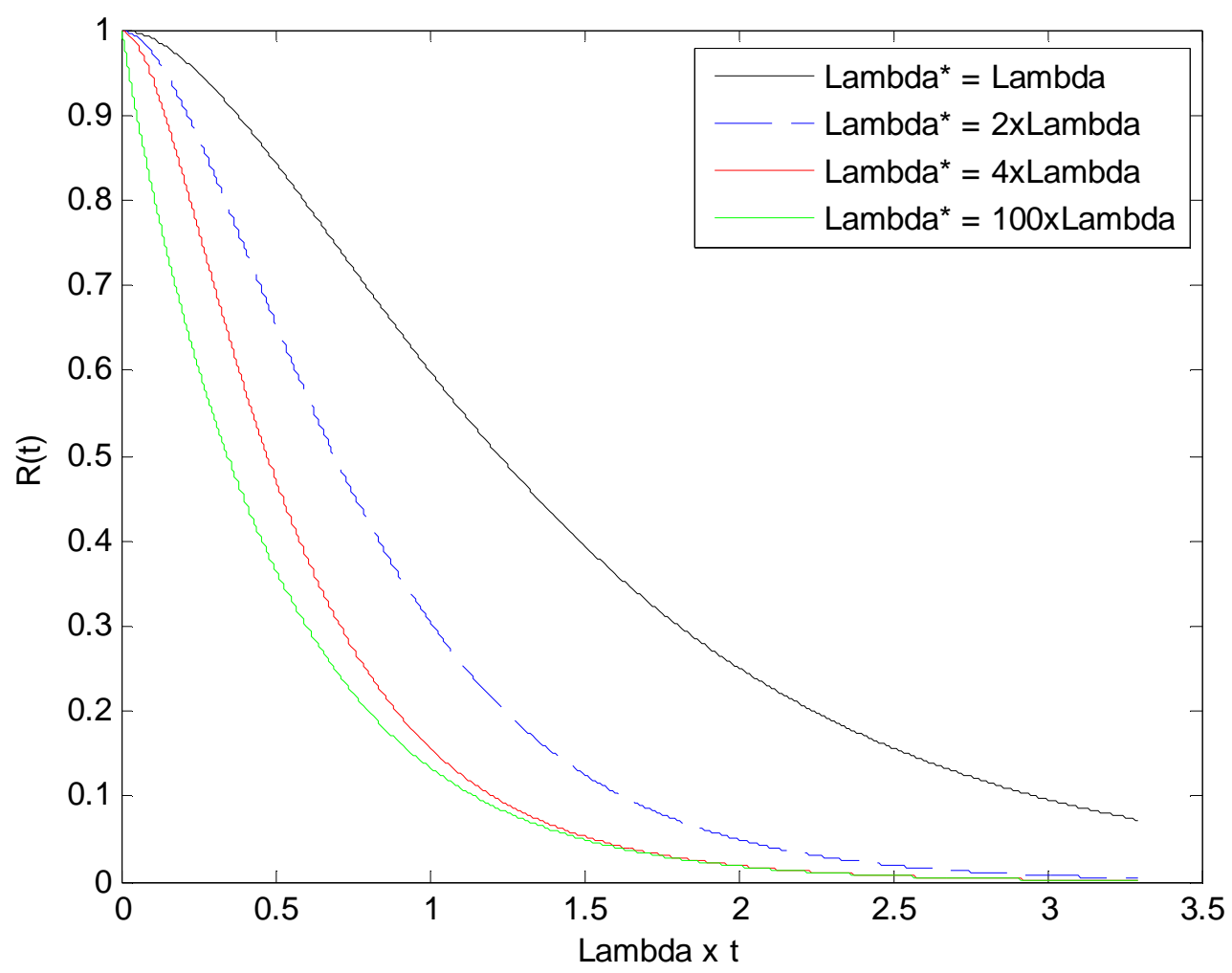

Figura 4-14 - Influencia do incremento da carga na confiabilidade

\subsubsection{Sistema paralelo em espera (Standby System)}

Sistemas em standby são altamente aplicados como redundância em sistemas, como por exemplo, chips lógicos extras, componentes de navegação ou geradores de força de emergência. Estes diferem, porém, dos sistemas paralelos ativos, pois uma das unidades é mantida em espera e somente entra em operação caso a primeira unidade falhe.

\subsubsection{Sistema ideal}

Vamos considerar, inicialmente, um sistema "ideal" de espera (standby), que consistem em uma unidade primária $A$ e uma backup $B$, e que a unidade backup não falhe enquanto não entrar em operação. Levando em consideração os estados de acordo com a tabela abaixo, o sistema pode ser representado pelo diagrama de transição mostrado na figura 4-7. 
Tabela 4-7 - Tabela de descrição dos estados - Sistema paralelo em espera

\begin{tabular}{cccc}
\hline Estado & Componente & Componente & Situação \\
& A & B & \\
\hline 1 & OK & OK & Disponível \\
\hline 2 & Falho & OK & Disponível \\
\hline 3 & OK & Falho & Disponível \\
\hline 4 & Falho & Falho & Indisponível \\
\hline
\end{tabular}

Quando a primeira unidade falha, há uma transição do estado 1 para o estado 2, e quando a unidade backup $B$ falha, há uma transição do estado 2 para o estado 4, com o estado 4 representando a falha do sistema. Percebe-se que, neste caso, não há possibilidade de o sistema passar pelo estado 3 , já que assumimos que a unidade backup não falha enquanto estiver em espera (isto, é, $P_{3}(t)=0$ ).

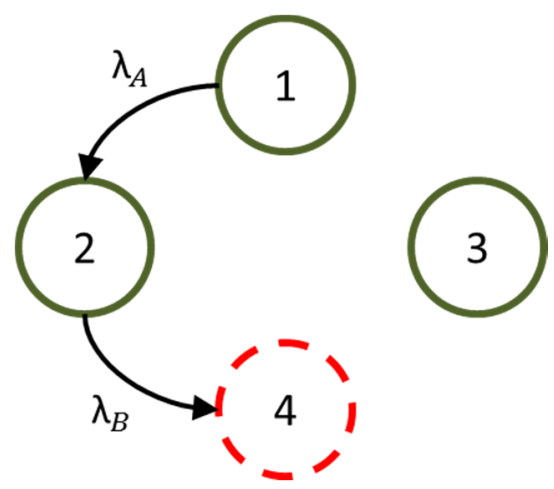

Figura 4-15 - Diagrama de transição - sistema paralelo em espera

Pelo diagrama de transição podemos construir as equações de Markov para os três estados:

$$
\begin{aligned}
& \frac{d p_{1}(t)}{d t}=-\lambda_{\mathrm{A}} p_{1}(t) \\
& \frac{d p_{2}(t)}{d t}=\lambda_{\mathrm{A}} p_{1}(t)-\lambda_{B} p_{2}(t) \\
& \frac{d p_{4}(t)}{d t}=\lambda_{\mathrm{B}} p_{2}(t)
\end{aligned}
$$

Resolvendo as equações acima, utilizando as condições iniciais: $P_{1}(0)=1$ e $P_{i}(t)=0, \mathrm{i} \neq 1$, obtemos:

$$
P_{1}(t)=e^{-\lambda_{A} t}
$$




$$
\begin{aligned}
& P_{2}(t)=\frac{\lambda_{A}}{\lambda_{B}-\lambda_{A}}\left(e^{-\lambda_{A} t}-e^{-\lambda_{B} t}\right) \\
& P_{3}(t)=0 \\
& P_{4}(t)=1-\frac{1}{\lambda_{B}-\lambda_{A}}\left(\lambda_{B} e^{-\lambda_{A} t}-\lambda_{A} e^{-\lambda_{B} t}\right)
\end{aligned}
$$

Visto que o estado 4 é o único que corresponde à falha do sistema, a confiabilidade pode ser descrita como:

$$
\begin{aligned}
& R(t)=P_{1}(t)+P_{2}(t) \\
& R(t)=e^{-\lambda_{A} t}+\frac{\lambda_{A}}{\lambda_{B}-\lambda_{A}}\left(e^{-\lambda_{A} t}-e^{-\lambda_{B} t}\right) \\
& R(t)=\frac{1}{\lambda_{B}-\lambda_{A}}\left(\lambda_{B} e^{-\lambda_{A} t}-\lambda_{A} e^{-\lambda_{B} t}\right)
\end{aligned}
$$

As propriedades de um sistema em standby são melhores ilustrados quando comparados sua confiabilidade com um sistema paralelo ativo. Para esta análise, iremos considerar que $\lambda_{A}=\lambda_{B}=\lambda$. Nesta situação, deve-se tomar cuidado pois as equações contêm $\lambda_{B}-\lambda_{A}$ no denominador. $A$ equação 4-68 pode ser reescrita como:

$$
R(t)=e^{-\lambda_{A} t}+\frac{\lambda_{A}}{\lambda_{B}-\lambda_{A}} e^{-\lambda_{A} t}\left(1-e^{-\left(\lambda_{B}-\lambda_{A}\right) t}\right)
$$

Indo para o limite onde $\lambda_{B}$ se aproxima de $\lambda_{A}$, temos $\lambda_{B}-\lambda_{A}<<1$, e podemos substituir:

$$
e^{-\left(\lambda_{B}-\lambda_{A}\right)}=1-\left(\lambda_{B}-\lambda_{A}\right) t+\frac{1}{2}\left(\lambda_{B}-\lambda_{A}\right)^{2} t^{2}-\ldots
$$

E combinando as duas equações acima, temos:

$$
R(t)=e^{-\lambda_{A} t}+\lambda_{A} e^{-\lambda_{A} t}\left(t-\frac{1}{2}\left(\lambda_{B}-\lambda_{A}\right)^{2} t^{2}+\ldots\right)
$$

Então, como estamos assumindo a premissa de que $\lambda_{A}$ e $\lambda_{B}$ são iguais, somente os dois primeiros termos da equação restam, tornando a equação da confiabilidade como:

$$
R(t)=(1+\lambda t) e^{-\lambda t}
$$

A figura abaixo compara as confiabilidades dos sistemas em paralelo ativo e em espera, no qual os componentes possuem taxas de falhas idênticas. Pelo 
gráfico percebe-se que o sistema em espera (standby) é mais confiável do que o sistema ativo, porque a unidade que está em espera (backup) não pode falhar antes da primeira unidade, apesar da confiabilidade da unidade principal não ser afetada pela presença da unidade backup.

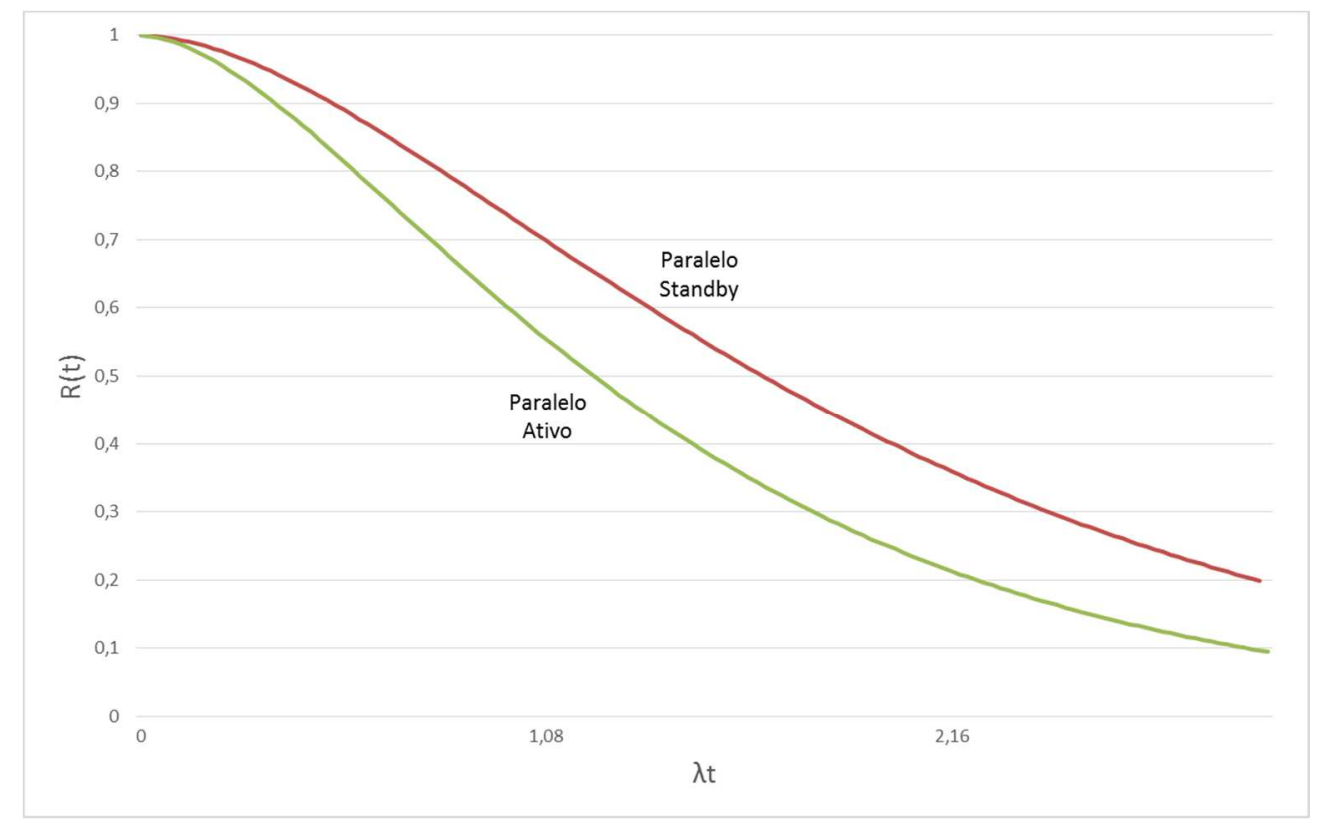

Figura 4-16 - Comparação de $R(t)$ : sist. paralelo ativo $x$ sist. paralelo standby

\subsubsection{Falha da unidade "em espera"}

Outra forma de analisar o sistema em espera (standby) é assumindo a possibilidade de a unidade em espera (backup) falhar antes de ser acionada. Para este cenário, o diagrama de transição é representado conforme segue abaixo:

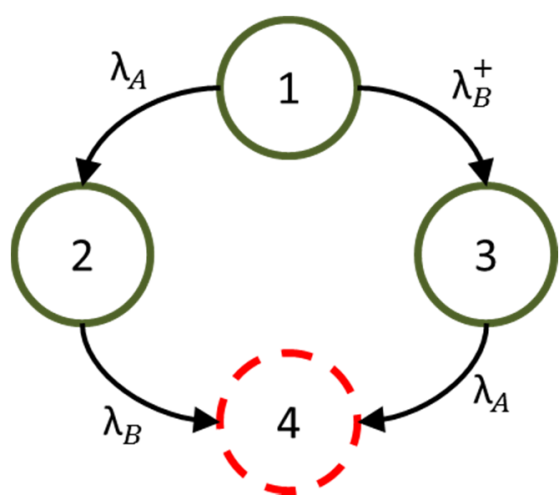

Figura 4-17 - Diagrama de transição - falha da unidade "em espera" 
A taxa de falha $\lambda_{B}^{+}$representa a falha da unidade de backup enquanto ela ainda está inativa, e o estado 3 representa a situação na qual a unidade principal está operando e há uma falha não detectada na unidade backup.

Pelo diagrama de transição podemos construir as equações de Markov para os três estados:

$$
\begin{aligned}
& \frac{d p_{1}(t)}{d t}=-\lambda_{\mathrm{A}} p_{1}(t)-\lambda_{B}^{+} p_{1}(t) \\
& \frac{d p_{2}(t)}{d t}=\lambda_{\mathrm{A}} p_{1}(t)-\lambda_{B} p_{2}(t) \\
& \frac{d p_{3}(t)}{d t}=\lambda_{B}^{+} p_{1}(t)-\lambda_{A} p_{3}(t) \\
& \frac{d p_{4}(t)}{d t}=\lambda_{\mathrm{B}} p_{2}(t)+\lambda_{\mathrm{A}} p_{3}(t)
\end{aligned}
$$

Resolvendo as equações acima utilizando as condições iniciais: $P_{1}(0)=1 \mathrm{e}$ $P_{i}(0)=0, \mathrm{i} \neq 1$, obtemos:

$$
\begin{aligned}
& P_{1}(t)=e^{-\left(\lambda_{A}+\lambda_{B}^{+}\right) t} \\
& P_{2}(t)=\frac{\lambda_{A}}{\lambda_{A}+\lambda_{B}^{+}-\lambda_{B}}\left(e^{-\lambda_{B} t}-e^{-\left(\lambda_{A}+\lambda_{B}^{+}\right) t}\right) \\
& P_{3}(t)=e^{-\lambda_{A} t}-e^{-\left(\lambda_{A}+\lambda_{B}^{+}\right) t}
\end{aligned}
$$

Não há a necessidade de resolver a equação para $\mathrm{P}_{4}(\mathrm{t})$, já que o estado 4 é o único que corresponde à falha do sistema. Assim, a confiabilidade pode ser descrita como:

$$
\begin{aligned}
& R(t)=P_{1}(t)+P_{2}(t)+P_{3}(t) \\
& R(t)=e^{-\lambda_{A} t}+\frac{\lambda_{A}}{\lambda_{A}+\lambda_{B}^{+}-\lambda_{B}}\left(e^{-\lambda_{B} t}-e^{-\left(\lambda_{A}+\lambda_{B}^{+}\right) t}\right)
\end{aligned}
$$

Considerando o caso que $\lambda_{A}=\lambda_{B}=\lambda$ e $\lambda_{B}^{+}=\lambda^{+}$, a equação acima pode ser simplificada:

$$
\boldsymbol{R}(\boldsymbol{t})=\left(1+\frac{\lambda}{\lambda^{+}}\right) \boldsymbol{e}^{-\lambda t}-\frac{\lambda}{\lambda^{+}}\left(e^{-\left(\lambda+\lambda^{+}\right) t}\right)
$$

A figura abaixo mostra os resultados possíveis, fazendo os valores de $\lambda^{+}$ variarem de zero a $\lambda$. Quando $\lambda^{+}=\lambda$, o resultado é idêntico ao sistema paralelo 
ativo. Este sistema é também chamado de "hot standby", pois as duas unidades ficam em funcionamento, bastando somente uma mudança de acionamento para a segunda unidade passar a ser a ativa.

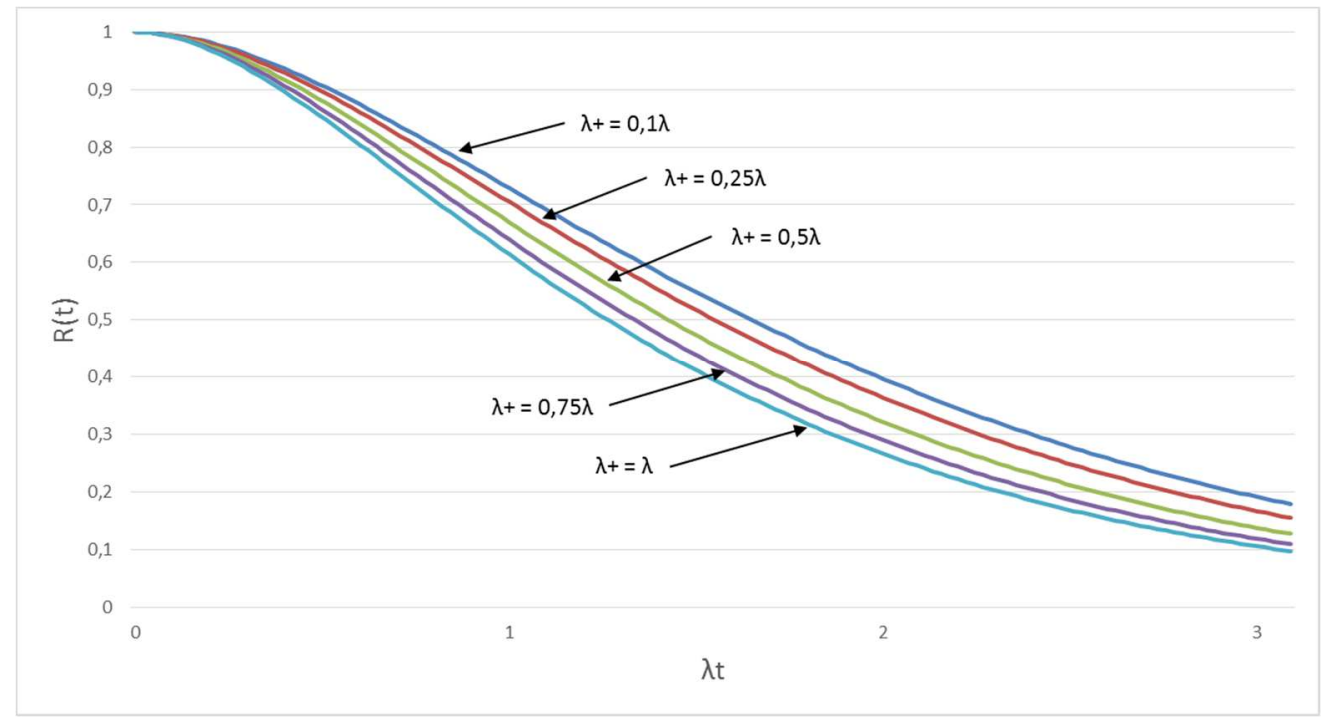

Figura 4-18 Influência da falha da unidade de backup na confiabilidade do sistema

\subsubsection{Falha no equipamento de acionamento do sistema em espera}

Outra dificuldade na utilização de sistemas em espera decorre da mudança da unidade primária para a segunda unidade. Esta mudança normalmente é realizada por relés elétricos, válvulas hidráulicas, circuitos eletrônicos, etc, onde sempre há a possibilidade destes equipamentos falharem com uma probabilidade $p$, independente das falhas das duas unidades.

O diagrama de transição abaixo descreve este caso: $\mathrm{A}$ taxa de falha relativa à mudança do estado 1 para o estado 2 agora é multiplicado por (1 - p), o que corresponde a um sucesso na mudança da unidade $A$ para a unidade $B$, e consequentemente o funcionamento do sistema com a unidade backup. $O$ caminho que multiplica a taxa de falha da unidade $A$ por $p$ indica que 0 equipamento de mudança de unidade falhou, e que neste caso não foi possível acionar a unidade $\mathrm{B}$ e, consequentemente, ocasiona uma falha em todo o sistema. 


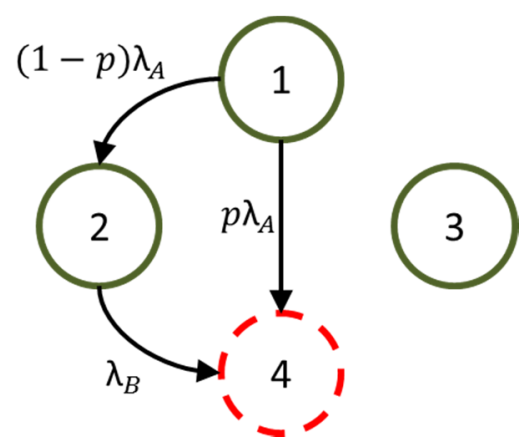

Figura 4-19 - Diagrama de transição - falha no equip. de acionamento do sist. espera

Pelo diagrama de transição podemos construir as equações de Markov para os três estados:

$$
\begin{aligned}
& \frac{d p_{1}(t)}{d t}=-\lambda_{\mathrm{A}} p_{1}(t) \\
& \frac{d p_{2}(t)}{d t}=(1-p) \lambda_{\mathrm{A}} p_{1}(t)-\lambda_{B} p_{2}(t) \\
& \frac{d p_{4}(t)}{d t}=\lambda_{\mathrm{B}} p_{2}(t)+p \lambda_{\mathrm{A}} p_{1}(t)
\end{aligned}
$$

Resolvendo as equações acima utilizando as condições iniciais: $P_{1}(0)=1 \mathrm{e}$ $P_{i}(0)=0, \mathrm{i} \neq 1$, obtemos:

$$
\begin{aligned}
& P_{1}(t)=e^{-\lambda_{A} t} \\
& P_{2}(t)=(1-p) \frac{\lambda_{A}}{\lambda_{B}-\lambda_{A}}\left(e^{-\lambda_{A} t}-e^{-\lambda_{B} t}\right)
\end{aligned}
$$

Levando em consideração que, neste caso,

$$
R(t)=P_{1}(t)+P_{2}(t)
$$

Não há a necessidade de calcularmos $P_{3}(t)$ e $P_{4}(t)$, e podemos escrever:

$$
R(t)=e^{-\lambda_{A} t}+\frac{(1-p) \lambda_{A}}{\lambda_{B}-\lambda_{A}}\left(e^{-\lambda_{A} t}-e^{-\lambda_{B} t}\right)
$$

Se, mais uma vez, considerarmos $\lambda_{A}=\lambda_{B}=\lambda$, a equação acima pode ser simplificada:

$$
R(t)=[1+(1-p) \lambda t] e^{-\lambda t}
$$

Se analisarmos a equação acima, podemos perceber que a medida que o valor de $p$ aumenta, o valor do sistema backup se torna menor, e no caso extremo de $p$ 
ser igual a 1 , isto é, ter a certeza de falha no equipamento de acionamento do sistema em espera, o sistema backup não tem nenhum efeito na confiabilidade do sistema como um todo.

\subsubsection{Efeitos combinados}

Os efeitos combinados de falhas tanto do sistema em standby como do equipamento de acionamento do sistema backup, quando consideradas duas unidades idênticas, isto é, com a mesma taxa de falha, é descrita na fórmula abaixo:

$$
R(t)=\left[1+(1-p) \frac{\lambda}{\lambda^{+}}\right] e^{-\lambda t}-(1-p) \frac{\lambda}{\lambda^{+}} e^{-\left(\lambda+\lambda^{+}\right) t}
$$

Observa-se que, quando não levamos em consideração a possibilidade de falha do sistema em standby, a equação reduz-se a eq 4-84.

Para um sistema em "hot stanby", no qual os dois sistemas, tanto o principal como o backup estão ativos, e logo $\lambda^{+}=\lambda$, a equação acima pode ser escrita da seguinte forma:

$$
R(t)=(2-p) e^{-\lambda t}-(1-p) e^{-2 \lambda t}
$$

Portanto, a confiabilidade de um sistema em "hot standby" é menor do que a confiabilidade de um sistema paralelo ativo, pois o sistema "hot standby" precisa de acionamento externo e existe a possibilidade de falha do equipamento de acionamento do sistema backup, o que não existe no sistema paralelo ativo.

\subsubsection{Sistemas com mais de dois componentes}

Os modelos descritos acima estão relacionados a dependência entre dois componentes, somente. Com o objetivo de utilizar o método de Markov em situações reais, é quase sempre necessário considerar a dependência entre mais de dois componentes ou construir um modelo de dependência de um sistema multi-componente.

O tratamento de um sistema com vários componentes pelo processo de Markov pode ser através da representação do conjunto de equações de transição de estado na forma matricial. Considere um sistema com três componentes em paralelo, conforme mostrado na figura abaixo, e supondo que o sistema é de carga 
compartilhada, na qual a taxa de falha aumenta com a falha de um equipamento. Assim, teríamos:

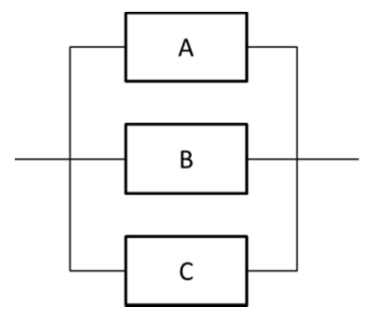

Onde:

Figura 4-20 - Três componentes em paralelo

- $\lambda_{1}=$ taxa de falha do componente, sem nenhum componente falho;

- $\lambda_{2}=$ taxa de falha do componente, com um componente falho;

- $\lambda_{3}=$ taxa de falha do componente, com dois componentes falhos.

Para este cenário, a tabela de estados pode ser mostrada conforme

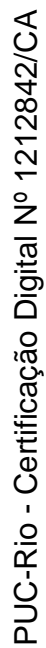
abaixo:

Tabela 4-8 - Tabela de estados - três componentes

\begin{tabular}{|c|c|c|c|c|c|c|c|c|}
\hline Componente & \multicolumn{8}{c|}{ Estado } \\
\hline & $\mathbf{1}$ & $\mathbf{2}$ & $\mathbf{3}$ & $\mathbf{4}$ & $\mathbf{5}$ & $\mathbf{6}$ & $\mathbf{7}$ & $\mathbf{8}$ \\
\hline $\mathrm{A}$ & $\mathrm{O}$ & $\mathrm{X}$ & $\mathrm{O}$ & $\mathrm{O}$ & $\mathrm{X}$ & $\mathrm{X}$ & $\mathrm{O}$ & $\mathrm{X}$ \\
\hline $\mathrm{B}$ & $\mathrm{O}$ & $\mathrm{O}$ & $\mathrm{X}$ & $\mathrm{O}$ & $\mathrm{X}$ & $\mathrm{O}$ & $\mathrm{X}$ & $\mathrm{X}$ \\
\hline $\mathrm{C}$ & $\mathrm{O}$ & $\mathrm{O}$ & $\mathrm{O}$ & $\mathrm{X}$ & $\mathrm{O}$ & $\mathrm{X}$ & $\mathrm{X}$ & $\mathrm{X}$ \\
\hline $\mathrm{O}$ & & & & & & & \\
\hline $\mathrm{X}=$ operando falho & & & & & & & & \\
\hline
\end{tabular}

E o diagrama de transição de estados será: 


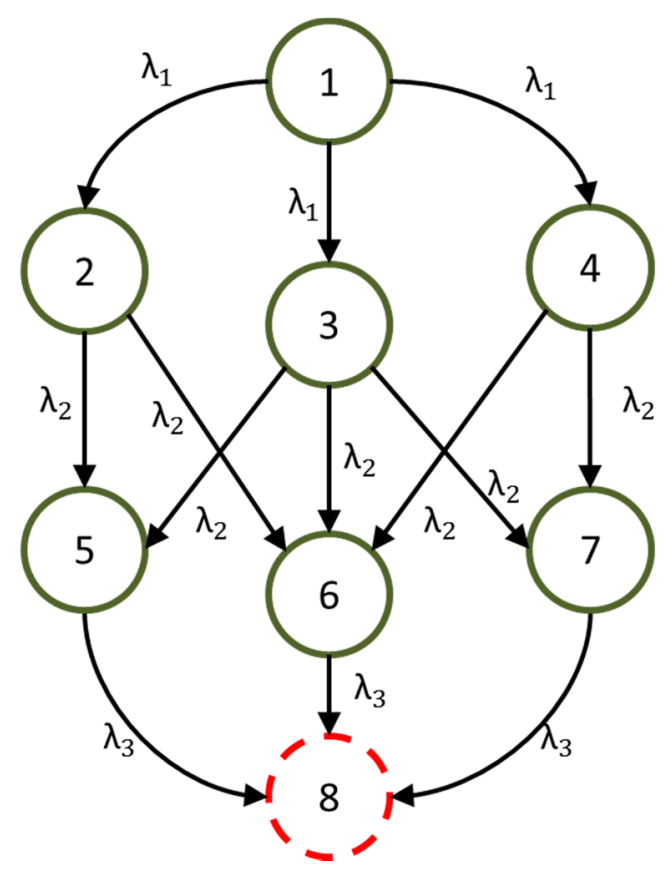

Figura 4-21 - Diagrama de transição - três componentes em paralelo

Para este diagrama, podemos construir as equações para $P_{i}(t)$, que na forma matricial pode ser escrita como:

$$
\frac{d}{d t}\left[\begin{array}{l}
P_{1}(t) \\
P_{2}(t) \\
P_{3}(t) \\
P_{4}(t) \\
P_{5}(t) \\
P_{6}(t) \\
P_{7}(t) \\
P_{8}(t)
\end{array}\right]=\left[\begin{array}{cccccccc}
-3 \lambda_{1} & 0 & 0 & 0 & 0 & 0 & 0 & 0 \\
\lambda_{1} & -2 \lambda_{2} & 0 & 0 & 0 & 0 & 0 & 0 \\
\lambda_{1} & 0 & -2 \lambda_{2} & 0 & 0 & 0 & 0 & 0 \\
\lambda_{1} & 0 & 0 & -2 \lambda_{2} & 0 & 0 & 0 & 0 \\
0 & \lambda_{2} & \lambda_{2} & 0 & -\lambda_{3} & 0 & 0 & 0 \\
0 & \lambda_{2} & 0 & \lambda_{2} & 0 & -\lambda_{3} & 0 & 0 \\
0 & 0 & \lambda_{2} & \lambda_{2} & 0 & 0 & -\lambda_{3} 0 \\
0 & 0 & 0 & 0 & \lambda_{3} & \lambda_{3} & \lambda_{3} & 0
\end{array}\right]\left[\begin{array}{l}
P_{1}(t) \\
P_{2}(t) \\
P_{3}(t) \\
P_{4}(t) \\
P_{5}(t) \\
P_{6}(t) \\
P_{7}(t) \\
P_{8}(t)
\end{array}\right]
$$

Para sistemas maiores, é mais conveniente escrever as equações de Markov na forma matricial:

$$
\frac{d}{d t} P(t)=M P(t)
$$

Onde P é o vetor coluna com os componentes $P_{1}(t), P_{2}(t)$, etc, e $\mathrm{M}$ é referente à matriz de transição de Markov. A dimensão da matriz aumenta em $2^{N}$, onde $\mathrm{N}$ representa o número de componentes. 


\section{METODOLOGIA}

O primeiro trabalho realizado foi identificar as configurações de interesse do sistema de controle do DSSS para o estudo. Foram identificadas dez composições de interesse do sistema de controle a serem comparados. Estas configurações foram postas em forma de diagrama para uma melhor visualização do sistema, com a possibilidade de identificação de quais componentes estavam em série ou em paralelo.

Uma segunda etapa foi assumir que todos os equipamentos que estavam em série em uma determinada configuração poderiam ser agrupados em uma única "taxa de falha", pois caso qualquer um desses equipamentos em série que falhe, todo o sistema também falha. A vantagem de se realizar este agrupamento é que se obtém uma redução significativa de estados a serem incluídos no processo markoviano, sem uma perda significativa de qualidade do resultado. A maior desvantagem desta ação é que se perde um refinamento com relação aos componentes em série, não se podendo, de certa forma, definir qual dos componentes em série que se encontram agrupados é o que mais influencia na falha do sistema, a não ser que haja um "detalhamento" nestes componentes, o que não seria fácil de realizar.

Para cada sistema escolhido, será mostrado cada estado possível do sistema, informando se naquele estado o sistema se encontra disponível ou indisponível. Com estas informações definidas, será possível incluir estes estados no software E\&P Office e montar o diagrama de transição de Markov, incluindo as taxas de falhas de todos os componentes do sistema, levando em consideração os equipamentos em série agrupados.

O objetivo é iniciar o estudo por sistemas mais simples, e continuar o estudo incluindo equipamentos em paralelo no sistema a fim de avaliar onde está, na prática, o gargalo do sistema na visão de confiabilidade, além de avaliar se não está utilizando redundâncias em partes onde a confiabilidade já é alta o suficiente quando comparado a outras partes do sistema.

\subsection{Configurações estudadas}

Três formas principais de sistema serão estudadas: 
- Sistema hidráulico direto

- Sistema multiplexado

- Sistema elétrico

O sistema hidráulico direto é o mais utilizado atualmente em poços terrestres, poços offshore de completação seca e em poços offshore de completação molhada, e possibilita várias configurações, e algumas serão apresentadas neste trabalho. O sistema multiplexado é o sistema de controle utilizado nos poços do pré-sal (poços offshore de completação molhada, basicamente), e somente uma configuração é utilizada com este sistema, porém será estudada segunda configuração hipotética.

O sistema elétrico não é utilizado atualmente, e todas as configurações aqui apresentadas são hipotéticas e necessitariam de vários estudos detalhados para serem postos em operação, mas está sendo estudado para ser utilizado em poços offshore de completação molhada, mais especificamente para lamina d'água profunda.

Visando facilitar o entendimento e a rápida visualização de qual sistema estamos nos referindo, as configurações do sistema hidráulico direto terão a denominação "A", as configurações do sistema multiplexado a denominação "B" e do sistema elétrico, a denominação "C".

\subsubsection{Sistemas tipo A (hidráulico-direto)}

O primeiro caso de interesse (caso A1) representa todos os equipamentos em série, sem nenhuma redundância (apenas 01 umbilical, apenas 01 linha hidráulica e sem manifold). É o sistema mais simples que podemos ter para controle do DSSS, e isto implica em menos equipamentos a serem instalados, assim como menos equipamentos para falharem. Este primeiro sistema tem a seguinte configuração: 


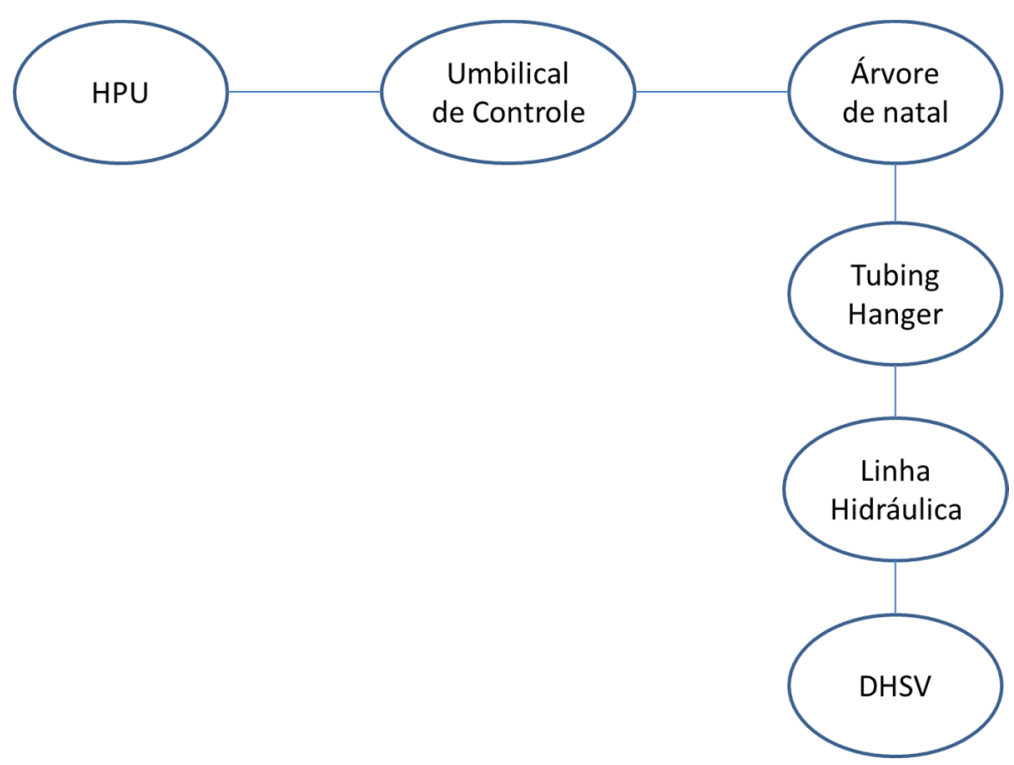

Figura 5-1 - Sistema A1 - HD sem Redundância

Esta configuração é utilizada para poços terrestres, onde há a necessidade de DSSS, assim como para poços marítimos de completação seca, e por isso o interesse de seu estudo. Além disso, poderá ser um sistema de comparação para outros mais complexos, pois caso algum sistema se mostre com o mesmo grau de confiabilidade do que este, não se mostrará interessante, pois qualquer complexidade a mais no sistema poderá acarretar maiores dificuldades durante sua instalação.

A segunda configuração (caso A2) é um sistema hidráulico direto com redundância somente no umbilical de controle. Como normalmente o umbilical de controle possui linhas hidráulicas reservas, esta configuração pode ser adotada, tanto para um sistema paralelo ativo, em hot stand by ou em espera. Inicialmente estudaremos somente o sistema em hot stand by desta configuração. 


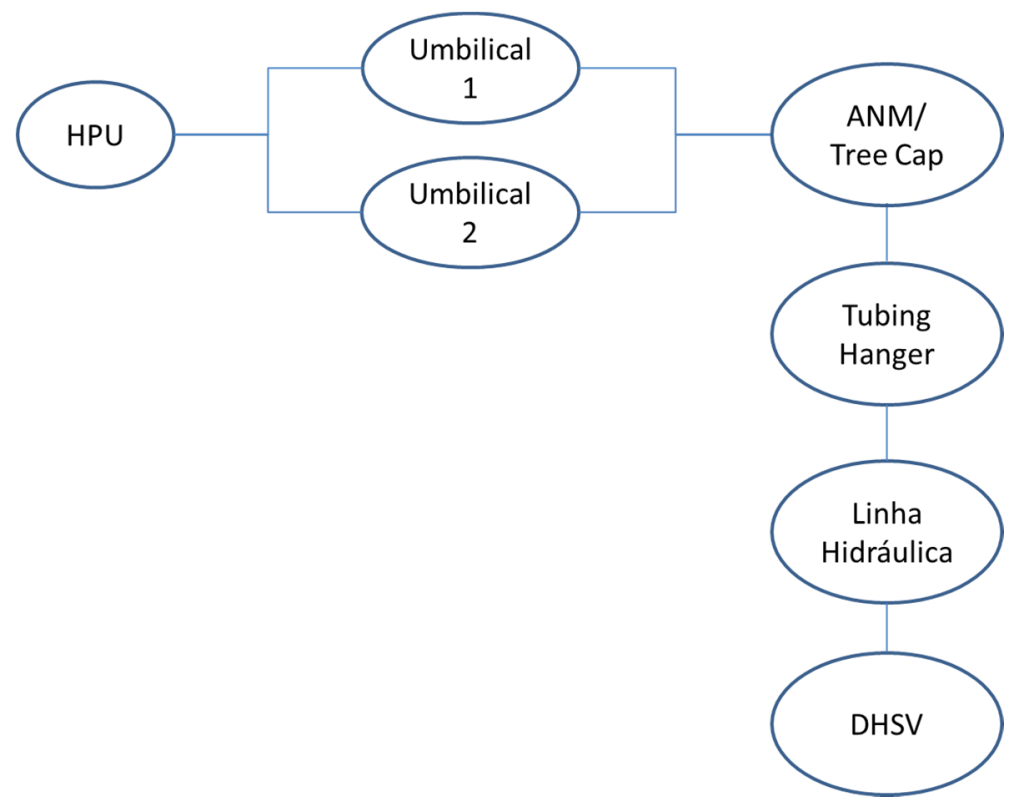

Figura 5-2 - Sistema A2 - HD com Redundância no Umbilical

Atualmente, todas as modificações de configuração da completação estão no sentido de diminuir as linhas dentro do poço, e esta configuração seria bem interessante do ponto de vista prático, isto é, facilitar e agilizar a instalação da completação, trazendo redução de custo e tempo de operação para a construção do poço.

$\mathrm{Na}$ terceira configuração estudada (caso A3) será incluída mais uma linha reserva no umbilical de controle, mantendo-se sem redundância no restante do sistema. Esta é a primeira configuração que não é utilizada na prática, pois as outras linhas de controle do umbilical atualmente já são utilizadas para acionamento de outras válvulas do sistema poço (válvulas da árvore de natal, por exemplo). Mas o objetivo, neste caso, é avaliar se há algum ganho significativo de confiabilidade caso esta configuração fosse adotada. Neste caso também será adotado o sistema hidráulico direto em hot stand by.

Os umbilicais de controle atuais possuem oito linhas hidráulicas, sendo que normalmente somente duas destas são disponíveis para o sistema DSSS e as outras são utilizadas para as válvulas da árvore de natal e para acionamento de outras válvulas instaladas ao longo do poço (VHIF, válvulas de completação inteligente, etc). Porém, os umbilicais mais recentes tem sido construídos com doze funções, isto é, doze linhas hidráulicas ao invés de oito, o que possibilita a utilização de mais alguma linha hidráulica para o sistema do DSSS. 


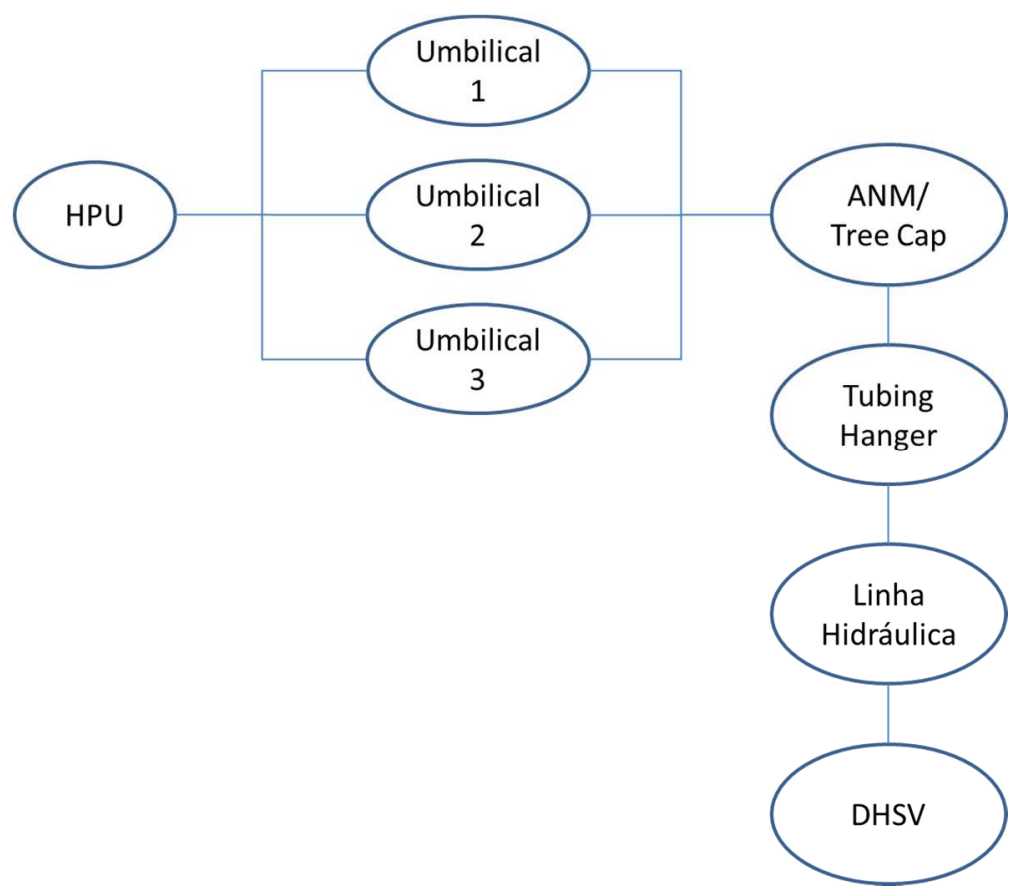

Figura 5-3 - Sistema A3 - HD com duas redundâncias do Umbilical

A quarta configuração (Caso A4) terá como característica a redundância na linha hidráulica somente, sendo que os outros equipamentos do sistema não terão nenhum tipo de redundância.

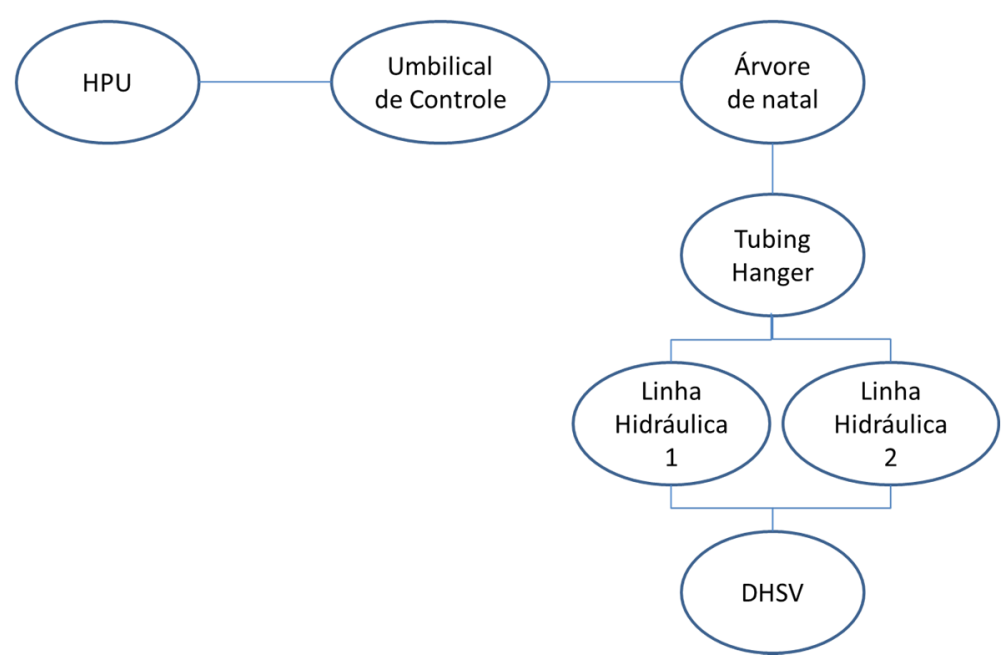

Figura 5-4 - Sistema A4 - HD com Redundância na Linha Hidráulica

A redundância nas linhas hidráulicas é uma característica dos poços offshore de completação molhada, e o principal motivo é que o acesso a estas linhas é mais complicado do que o acesso ao umbilical, pois as linhas de controle ficam dentro do poço (mais especificamente, no anular coluna de produção revestimento de produção). 
Esta configuração tem a vantagem de aumentar a redundância em uma área de difícil acesso (dentro do poço), e quando há algum problema nesta área do sistema, somente uma intervenção com sonda e, possivelmente, com a necessidade de instalação do BOP de perfuração (isto é, heavy workover), conseguirá resolver a falha. Por outro lado, caso esta seja uma área menos sensível do sistema, com uma alta confiabilidade, seria uma inclusão de equipamentos desnecessária.

A quinta configuração de interesse (caso A5) é a atualmente utilizada em águas profundas e ultra profundas, pois é considerada como a mais confiável entre todas as outras. O sistema estudado tem a seguinte configuração:

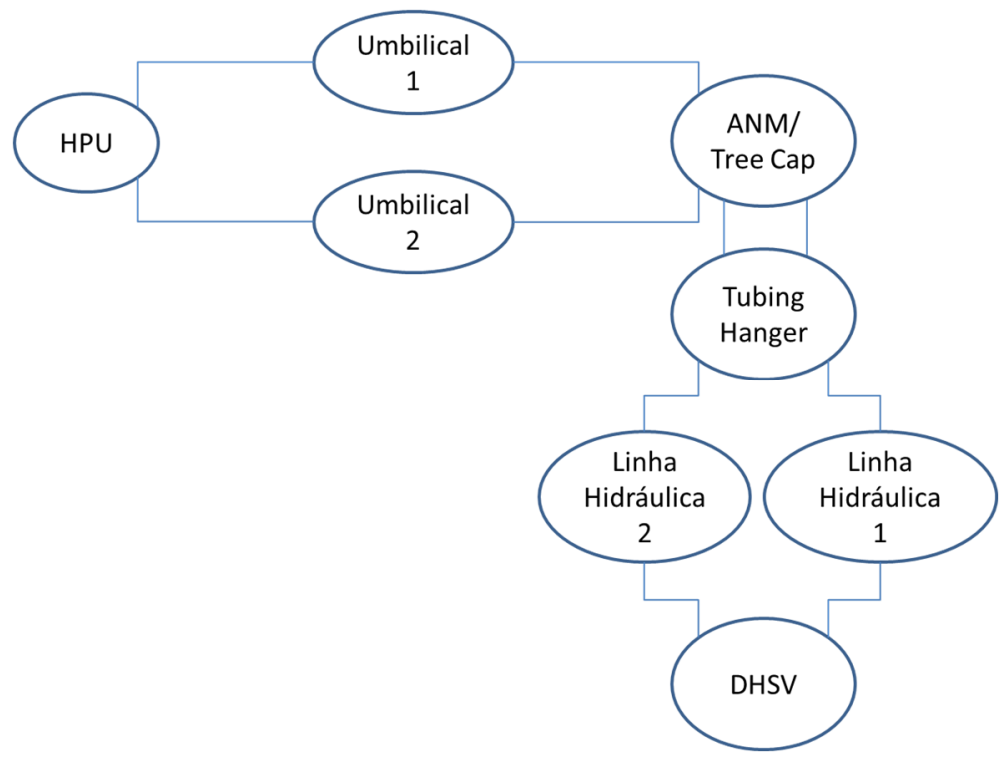

Figura 5-5 - Sistema A5 - HD com redundância na LC e no UC

No esquemático apresentado acima, percebemos que dois componentes do sistema possuem equipamentos em paralelo, que são as linhas de controle pertencentes ao umbilical e as linhas hidráulicas que ficam dentro do poço, fazendo a interligação entre o suspensor de coluna e o dispositivo de segurança de sub-superfície. Esta configuração será em hot stand by, pois não leva em consideração uma possível falha de um equipamento de acionamento das linhas de reserva.

A sexta configuração (caso A6) é bem parecida com a configuração anterior, porém agora assumindo a possibilidade de falha no equipamento de acionamento, conforme a figura abaixo: 


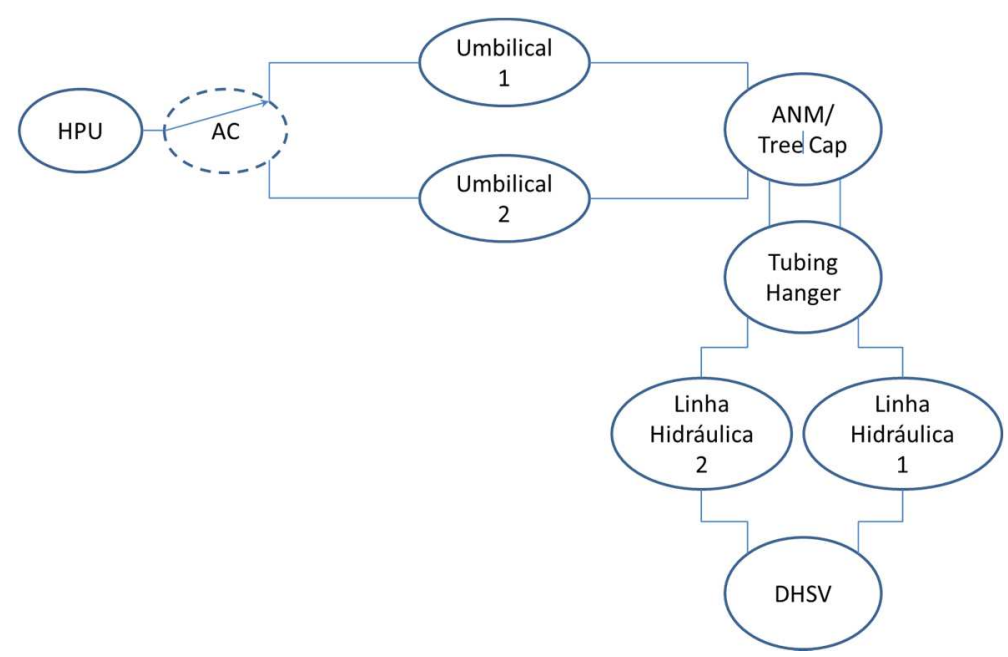

Figura 5-6 - Sistema A6 - HD com redundância no UC e LC e falha no acionamento

Esta configuração é um sistema hidráulico direto, com redundância no umbilical e na linha de controle, assumindo a possibilidade de falha no acionamento dos equipamentos em espera.

\subsubsection{Sistemas tipo B (eletro-hidráulico multiplexado)}

Diferente do sistema hidráulico direto, a principal característica do sistema eletro-hidráulico multiplexado é que o comando para acionamento de qualquer válvula pertencente ao sistema é feito eletricamente, sendo que o acionamento continua sendo hidráulico. Além disso, o sistema hidráulico possui um acumulador de pressão na cabeça do poço (fundo do mar), o que também modifica a lógica de operação assim como a lógica de falha do sistema.

O MCS - "Master Control Station" - é um equipamento de superfície e é a estação de controle central responsável pelo fornecimento de energia elétrica, comunicação e controle elétrico dos equipamentos. Atualmente os equipamentos EPU (unidade de energia elétrica) e modem (modulador e demodulador) são partes integrantes do MCS. O EPU (Eletrical Power Unit) fornece até cinco fontes de energia elétrica, todas redundantes, para os equipamentos do sistema de controle subsea. O MCS fica localizado na unidade estacionária de produção (UEP) e normalmente são fornecidas duas unidades em paralelo na configuração hot standby.

O HPU - "Hydraulic Power Unit" - continua sendo o responsável pelo fornecimento de energia hidráulica do sistema. O HPU gera a pressão hidráulica necessária para operar as válvulas da ANM e DSSS, sendo que pode-se subdividir 
o sistema em dias partes: as linhas de alta pressão (HP - High pressure) e as linhas de baixa pressão (LP - Low pressure), onde as linhas HP são responsáveis pelo acionamento do DSSS e as linhas LP das demais válvulas.

No grupo de equipamentos submarinos, temos os sensores e medidores submarinos, as válvulas que serão controladas, todos os componentes necessários para a interligação elétrica e hidráulica submarina e o elemento principal: o SCM (Subsea Control Module), responsável pelos acionamentos hidráulicos nos equipamentos submarinos e aquisição de informações necessárias à operação dos equipamentos.

O SCM é uma unidade que consiste, geralmente, em uma carcaça circular na qual possui internamente acumuladores hidráulicos, filtros, válvulas de controle sensores de pressão o SEM (Subsea Electronic Module), os quais geralmente são fornecidos com redundância. O SCM normalmente é instalado em uma base recuperável, o que permite a substituição deste equipamento em caso de falha.

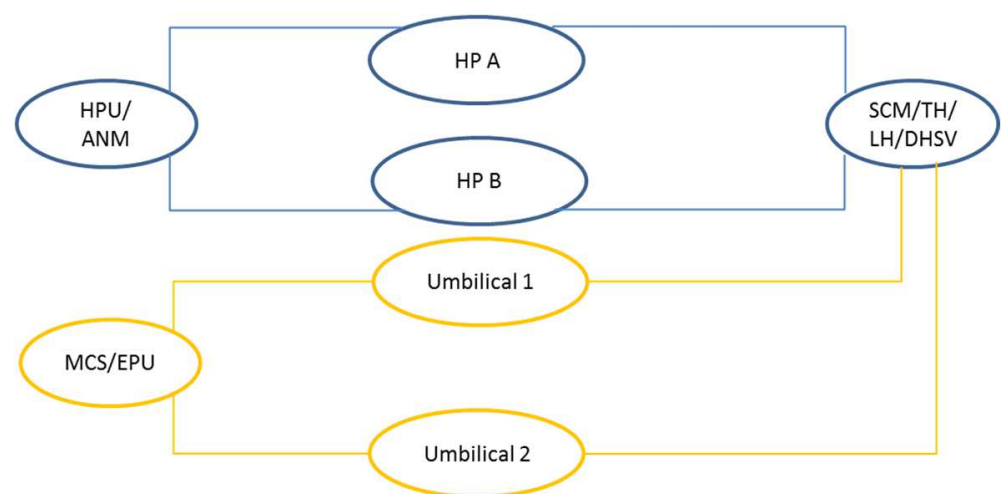

Figura 5-7 - Sistema B1 - Hidráulico - ANM Multiplexada sem redundância na LC

O primeiro sistema multiplexado a ser analisado (caso B1) consiste em ter redundância nos umbilicais hidráulicos (agora chamados de HP A e HP B), porém sem a redundância na linha hidráulica. Como o sistema elétrico tem a característica de "safe as is", isto é, as válvulas permanecem na posição em que se encontram em caso de falha, e com uma redundância em paralelo ativo, acreditamos que a parte elétrica pode ser removida das equações visando simplificar o sistema.

Atualmente, os sistemas multiplexados utilizados contém, além da redundância nos umbilicais, redundância nas linhas hidráulicas (caso B2). Esta modificação parece simples e sem grandes ganhos, mas na prática esta redução da redundância permitiria grandes modificações na construção de poços marítimos 
de lamina d'água ultra profunda, pois permitiria a utilização de outras tecnologias de DSSS neste cenário que, atualmente não são utilizadas por não terem redundância de acionamento. Além disso, existiria também um ganho de tempo e uma diminuição de risco durante a operação de instalação da coluna de completação

O segundo sistema multiplexado (caso B2) é bem parecido com o primeiro, porém com a redundância na linha hidráulica. É configuração do sistema de DSSS eletro-hidráulicos multiplexados atualmente utilizado:

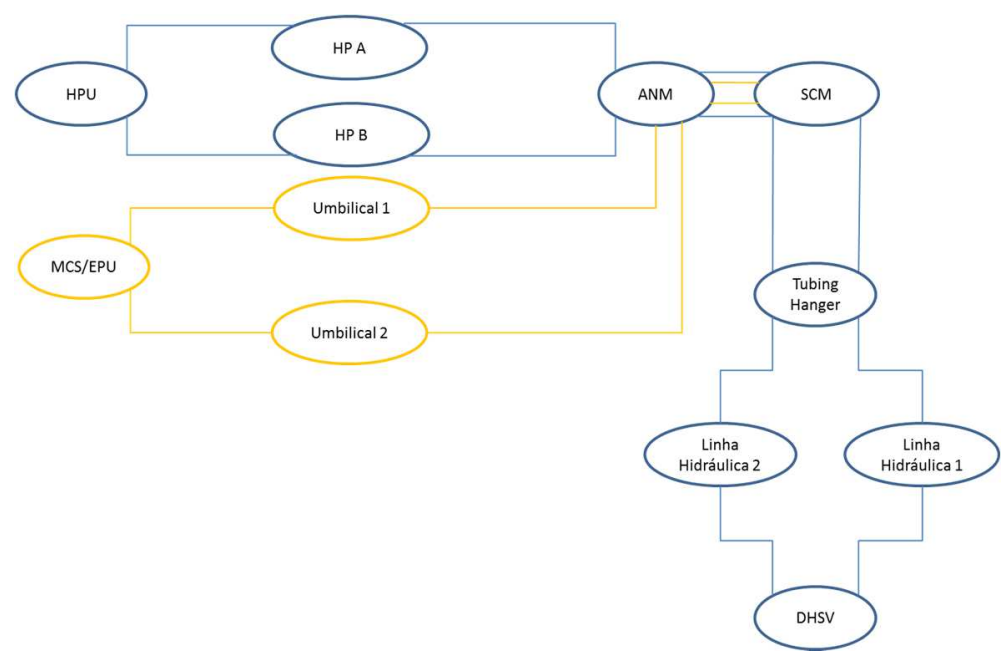

Figura 5-8 - Sistema B2 - Hidráulico - ANM Multiplexada com redundância na LC

\subsubsection{Sistema Tipo C - Elétrico}

Os sistemas aqui denominado tipo "C" são os sistemas de acionamento totalmente elétrico, sem nenhuma parte hidráulica envolvida. Este sistema não é utilizado atualmente, porém a sua viabilidade está em estudo faz alguns anos. Alguns dos maiores gargalos para a implementação deste modelo de sistema são:

- Modificações no sistema ANM - Como, atualmente, todos os sistemas utilizam linhas hidráulicas no trecho entre a árvore de natal e a válvula (BAP, tubing Hanger, e a própria ANM), estes equipamentos possuem passagens hidráulicas, e o novo sistema irá necessitar de passagens elétricas. Atualmente não se sabe efetivamente qual seria a dificuldade de se realizar este tipo de modificação, nem tampouco o prazo a ser realizado e seus custos.

- Dúvida com relação à sua efetividade - O sistema hidráulico é altamente conhecido do corpo técnico, porém um sistema elétrico gera várias dúvidas 
com relação à sua efetividade, já que o ambiente em que irão se encontras as conexões elétricas não são as mais favoráveis para o trabalho, apesar de já existirem outros equipamentos que utilizam este tipo de acionamento (bombas centrífugas, sensores, etc), também instalados dentro do poço porém nenhum deles é ligado diretamente à segurança.

Um estudo realizado através da NTNU (Norwegian University of Science and Technology) teve como objetivo se um DSSS com acionamento elétrico pode substituir um com acionamento hidráulico, e contém uma tabela de prós e contras dos sistemas elétricos e hidráulicos (SEIME, 2012):

Tabela 5-1 - Vantagens e desvantagens dos sistemas hidráulico e elétrico

\begin{tabular}{|c|c|c|c|}
\hline & Hudráulico & & Elétrico \\
\hline+ & Tecnologia consolidada & - & Sistema novo \\
\hline+ & $\begin{array}{l}\text { Sistema simples, poucos componentes (tanques, linha de } \\
\text { controle, bombas, atuador) }\end{array}$ & - & $\begin{array}{l}\text { Mais complexo, mais componentes (EPU, cabos, motor, } \\
\text { freios }\end{array}$ \\
\hline+ & $\begin{array}{l}\text { Principais componentes alocados na superfície (bomba, } \\
\text { tanque, válvulas) }\end{array}$ & - & $\begin{array}{l}\text { maioria dos componentes alocados na subsuperfície (motor, } \\
\text { engrenagem, embreagem, freios) }\end{array}$ \\
\hline+ & Sem necessidade de caixa de transmissão & - & caixa de engrenagem redus a eficiencia \\
\hline - & $\begin{array}{l}\text { Necessário o flushing das linhas de contrle de tempos em } \\
\text { tempos }\end{array}$ & + & Sem necessidade de flushing \\
\hline- & A distãncia impacta no tempo de resposta & + & Resposta rápida \\
\hline - & Linha de controle limita a profundidade de instalação & + & $\begin{array}{l}\text { Sem limitação de profundidade de assentamento, } \\
\text { teoricamente }\end{array}$ \\
\hline - & $\begin{array}{l}\text { Vazamento dos fuidos hidráulicos é perigoso para o meio- } \\
\text { ambiente }\end{array}$ & + & Sistema limpo, sem utilização de fluidos \\
\hline - & Compatibilidade ruim com sensores & + & $\begin{array}{l}\text { Possibilidade de utilização de sensores, aumentando a } \\
\text { precisão }\end{array}$ \\
\hline- & $\begin{array}{l}\text { Eficiencia reduzida com o aumento da lamina dagua } \\
\text { (necessário vencer a pressão hidrostática) }\end{array}$ & + & $\begin{array}{l}\text { Motores elétricos mantem sua eficiencia e torque, } \\
\text { independentemente da lamina dagua (mas há perda de } \\
\text { eficiencia nos cabos) }\end{array}$ \\
\hline
\end{tabular}

Apesar de não concordar com algumas das opiniões listadas na tabela acima, outras são interessantes destacá-las, como por exemplo a não utilização de fluidos hidráulicos como uma vantagem de um sistema com acionamento elétrico. Outra característica interessante é a possibilidade de se trabalhar com sensores para saber exatamente a posição em que a válvula se encontra.

O sistema C1 ilustra o mais simples dos sistemas elétricos que poderíamos montar, um "sistema elétrico direto", para fazer uma analogia com o sistema hidráulico direto. Este sistema também pode ser utilizado como base de 
comparação para outros sistemas, já que é o mais simples dos sistemas que pode ser montado. A figura 5-10 ilustra esta configuração:

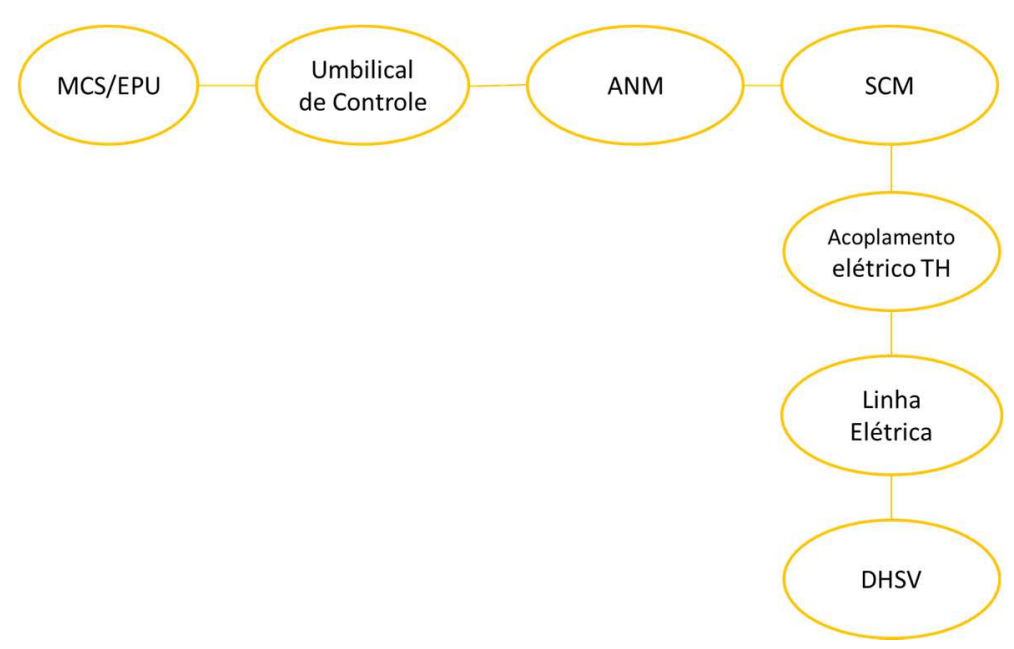

Figura 5-9 - Sistema C1 - Sistema Elétrico sem Redundância

O outro sistema elétrico apresentado neste trabalho - sistema C2 - pode ser chamado de sistema elétrico multiplexado. Até a árvore de natal, o sistema é o mesmo de um sistema hidráulico multiplexado, porém após o SCM linhas elétricas iriam controlar a válvula, ao invés de linhas hidráulicas. A figura abaixo ilustra esta configuração:

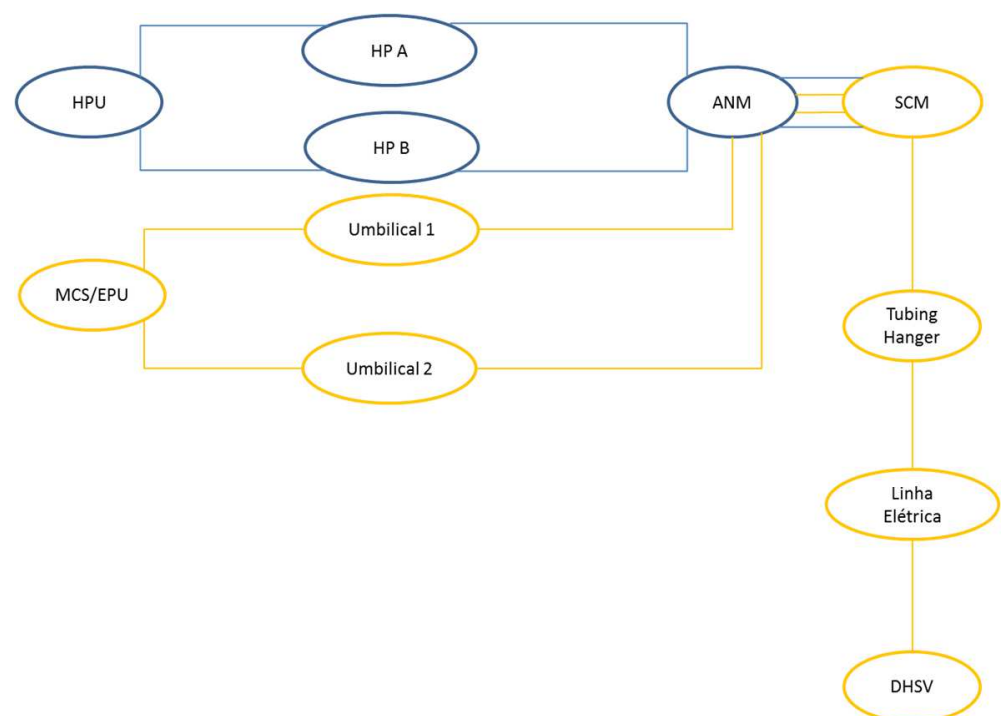

Figura 5-10 - Sistema C2 - Sistema Elétrico Multiplexado

No sistema multiplexado com controle hidráulico, o sistema elétrico tem a característica de "fail as is", o que para o sistema multiplexado com controle elétrico não atende aos requisitos de projeto. Por conceito, o sistema de controle 
do DSSS deve ser "fail safe close" e, portanto, esta modificação deve ser levada em consideração.

\subsection{Software Utilizado}

O software utilizado para a realização dos cálculos de confiabilidade dessa dissertação foi o E\&P Office. O E\&P Office é um software desenvolvido em parceria entra a Petrobras e o departamento de engenharia de produção da Universidade Federal de Pernambuco - UFPE. Os pacotes incluídos no programa acoplam técnicas para a análise de ESD's (diagramas de seqüências de eventos), FTA's (árvores de falhas) e BBN's (redes de crenças Bayesianas), Cadeias de Markov e Modelo de Bayes. Todas as técnicas envolvidas na avaliação quantitativa dos modelos via ESD's, FTA's e BBN's realizam os cálculos de maneira exata, sem o auxílio de técnicas de simulação.

A figura abaixo ilustra uma tela do E\&P-Office, na visualização de processos Markovianos.

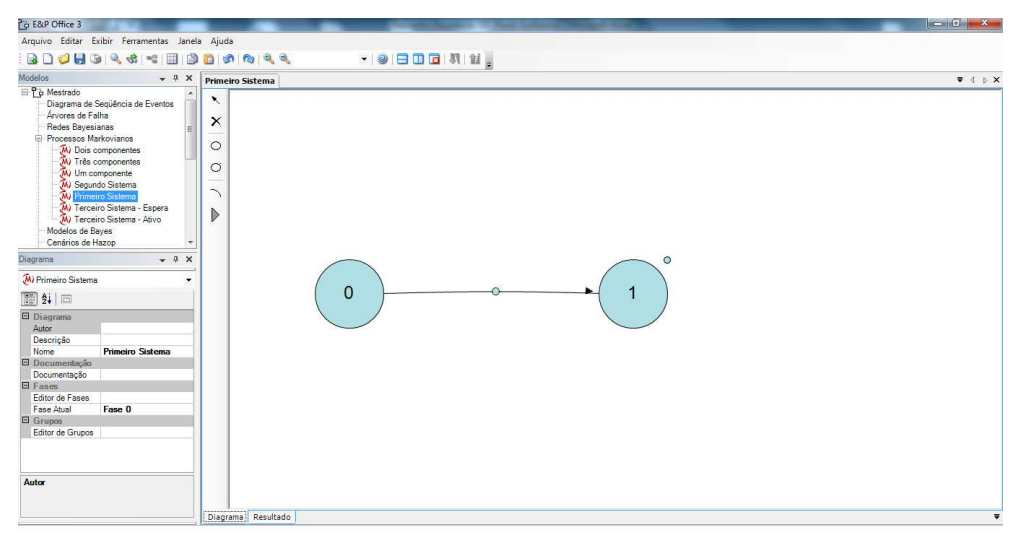

Figura 5-11 - Visualização dos estados de Markov

O editor de propriedades mostra as propriedades do diagrama da cadeia de Markov. O nome, a descrição, o autor e o número de pontos são visualizados e podem ser editados. Além disso, na seção "Fases", pode-se editar as fases do diagrama indicar a fase inicial. E na seção "Grupos”, pode-se editar os grupos para cada nó. 


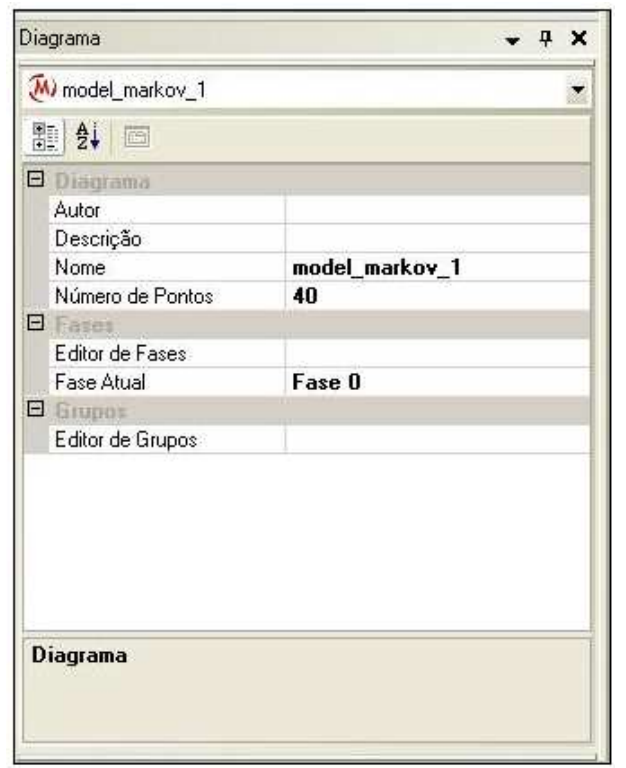

Figura 5-12 - Editor de propriedades - Detalhamento do diagrama

O editor também mostra as propriedades do último nó. Nele, o nome, a descrição e o estado do nó podem ser visualizados editados, além de informar os valores das suas possíveis transições, inclusive associação deste com outros modelos.

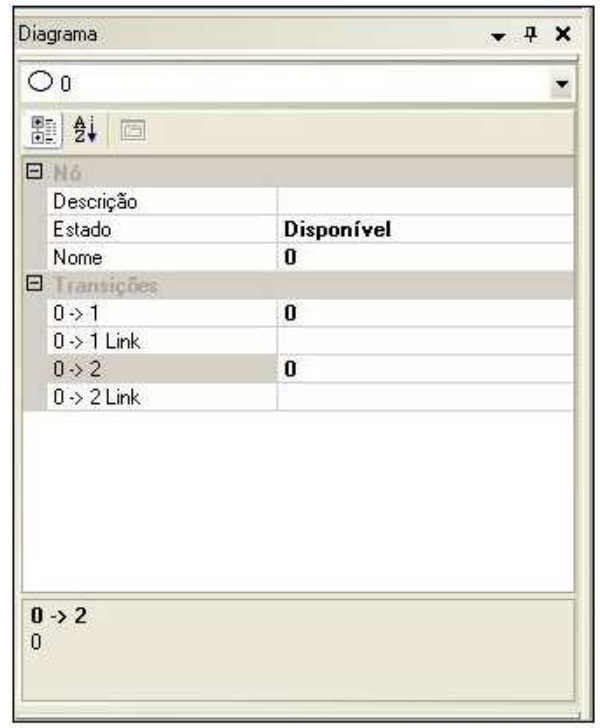

Figura 5-13 - Editor de propriedades - Detalhamento do nó

No módulo do processo de Markov do E\&P Office, existe a simbologia do estado disponível e do estado indisponível, como pode ser visualizado abaixo:

- Sistema Disponível 
= Sistema Indisponível

Além disso, a barra de ferramentas permite desde a edição até a simulação de uma cadeia de Markov. Abaixo se encontra a funcionalidade de cada botão:

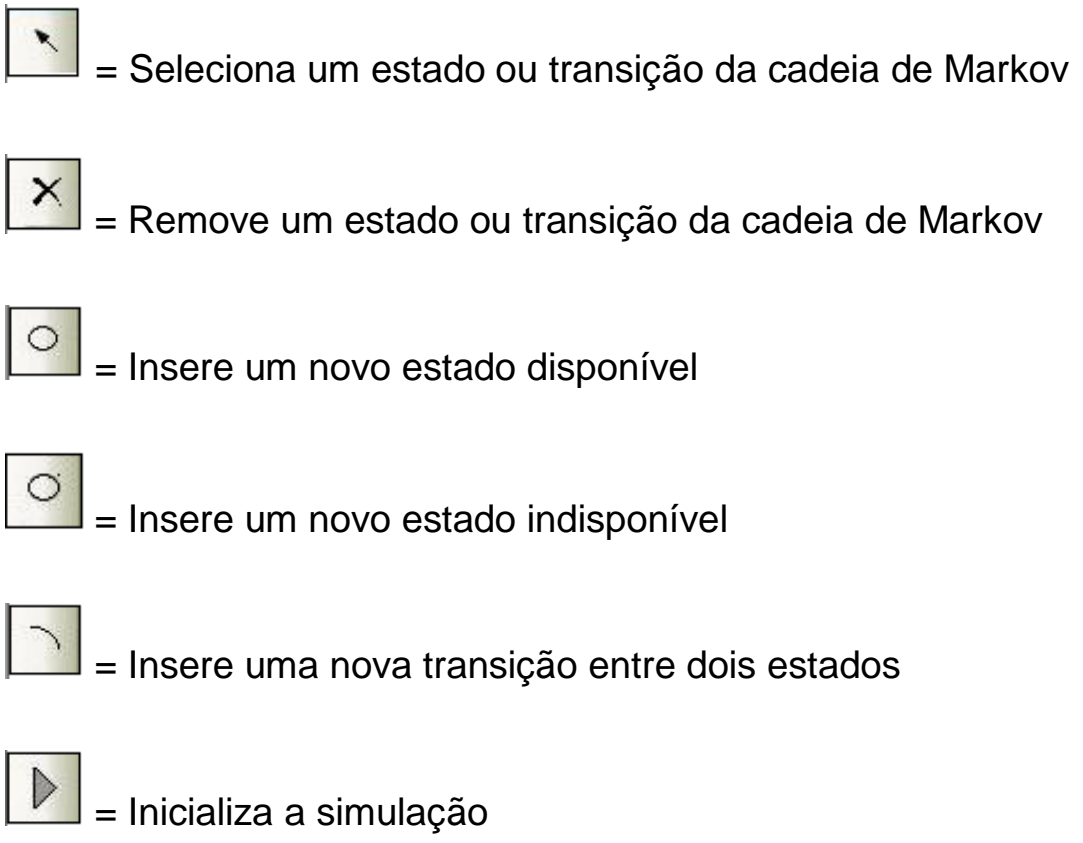

\subsection{Dados Utilizados}

Uma dificuldade da realização deste tipo de trabalho é obter uma fonte de dados confiável para utilização. Normalmente, dados de falha de equipamentos de poços não são registrados, e quando são, há incertezas envolvidas quanto à natureza da falha, data do início da falha, entre outros. Vale a pena comentar que, a área de construção de poços é um pouco diferente da maioria das outras áreas da indústria em geral pois, para se verificar a real natureza da falha, na maioria das vezes é necessária a análise do equipamento em questão, e no caso de um poço de petróleo, a retirada de um equipamento é muito cara (pois necessita de um workover, com sonda de perfuração), e por isso nem sempre é possível ter acesso ao equipamento após sua falha.

A solução adotada, neste caso, foi procurar na literatura uma base de dados para fornecer os dados de entrada para o calcula da confiabilidade dos sistemas, e o escolhido foi o OREDA (Offshore Reliability Data) (SINTEF, 2009). O OREDA é um projeto patrocinado por companhias produtoras de óleo e gás de todo o mundo e tem como principal objetivo a coleta e a troca de dados de confiabilidade 
entre as companhias participantes. OREDA estabeleceu um abrangente banco de dados com informações de manutenção e confiabilidade de equipamentos de produção e exploração de petróleo, principalmente de equipamentos subsea offshore e equipamentos topside. Segue abaixo a tabela que compila as informações de taxa de falha utilizadas para este estudo:

Tabela 5-2 - Informações de taxa de fallha utilizadas para o estudo

\begin{tabular}{|c|c|c|c|}
\hline \multicolumn{4}{|c|}{ Taxas de Falha } \\
\hline Equipamento & $\begin{array}{c}\text { Lambda }-\lambda \\
\text { (1/hora) }\end{array}$ & Fonte & OBS \\
\hline HPU Hidáulico & $7,250 \mathrm{E}-05$ & OREDA 2009, vol.2, Pág 56 & \\
\hline HPU Hidáulico & $7,227 \mathrm{E}-04$ & OREDA 2009, vol.2, Pág 79 & \\
\hline EPU & $1,601 \mathrm{E}-05$ & OREDA 2009, vol.2, Pág 56 & \\
\hline Acionamento $(p)$ & $1,712 \mathrm{E}-04$ & OREDA 2009, vol.2, Pág 79 & Master control station \\
\hline Umbilical - Parte Hidráulica & $1,610 \mathrm{E}-06$ & OREDA 2009, vol.2, Pág 55 & Dynamic umbilical \\
\hline Umbilical - Parte elétrica & $2,700 \mathrm{E}-07$ & OREDA 2009, vol.2, Pág 55 & Dynamic umbilical \\
\hline $\begin{array}{l}\text { Umbilical - Parte Hidráulica - em } \\
\text { espera }\left(\lambda_{U C}{ }^{*}\right)\end{array}$ & $4,830 \mathrm{E}-07$ & N/A & \\
\hline ANM-Conjunto & $1,226 \mathrm{E}-05$ & OREDA 2009, vol.2, Pág 139 & \\
\hline ANM - Acoplamento Hidráulico & $6,000 \mathrm{E}-08$ & OREDA 2009, vol.2, Pág 140 & \\
\hline ANM - Sinal elétrico & $5,900 \mathrm{E}-07$ & OREDA 2009, vol.2, Pág 80 & \\
\hline Tree Cap & $1,080 \mathrm{E}-06$ & OREDA 2009, vol.2, Pág 140 & \\
\hline SCM & $2,383 \mathrm{E}-05$ & OREDA 2009, vol.2, Pág 80 & \\
\hline Tubing Hanger & $2,200 \mathrm{E}-07$ & OREDA 2009, vol.2, Pág 149 & \\
\hline $\begin{array}{l}\text { Tubing Hanger - Acoplamento } \\
\text { Hidráulico }\end{array}$ & $4,000 \mathrm{E}-08$ & OREDA 2009, vol.2, Pág 149 & \\
\hline Tubing Hanger - Acoplamento Elétrico & $1,300 \mathrm{E}-07$ & OREDA 2009, vol.2, Pág 149 & \\
\hline Linha Hidráulica & $2,400 \mathrm{E}-07$ & OREDA 2009, vol.2, Pág 80 & Static umbilical \\
\hline Linha Elétrica & $5,900 \mathrm{E}-07$ & OREDA 2009, vol.2, Pág 80 & Static umbilical \\
\hline Linha Hidráulica em espera $\left(\lambda_{\mathrm{LH}}{ }^{*}\right)$ & $7,200 \mathrm{E}-08$ & $\mathrm{~N} / \mathrm{A}$ & $30 \%$ de chance de falhar - Despressurizado \\
\hline DHSV - PLC & $3,200 \mathrm{E}-07$ & Exprosoft 2012, Apencide A & Premature valve close \\
\hline DHSV - FTO & $1,420 \mathrm{E}-07$ & Exprosoft 2012, Apencide A & Fail to open on command \\
\hline DHSV - CLW & $1,420 \mathrm{E}-07$ & Exprosoft 2012, Apencide A & Control line to well communication \\
\hline DHSV - WCL & $3,200 \mathrm{E}-07$ & Exprosoft 2012, Apencide A & Well to control line communication \\
\hline
\end{tabular}

O OREDA fornece informações da taxa de falha média, o intervalo de incerteza da taxa de falha, o desvio padrão e o total de falhas dividido pelo número de horas em serviço.

\subsubsection{Estimador da taxa de falha}

Quando se obtém dados de falha de itens idênticos, operando nas mesmas condições ambientais e operacionais, podemos dizer que se tem uma amostra homogênea e, nestes casos, um bom estimador para a taxa de falha $\lambda$ é:

$$
\hat{\lambda}=\frac{\eta}{\tau}
$$

Onde: 
$\hat{\lambda}=$ Taxa de falha estimada

$\eta=$ Número de falhas observadas no intervalo de tempo $\tau$

$\tau=$ Intervalo de tempo de serviço

Porém, em muitos casos se tem uma amostra de dados homogênea. Dados agregados para um item podem vir de diferentes instalações, com diferentes condições ambientais e operacionais. As várias amostras podem ter diferentes taxas de falha, e diferentes quantidades de dados, e assim diferentes intervalos de confiança. Misturar todas as amostras e estimar a taxa de falha "média" como sendo o total de números de falha dividido pelo tempo total em serviço não irá fornecer um resultado adequado.

Por isso, há um estimador próprio do OREDA para estimar a média das taxas de falha, e a sua variação entre os diferentes ambientes operacionais pode ser modelado assumindo que a taxa de falha é uma variável aleatória com uma distribuição dada pela função densidade de probabilidade $\pi(\lambda)$. Assim, a taxa de falha média será:

$$
\theta=\int_{0}^{\infty} \lambda \cdot \pi(\lambda) d \lambda
$$

E sua variância:

$$
\sigma^{2}=\int_{0}^{\infty}(\lambda-\theta)^{2} \cdot \pi(\lambda) d \lambda
$$

Assim, o OREDA possui o seguinte procedimento:

1. Calcular uma estimativa inicial da taxa de falha média:

$$
\widehat{\Theta}_{1}=\frac{n^{\circ} \text { de falhas total }}{\text { tempo total de serviço }}=\frac{\sum_{i=1}^{k} n_{i}}{\sum_{i=1}^{k} \tau_{i}}
$$

2. Calcular:

$$
\begin{gathered}
S_{1}=\sum_{i=1}^{k} \tau_{i} \\
S_{2}=\sum_{i=1}^{k} \tau_{i}^{2} \\
V=\sum_{i=1}^{k} \frac{\left(n_{i}-\widehat{\Theta}_{1} \tau_{i}\right)^{2}}{\tau_{i}}=\sum_{i=1}^{k} \frac{n_{i}^{2}}{t_{i}}-\widehat{\Theta}_{1}^{2} S_{1}
\end{gathered}
$$


3. Calcular a variância $\hat{\sigma}^{2}$ :

$$
\hat{\sigma}^{2}=\frac{V-(k-1) \widehat{\theta}_{1}}{S_{1}^{2}-S_{2}} \times S_{1}, \quad \text { para } \hat{\sigma}^{2} \geq 0, \quad \text { ou } \quad \hat{\sigma}^{2}=\sum_{i=1}^{k} \frac{\left(\frac{n_{i}}{\tau_{i}}-\widehat{\theta}_{1}\right)^{2}}{k-1}
$$

4. Calcular o estimador final $\theta^{*}$ da média da taxa de falha:

$$
\theta^{*}=\frac{1}{\sum_{i=1 \frac{\hat{\theta}_{1}}{\tau_{i}}+\widehat{\sigma}^{2}}^{k}} \times \sum_{i=1}^{k}\left(\frac{1}{\frac{\bar{\theta}_{1}}{\tau_{i}}+\widehat{\sigma}^{2}} \times \frac{n_{i}}{\widehat{\sigma}_{i}}\right)
$$

Todas as estimativas de taxa de falha apresentadas no OREDA são baseadas assumindo que a função taxa de falha é constante e independente do tempo, isto é, possuem uma distribuição exponencial com parâmetro $\lambda$. Assim, os itens são considerados "as good as new", desde que esteja funcionando, e todas as falhas são independentes da idade do equipamento.

\subsubsection{Intervalo de confiança da taxa de falha}

A incerteza do estimador $\hat{\lambda}$ é apresentado com um intervalo de confiança de $90 \%$, isto é:

$$
P\left(\lambda_{\lim \text { Inf }} \leq \lambda \leq \lambda_{\lim \text { Sup }}\right)=90 \%
$$

E para um sistema com $n$ falhas durante um período de tempo $\tau$ - isto é, um ambiente homogêneo, este intervalo de confiança pode ser dado por:

$$
\left(\frac{1}{2 \tau} z_{0,95,2 n}, \frac{1}{2 \tau} z_{0,05,2(n+1)}\right)
$$

Onde $z_{0,95,2 n}$ e $z_{0,05,2(n+1)}$ indicam os percentuais superior (95\%) e inferior (5\%) da distribuição Qui-quadrada $\left(x^{2}\right)$. Porém, nos casos em que se tem várias amostras de diferentes condições de operação, é necessária uma estimativa um pouco mais avançada para que esta se torne mais realista.

Assim, tomando como base que o valor da incerteza pode ser dado por:

$$
\int_{\lim \text { Inferior }}^{\text {Lim Superior }} \pi(\lambda) d \lambda=90 \%
$$

E que a distribuição $\pi(\lambda)$ não é conhecida, o OREDA assumiu as seguintes posições: 
- A função $\pi(\lambda)$ é uma função de densidade de probabilidade com uma distribuição gama, de parâmetros $\alpha$ e $\beta$, onde estes são estimados da seguinte forma:

$$
\begin{aligned}
& \hat{\beta}=\frac{\theta^{*}}{\hat{\sigma}^{2}} \\
& \hat{\alpha}=\hat{\beta} \times \theta^{*}
\end{aligned}
$$

E os limites superiores e inferiores do intervalo de confiança são calculados segundo as equações abaixo:

$$
\begin{aligned}
& \text { Lim Superior }=\frac{1}{2 \widehat{\beta}} z_{0,95,2 \widehat{\alpha}} \\
& \text { Lim Inferior }=\frac{1}{2 \widehat{\beta}} z_{0,05,2 \widehat{\alpha}}
\end{aligned}
$$

Onde $z_{0,95,2 \widehat{\alpha}}$ e $z_{0,05,2 \widehat{\alpha}}$ indicam os percentuais superior (95\%) e inferior (5\%) da distribuição Qui-quadrada $\left(x^{2}\right)$, respectivamente.

A maioria dos dados necessários para este estudo foram encontrados no OREDA, porém este não contempla equipamentos instalados dentro de um poço offshore, e por isso não possui dados de confiabilidade do próprio dispositivo de segurança de sub-superfície. Assim, os dados de confiabilidade do DSSS foram retirados do Wellmaster, através de um outro estudo da SINTEF feito para análise e comparação de risco total de um poço offshore com e sem sistema de DSSS (EXPROSOFT, 2012). Wellmaster é uma base de dados baseada no armazenamento e análise de dados de confiabilidade de equipamentos de poços de petróleo.

\subsubsection{Propagação das incertezas}

A incerteza da medição é uma estimativa que procura caracterizar o intervalo de valores dentro do qual se encontra o verdadeiro valor da grandeza medida (CABRAL, 2004). Uma vez que os valores verdadeiros são desconhecidos, os valores estimados devem ser usados na avaliação da incerteza combinada - as variâncias, os desvios-padrão ou as covariâncias, no caso de correlação as grandezas de entrada. 
Nos modelos matemáticos envolvendo somas, a incerteza padrão combinada é a soma quadrática das incertezas padrão dos diversos componentes:

$$
\sigma_{y}=\sqrt{{\sigma_{x_{1}}{ }^{2}+{\sigma_{x_{2}}}^{2}+\cdots}}
$$

Nos modelos matemáticos que envolvam apenas produtos, a incerteza padrão combinada será é a soma quadrática das incertezas padrão dos diversos componentes.

$$
\frac{\sigma_{y}}{\overline{\theta^{*}}}=\sqrt{\left(\frac{\sigma_{x_{1}}}{\overline{x_{1}}}\right)^{2}+\left(\frac{\sigma_{x_{2}}}{\overline{x_{2}}}\right)^{2}+\cdots}
$$

Para este trabalho, a propagação das incertezas não foi realizada, apesar de se entender sua importância. 


\section{ANÁLISE DOS RESULTADOS}

\subsection{Caso A1 - Sistema HD sem redundância}

O caso A1 representa o sistema hidráulico direto com todos os equipamentos em série, sem nenhuma redundância. Não há necessidade de realizar nenhum estudo baseado no processo de Markov para calcular a confiabilidade deste sistema, pois com todos os equipamentos em série basta multiplicar as confiabilidades, pois:

$$
\begin{aligned}
& R_{S}(t)=R_{H P U}(t)+R_{U C}(t)+R_{A N M}(t)+R_{T H}(t)+R_{L H}(t)+R_{D H S V}(t) \\
& R_{S}(t)=e^{-\lambda_{H P U} t} * e^{-\lambda_{U C} t} * e^{-\lambda_{A N M} t} * e^{-\lambda_{T H} t} * e^{-\lambda_{L H} t} * e^{-\lambda_{D H S V} t}
\end{aligned}
$$

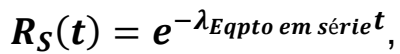

Onde:

$$
\lambda_{\text {Eqpto em série }}=\lambda_{H P U}+\lambda_{U C}+\lambda_{A N M}+\lambda_{T H}+\lambda_{L H}+\lambda_{D H S V}
$$

Porém, para termos como comparar os resultados com outros estudos mais complexos, também faremos este estudo através do processo de Markov. Assim, o primeiro sistema pode ser representado pelo seguinte esquema (Figura 6-1):

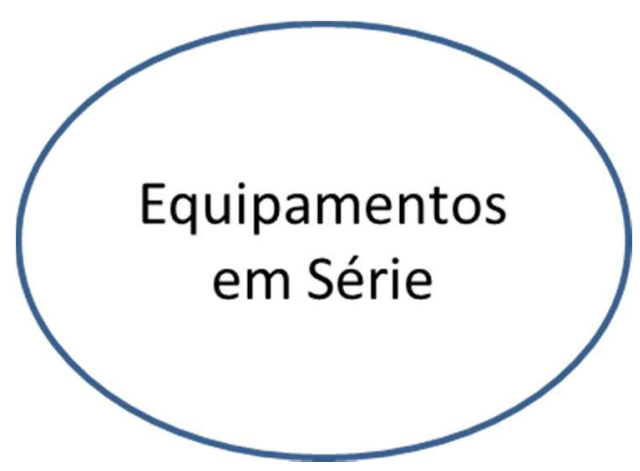

Figura 6-1 - Simplificação do sistema A1

Baseado no diagrama de estados, podemos dizer que, no caso de todos os equipamentos em série, só teremos dois estados para o sistema: disponível e indisponível, já que a falha de qualquer equipamento do sistema leva à falha do sistema como um todo. A Figura 6-2 abaixo ilustra os estados possíveis do sistema em série: 


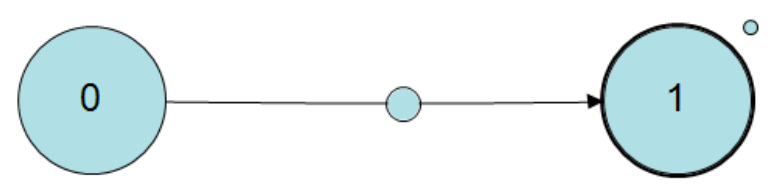

Figura 6-2 - Estados possíveis do sistema A1

Onde:

Tabela 6-1 - Descrição dos estados do sistema A1

\begin{tabular}{cccc}
\hline \multicolumn{4}{c}{ Sistema A1 - Hidráulico em Série } \\
\hline Estado & Nome & $\begin{array}{c}\text { Eqptos em } \\
\text { série }\end{array}$ & $\begin{array}{c}\text { Disponibilidad } \\
\text { e }\end{array}$ \\
\hline 0 & Sem falhas & $\mathrm{D}$ \\
\hline 1 & Falha Equipamentos em Série & $\mathrm{I}$ \\
\hline $\begin{array}{c}\text { Legenda: } \\
=\end{array}$ & & \\
$\mathrm{I}=$ Disponivel & &
\end{tabular}

Utilizando as taxas de falha já levantadas, podemos ter uma taxa de falha do sistema, apenas somando as taxas de falha dos componentes do sistema (Tabela 6-2):

Tabela 6-2 - Taxas de fallha dos equipamentos - Sistema A1

\begin{tabular}{|l|c|}
\hline \multicolumn{1}{|c|}{ Equipamentos } & Lambda $-\boldsymbol{\lambda}$ (1/hora) \\
\hline HPU Hidráulico & $7,250 \mathrm{E}-05$ \\
\hline Umbilical - Parte Hidráulica & $1,610 \mathrm{E}-06$ \\
\hline ANM/Tree cap & $1,140 \mathrm{E}-06$ \\
\hline Tubing Hanger - Acoplamento Hidráulico & $4,000 \mathrm{E}-08$ \\
\hline Linha Hidráulica & $2,400 \mathrm{E}-07$ \\
\hline DHSV (PLC + FTO) & $4,620 \mathrm{E}-07$ \\
\hline Equipamentos em Série & $7,599 \mathrm{E}-05$ \\
\hline
\end{tabular}

Assim, traçar uma curva de confiabilidade conforme mostrado na Figura 6-3 abaixo: 


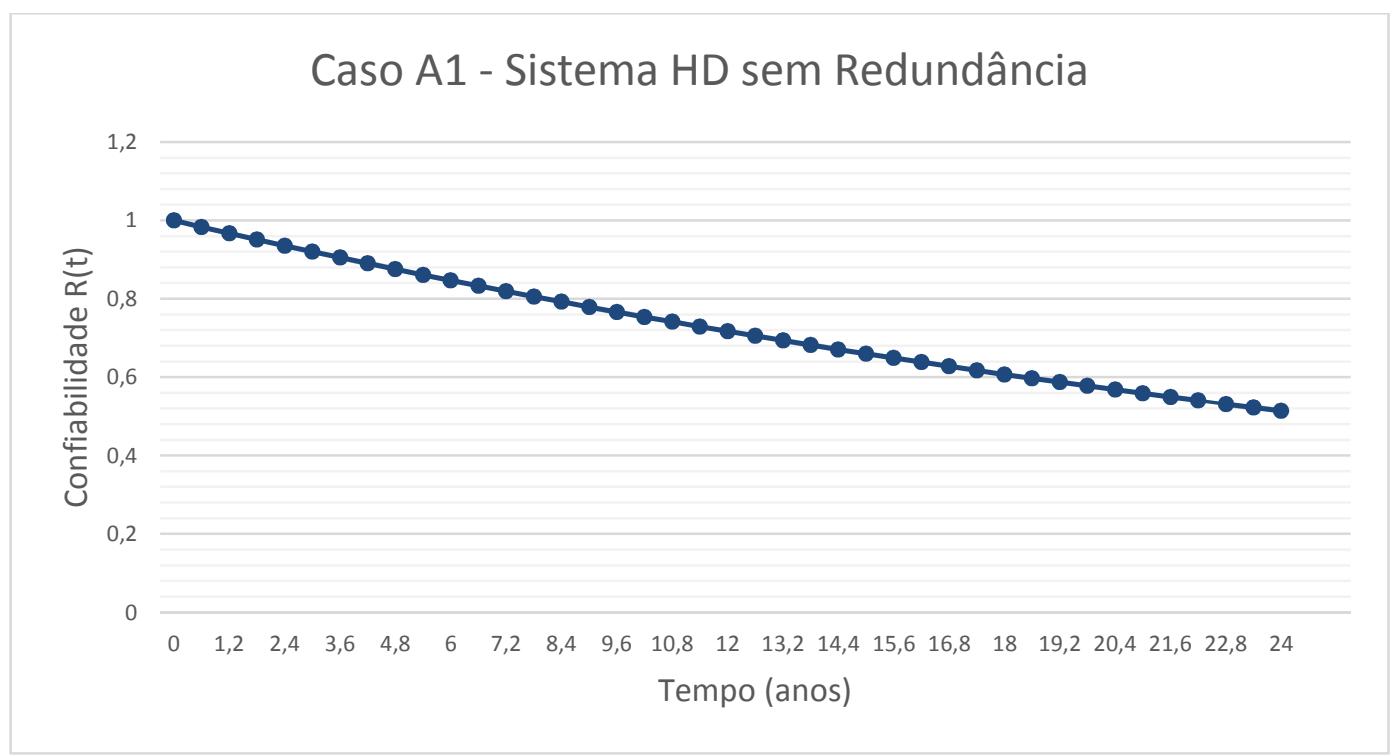

Figura 6-3 - Confiabilidade x Tempo - Sistema HD equipamentos em série

O tempo operacional médio é de $6.396,5$ dias (17,5 anos), a taxa de falha instantânea no final da missão é de $3,905 \times 10^{-5}$, a disponibilidade média do sistema é de 0,7302 e a disponibilidade instantânea do sistema no final da missão é de 0,5139 .

\subsection{Caso A2 - Sistema HD com redundância no umbilical}

O segundo sistema estudado é um sistema hidráulico direto com redundância no umbilical de controle, que pode ser representado pela Figura 5-2 e, conforme pode ser visto, o sistema contém 7 equipamentos, o que, se não houver nenhuma simplificação para a análise, o sistema terá $2^{7}=128$ estados, bastante complicado de analisar. Uma simplificação plausível de se fazer é a compilação de todos os equipamentos em série em um só (somando suas taxas de falha), e calculando a disponibilidade do sistema com esta pseudo-configuração. Com a simplificação descrita acima, o sistema passa a ser conforme mostrado na Figura 6-4 abaixo: 


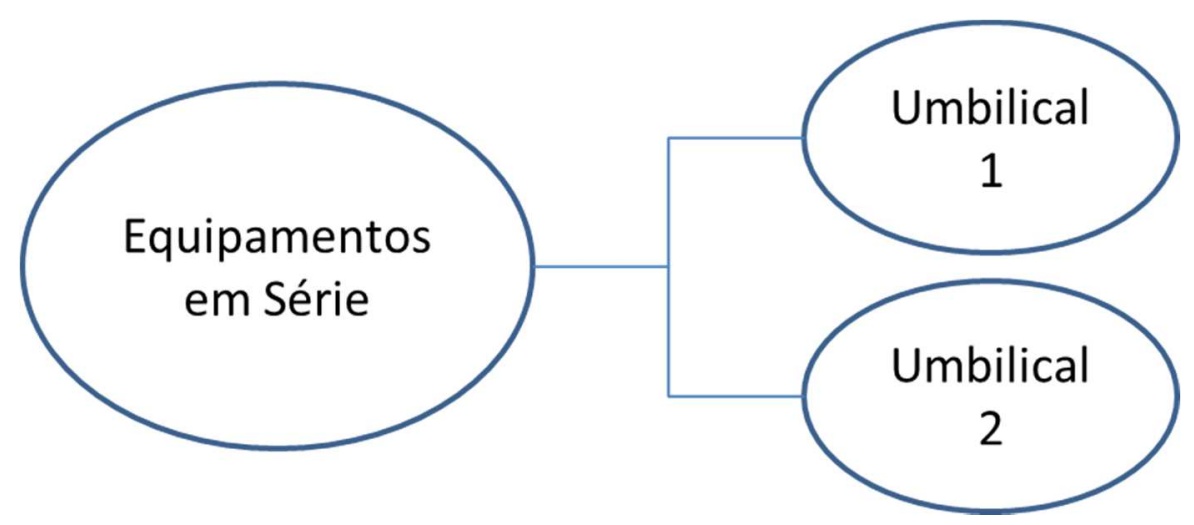

Figura 6-4 - Simplificação de sistema A2

O sistema acima passa a conter $2^{3}=8$ estados, ao invés dos 128 estados anteriores. Considerando o sistema em paralelo como um sistema ativo com cargas independentes, a tabela abaixo lista os estados disponíveis do sistema (Tabela 6-3):

Tabela 6-3 - Descrição dos estados do sistema A2

\begin{tabular}{|c|c|c|c|c|c|}
\hline \multicolumn{6}{|c|}{ Sistema A2 - HD com Redundância no Umbilical } \\
\hline Estado & Nome & Eqptos em série & UC 1 & UC 2 & Disponibilidade \\
\hline 0 & Sem falhas & & & & $\mathrm{D}$ \\
\hline 1 & Falha UC\#2 & & & & D \\
\hline 2 & Falha UC\#1 & & & & $\mathrm{D}$ \\
\hline 3 & Falha Equipamentos em série & & & & 1 \\
\hline 4 & Falha UC\#1 + Falha UC \#2 & & & & 1 \\
\hline 5 & Falha UC \#2 + Falha Equipamentos em série & & & & $\mathrm{I}$ \\
\hline 6 & Falha UC\#1 + Falha Equipamentos em série & & & & 1 \\
\hline 7 & Falha todos os equipamentos & & & & $\mathrm{x}$ \\
\hline genda: & ( & & & & \\
\hline
\end{tabular}

Com as definições dos estados, pode-se estruturar o diagrama de transição de estados do sistema A2. O estado "0" do diagrama representa o sistema sem falhas, e para passar do estado "0" para o estado 1, é preciso que o umbilical № 2 falhe, e esta falha está representada pela seta que liga estes dois estados, o que representa uma taxa da falha $\lambda$. Esta representação se repete para todos os estados, abrangendo todas as transições possíveis para esta configuração. 


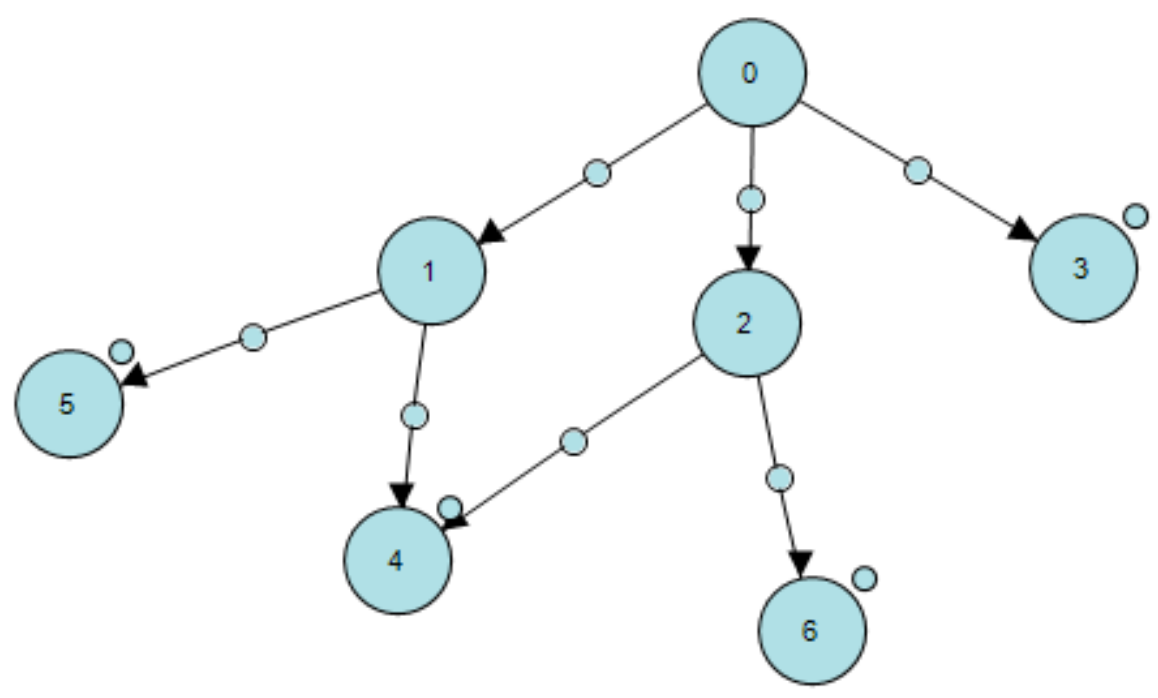

Figura 6-5 - Diagrama de transição de estados para sistema A2

A Tabela 6-4 apresenta as taxas de falha utilizadas para o cálculo da confiabilidade do sistema A2. Neste caso, somente três taxas de falhas são utilizadas no diagrama de transição de estados: taxa de falha do umbilical $\mathrm{N} 1$, taxa de falha do umbilical $\mathrm{N} 2$ e a taxa de falha dos equipamentos em série.

Tabela 6-4 - Taxas de falha dos equipamentos - Sistema A2

\begin{tabular}{l|c|}
\hline \multicolumn{1}{|c|}{ Equipamentos } & Lambda $-\boldsymbol{\lambda}$ (1/hora) \\
\hline HPU Hidáulico & $7,250 \mathrm{E}-05$ \\
\hline ANM/Tree cap & $1,140 \mathrm{E}-06$ \\
\hline Tubing Hanger - Acoplamento Hidráulico & $4,000 \mathrm{E}-08$ \\
\hline Linha Hidráulica & $2,400 \mathrm{E}-07$ \\
\hline DHSV (PLC + FTO) & $4,620 \mathrm{E}-07$ \\
\hline Equipamentos em Série & $7,438 \mathrm{E}-05$ \\
\hline & \\
\hline Umbilical - Parte Hidráulica - 1 & $1,610 \mathrm{E}-06$ \\
\hline Umbilical - Parte Hidráulica - 2 & $1,610 \mathrm{E}-06$ \\
\hline
\end{tabular}

Com o diagrama de transição de estados pronto, o programa nos entrega como resultado uma curva de confiabilidade, conforme mostrado na figura abaixo: 


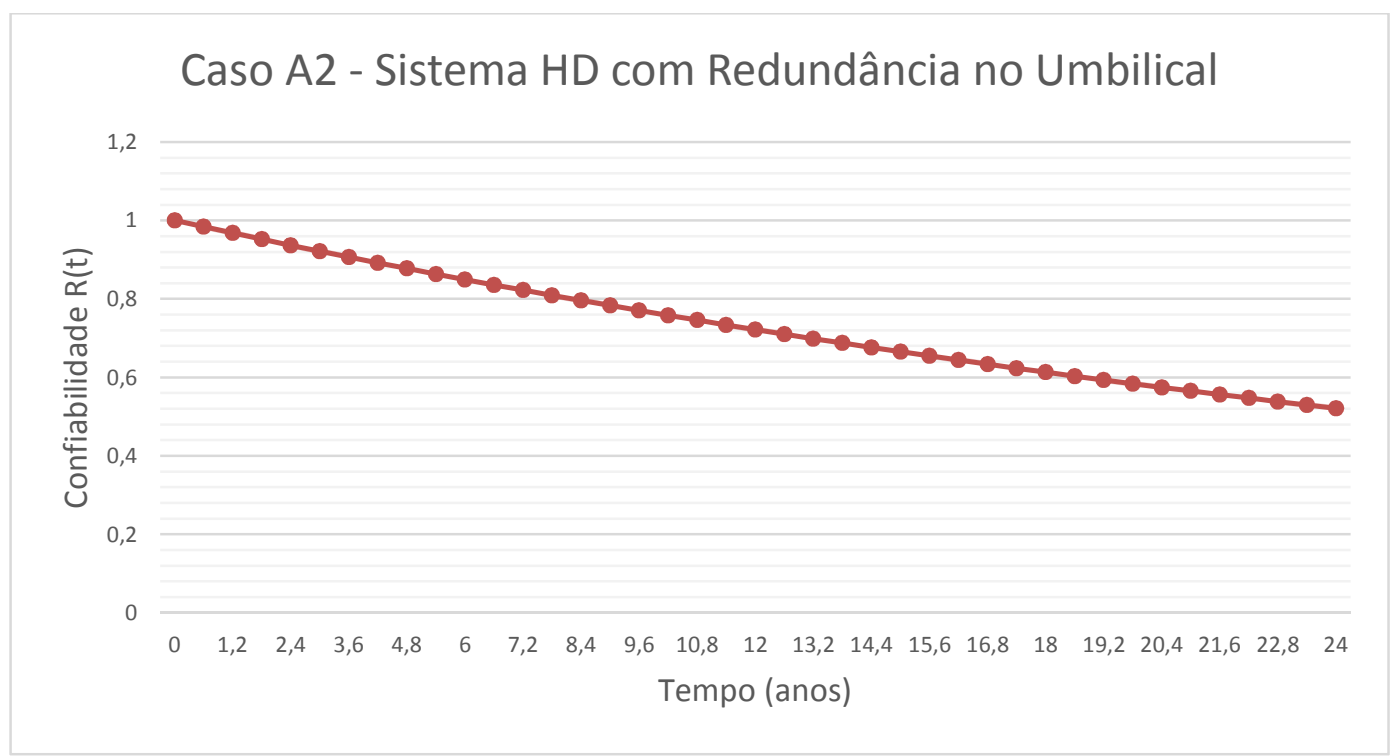

Figura 6-6 - Confiabilidade x Tempo - Sistema HD com redundância no UC

O tempo operacional médio é de $6.436,5$ dias (17,6 anos), a taxa de falha instantânea no final da missão é de 3,878 x 10-5, a disponibilidade média do sistema é de 0,7348 e a disponibilidade instantânea do sistema no final da missão é de 0,5211 .

\subsection{Caso A3 - Sistema HD com duas redundâncias no umbilical}

O caso A3 representa o sistema hidráulico direto com duas redundâncias no umbilical. Da mesma forma que o estudo anterior, podemos simplificar o sistema agrupando todos os equipamentos em série para facilitar os cálculos. O sistema simplificado pode ser representado pela seguinte forma (Figura 6-7):

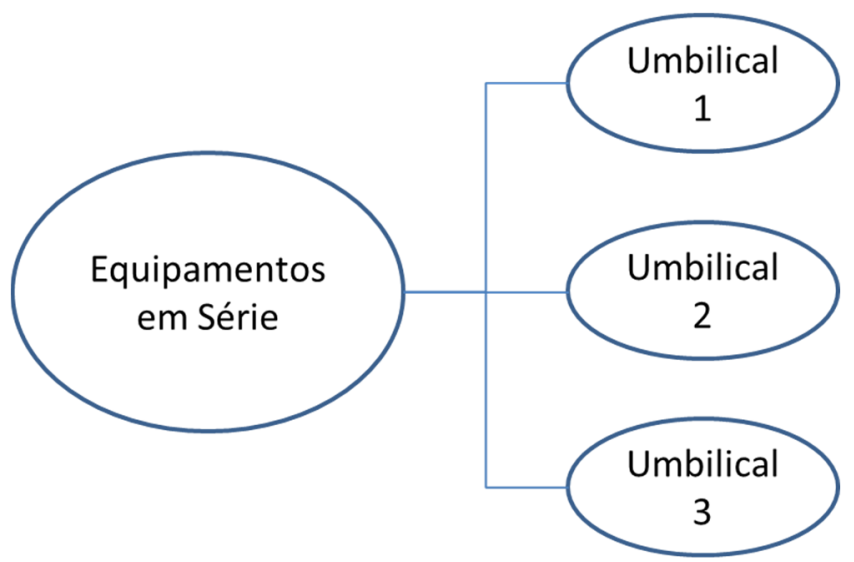

Figura 6-7 - Simplificação do sistema A3 
O sistema simplificado possui a possibilidade de ter $2^{4}=16$ estados, ao invés dos $2^{8}=256$ estados que seriam estudados caso não houvesse a simplificação. Estes estados estão representados na Tabela 6-5 abaixo:

Tabela 6-5 - Descricão dos estados do sistema A3

\begin{tabular}{|c|c|c|c|c|c|c|}
\hline \multicolumn{7}{|c|}{ Sistema A3 - HD com duas redundâncias do Umbilical } \\
\hline Estado & Nome & Eqptos em série & UC3 & UC 2 & UC 1 & Disponibilidade \\
\hline 0 & Sem falhas & & & & & $\mathrm{D}$ \\
\hline 1 & Falha UC\#1 & & & & & $\mathrm{D}$ \\
\hline 2 & Falha UC\#2 & & & & & $\mathrm{D}$ \\
\hline 3 & Falha UC\#3 & & & & & $\mathrm{D}$ \\
\hline 4 & Falha Equipamentos em série & & & & & 1 \\
\hline 5 & Falha UC\#1 + Falha UC\#2 & & & & & $\mathrm{D}$ \\
\hline 6 & Falha UC\#1 + Falha UC\#3 & & & & & $\mathrm{D}$ \\
\hline 7 & Falha UC\#1 + Falha Equipamentos em série & & & & & 1 \\
\hline 8 & Falha UC \#2 + Falha UC\#3 & & & & & $\mathrm{D}$ \\
\hline 9 & Falha UC \#2+ Falha Equipamentos em série & & & & & 1 \\
\hline 10 & Falha UC\#3 + Falha Equipamentos em série & & & & & 1 \\
\hline 11 & Falha UC\#1+ Falha UC \#2 + Falha UC\#3 & & & & & 1 \\
\hline 12 & Falha UC \#1 + Falha UC \#2 + Fal ha Equipamentos em série & & & & & 1 \\
\hline 13 & Falha UC \#1 + Falha UC \#3 + Fal ha Equipamentos em série & & & & & 1 \\
\hline 14 & Fal ha UC \#2 + Falha UC \#3 + Fal ha Equipamentos em série & & & & & 1 \\
\hline 15 & Falha todos os equipamentos & & & & & $\mathrm{x}$ \\
\hline
\end{tabular}

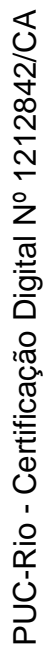

Construindo o diagrama de transição de estados, tem-se:

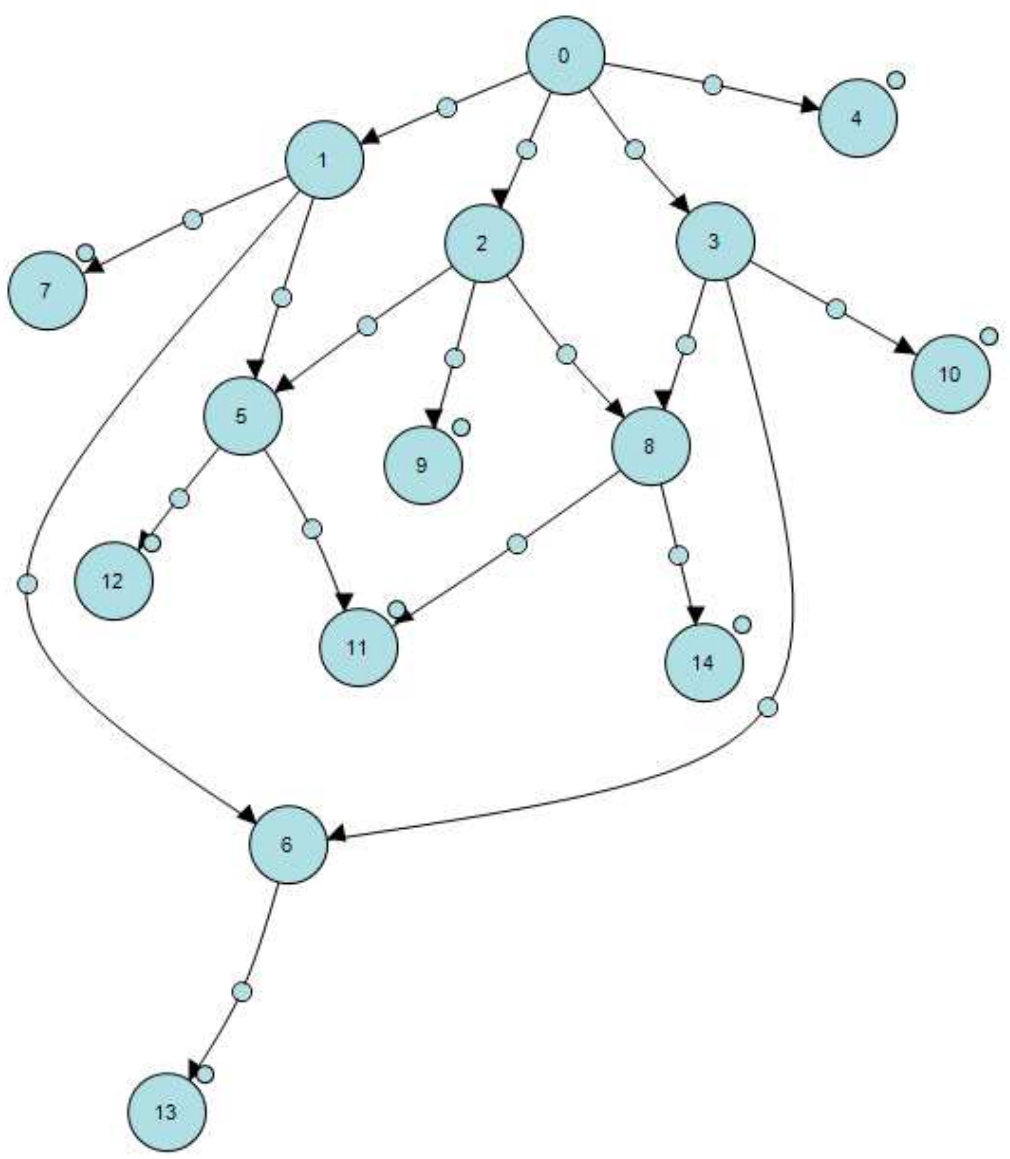

Figura 6-8 - Diagrama de transição de estados para sistema A3 
A Tabela 6-6 apresenta as taxas de falha utilizadas para o cálculo da confiabilidade do sistema A3. Neste caso, serão utilizadas quatro taxas de falha: as dos três umbilicais em paralelo e a taxa de falha dos equipamentos em série.

Tabela 6-6 - Taxas de falha dos equipamentos - Sistema A3

\begin{tabular}{l|c|}
\hline \multicolumn{1}{|c|}{ Equipamentos } & Lambda $-\boldsymbol{\lambda}$ (1/hora) \\
\hline HPU Hidáulico & $7,250 \mathrm{E}-05$ \\
\hline ANM/Tree cap & $1,140 \mathrm{E}-06$ \\
\hline Tubing Hanger - Acoplamento Hidráulico & $4,000 \mathrm{E}-08$ \\
\hline Linha Hidráulica & $2,400 \mathrm{E}-07$ \\
\hline DHSV (PLC + FTO) & $4,620 \mathrm{E}-07$ \\
\hline Equipamentos em Série & $7,438 \mathrm{E}-05$ \\
\hline & \\
\hline Umbilical - Parte Hidráulica - 1 & $1,610 \mathrm{E}-06$ \\
\hline Umbilical - Parte Hidráulica - 2 & $1,610 \mathrm{E}-06$ \\
\hline Umbilical - Parte Hidráulica - 3 & $1,610 \mathrm{E}-06$ \\
\hline
\end{tabular}

E assim, pode-se traçar a curva de confiabilidade do sistema A3:

\section{Caso A3 - Sistema HD com Duas Redundâncias no} Umbilical

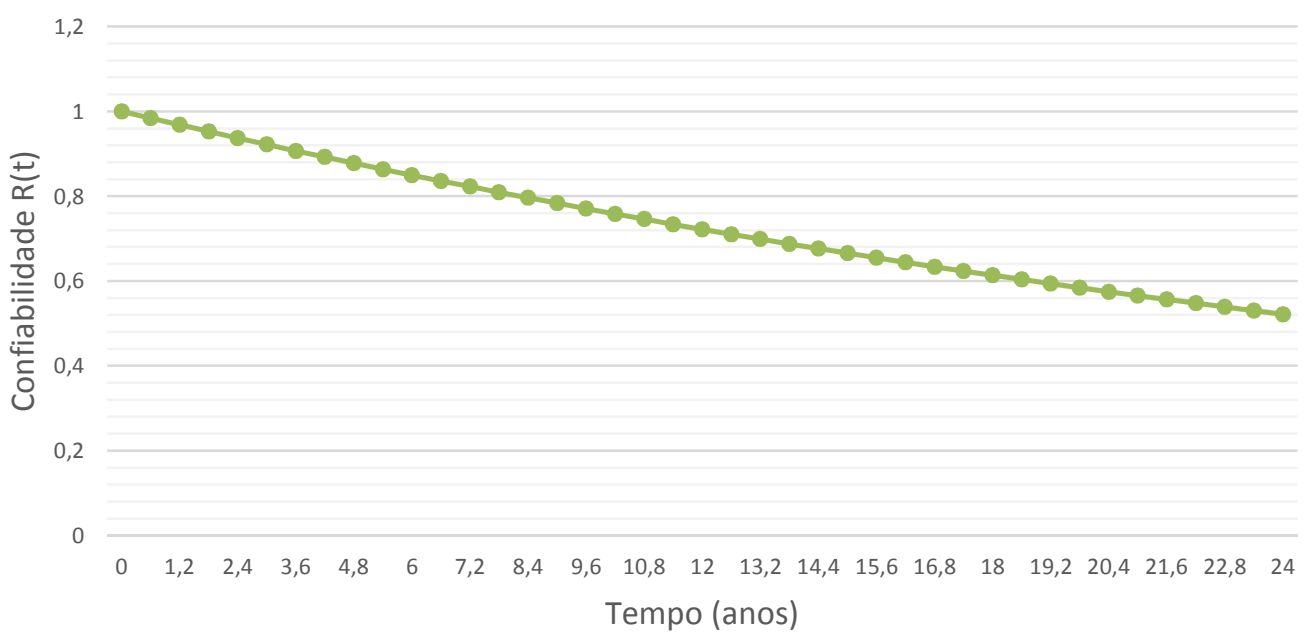

Figura 6-9 - Confiabilidade x Tempo - Sistema HD com duas redundâncias no UC

O tempo operacional médio é de $6.436,9$ dias (17,6 anos), a taxa de falha instantânea no final da missão é de $3,877 \times 10^{-5}$, a disponibilidade média do sistema é de 0,7348 e a disponibilidade instantânea do sistema no final da missão é de 0,5212. 


\subsection{Caso A4 - Sistema HD com redundância na linha de controle}

O caso A4 representa o sistema hidráulico direto com redundância na linha de controle. A Figura 5-4 ilustra o sistema proposto, porém da mesma forma que teríamos um grande conjunto de estados a serem analisados, foi realizada a mesma simplificação dos sistemas anteriores, agrupando os equipamentos em série, e a Figura 6-9 representa esta simplificação:

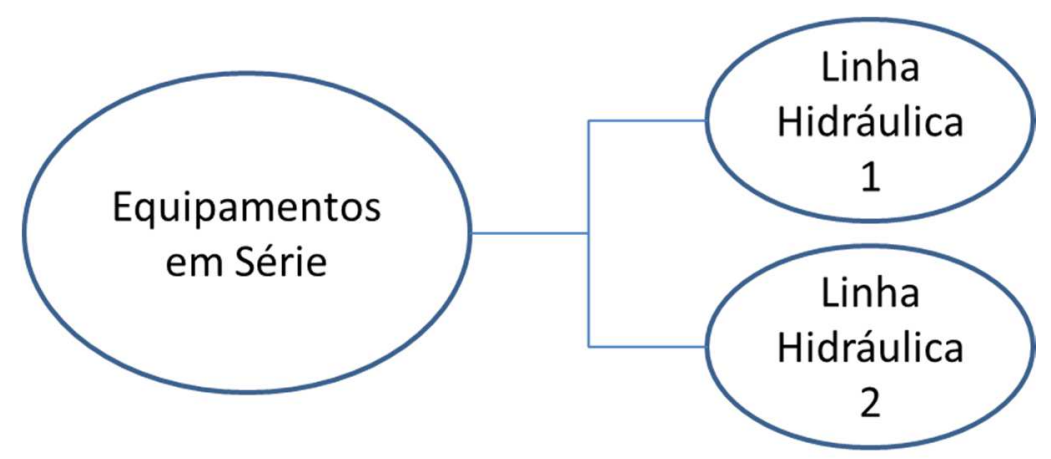

Figura 6-10 - Simplificação do sistema A5

Com a estrutura cima tem-se 8 estados a serem analisados, que estão descritos na Tabela 6-7 abaixo:

Tabela 6-7 - Descrição dos estados do sistema A4

\begin{tabular}{|c|c|c|c|c|c|}
\hline \multicolumn{6}{|c|}{ Sistema A4 - HD com Redundância na Linha de Controle } \\
\hline Estado & Nome & Eqptos em série & LH 1 & $\mathrm{LH} 2$ & Disponibilidade \\
\hline 0 & Sem falhas & & & & D \\
\hline 1 & Falha LH\#2 & & & & $\mathrm{D}$ \\
\hline 2 & Falha LH\#1 & & & & $\mathrm{D}$ \\
\hline 3 & Falha Equipamentos em série & & & & 1 \\
\hline 4 & Falha LH \#1 + Falha LH \#2 & & & & 1 \\
\hline 5 & Falha LH \#2+ Falha Equipamentos em série & & & & 1 \\
\hline 6 & Falha LH \#1+ Falha Equipamentos em série & & & & 1 \\
\hline 7 & Falha todos os equipamentos & & & & $\mathrm{x}$ \\
\hline $\begin{array}{l}\text { Legenda: } \\
D=\text { Disponi } \\
=\text { Indispon } \\
X=\text { Sem pos }\end{array}$ & ilidade de acontecer & & & & \\
\hline
\end{tabular}

Construindo o diagrama de estados, temos: 


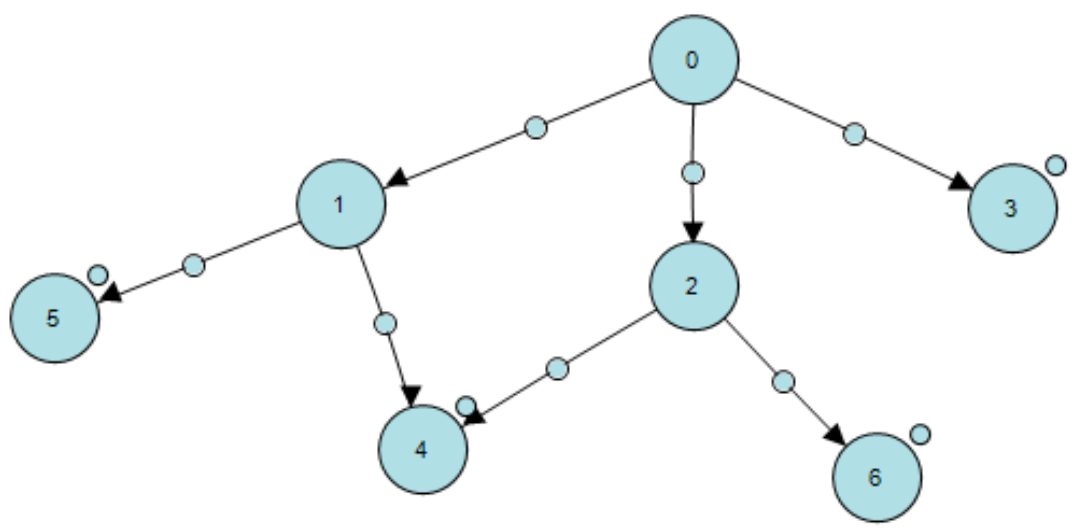

Figura 6-11 - Diagrama de transição de estados para sistema A4

No sistema A4 serão utilizadas três taxas de falha, uma relacionada aos componentes em série, onde o umbilical foi incluído e a linha de controle foi removida, e as taxas de falha das duas linhas hidráulicas de controle, presentes na parte interna do poço:

Tabela 6-8 - Taxas de falha dos equipamentos - Sistema A4

\begin{tabular}{l|c|}
\hline \multicolumn{1}{|c|}{ Equipamentos } & Lambda $-\boldsymbol{\lambda}(\mathbf{1} / \mathbf{h o r a})$ \\
\hline HPU Hidáulico & $7,250 \mathrm{E}-05$ \\
\hline Umbilical - Parte Hidráulica & $1,610 \mathrm{E}-06$ \\
\hline ANM/Tree cap & $1,140 \mathrm{E}-06$ \\
\hline Tubing Hanger - Acoplamento Hidráulico & $4,000 \mathrm{E}-08$ \\
\hline DHSV (PLC + FTO) & $4,620 \mathrm{E}-07$ \\
\hline Equipamentos em Série & $7,575 \mathrm{E}-05$ \\
\hline & \\
\hline Linha Hidráulica 1 & $2,400 \mathrm{E}-07$ \\
\hline Linha Hidráulica 2 & $2,400 \mathrm{E}-07$ \\
\hline
\end{tabular}

Assim, pode-se gerar o gráfico de confiabilidade ao longo da vida produtiva do poço: 


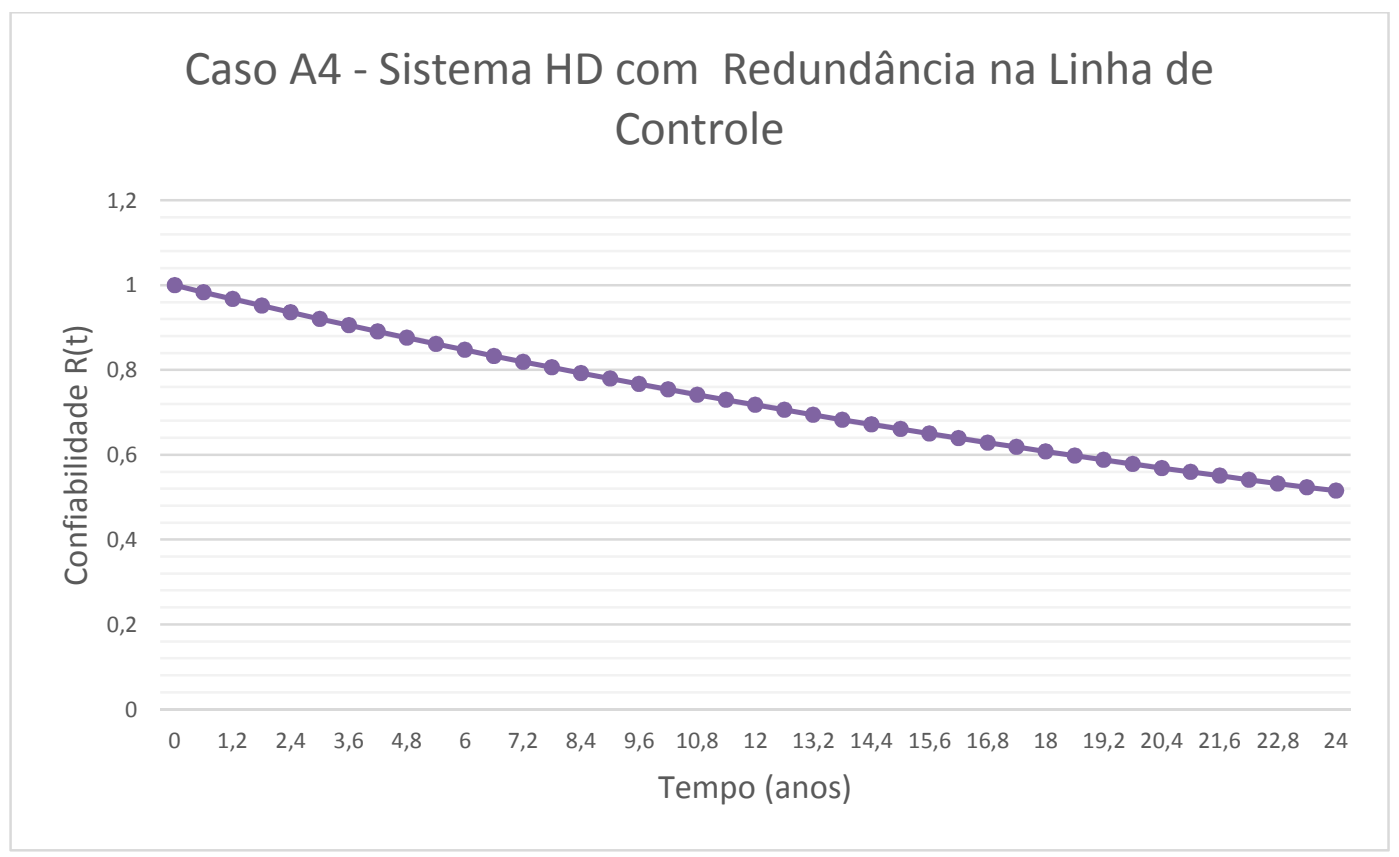

Figura 6-12 - Confiabilidade x Tempo - Sistema HD com redundância na LC

O tempo operacional médio é de $6.402,5$ dias (17,5 anos), a taxa de falha instantânea no final da missão é de $3,901 \times 10^{-5}$, a disponibilidade média do sistema é de 0,7309 e a disponibilidade instantânea do sistema no final da missão é de 0,5150 .

\subsection{Caso A5 - Sistema HD com redundância na linha de controle e no umbilical}

O caso A5 representa um sistema hidráulico direto com redundância na linha de controle e no umbilical, e a Figura 6-13 abaixo ilustra a simplificação deste sistema:

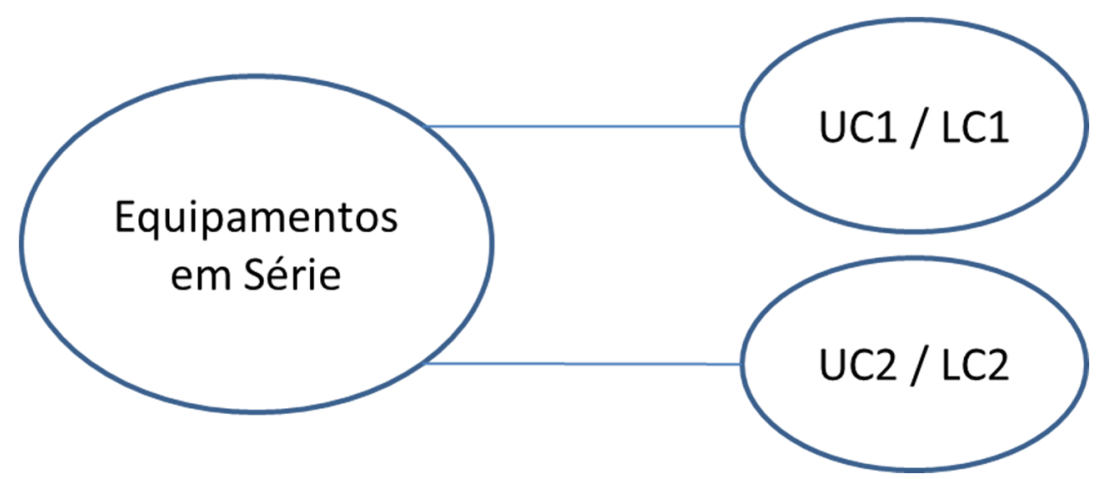

Figura 6-13 - Simplificação do sistema A5 
Esta simplificação reduz de 256 para 8 estados a serem analisados, que podem ser vistos na Tabela 6-9:

Tabela 6-9 - Descrição dos estados do sistema A5 Sistema A5 - HD com redundância na Linha de Controle e no Umbilical

\begin{tabular}{|c|c|c|c|c|c|}
\hline Estado & & & & & \\
\hline 0 & Sem falhas & & & & $\mathrm{D}$ \\
\hline 1 & Falha UC\#2 / LH \#2 & & & & $\mathrm{D}$ \\
\hline 2 & Falha UC\#1 / LH\#1 & & & & D \\
\hline 3 & Falha Equipamentos em série & & & & $\mathrm{I}$ \\
\hline 4 & Falha UC\#1 / LH\#1 + Falha UC\#2 / LH \#2 & & & & 1 \\
\hline 5 & Fal ha UC\#2 / LH \#2 + Falha Equipamentos em série & & & & $\mathrm{I}$ \\
\hline 6 & Fal ha UC\#1 / LH \#1 + Falha Equipamentos em série & & & & I \\
\hline 7 & Falha todos os equipamentos & & & & $\mathrm{x}$ \\
\hline
\end{tabular}

Construindo o diagrama de estados, temos (Figura 6-14):

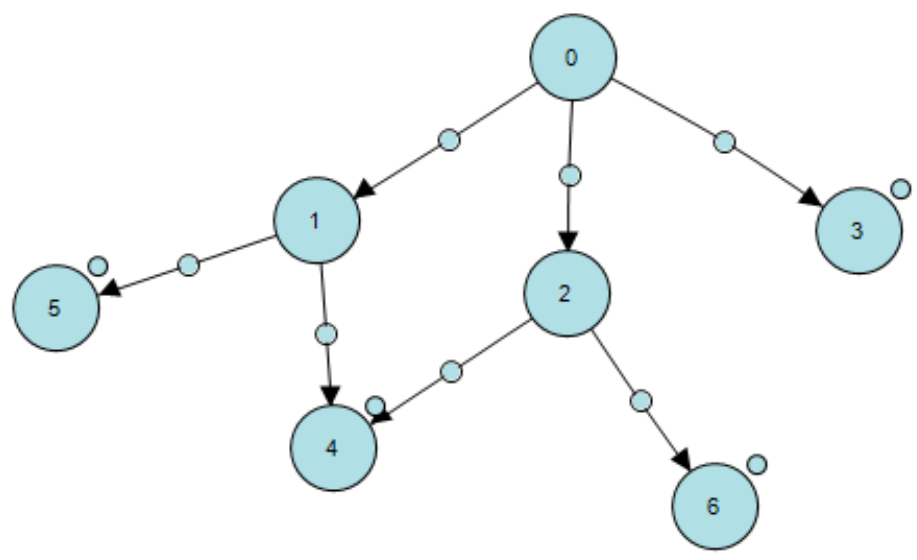

Figura 6-14 - Diagrama de transição de estados para sistema A5

Apesar deste sistema simplificado também utilizar três taxas de falha, a composição é um pouco diferente das demais até aqui apresentadas. Nos sistemas anteriores, somente uma taxa de falha utilizada possuía o somatório de taxas de falhas devido a equipamentos em série no sistema, enquanto as demais taxas eram referentes a um equipamento específico. Neste caso, as três taxas de falha possuem equipamentos em série, pois os dois sistemas em paralelo de acionamento da válvula trabalham, cada um com o umbilical de controle (UC) e a linha de controle hidráulica (LH) trabalhando em série. Apesar de alguns equipamentos estarem entre o UC e LH (tubing hanger, por exemplo), suas taxas de falha foram adicionadas no conjunto "Equipamentos em Série", pois se fossem incluídos nos dois sistemas em paralelo, estaríamos repetindo suas taxas de falha no sistema, dobrando assim seu valor. 
Tabela 6-10 - Taxas de fallha dos equipamentos - Sistema A5

\begin{tabular}{lc}
\hline \multicolumn{1}{c}{ Equipamentos } & Lambda $-\boldsymbol{\lambda}$ (1/hora) \\
\hline HPU Hidráulico & $7,250 \mathrm{E}-05$ \\
\hline ANM/Tree cap & $1,140 \mathrm{E}-06$ \\
\hline Tubing Hanger - Acoplamento Hidráulico & $4,000 \mathrm{E}-08$ \\
\hline DHSV (PLC + FTO) & $4,620 \mathrm{E}-07$ \\
\hline Equipamentos em Série & $7,414 \mathrm{E}-05$ \\
\hline & \\
\hline & $1,610 \mathrm{E}-06$ \\
\hline Umbilical - Parte Hidráulica - 1 & $2,400 \mathrm{E}-07$ \\
\hline Uinha Hidráulica 1 1 / LH 1 & $1,850 \mathrm{E}-06$ \\
\hline & \\
\hline & $1,610 \mathrm{E}-06$ \\
\hline Umbilical - Parte Hidráulica - 2 & $2,400 \mathrm{E}-07$ \\
\hline Linha Hidráulica 2 2 / LH 2 & $1,850 \mathrm{E}-06$ \\
\hline
\end{tabular}

A Figura 6-15 mostra o gráfico de confiabilidade ao longo da vida produtiva do poço para um sistema hidráulico direto com redundância no umbilical de controle e na linha de controle:

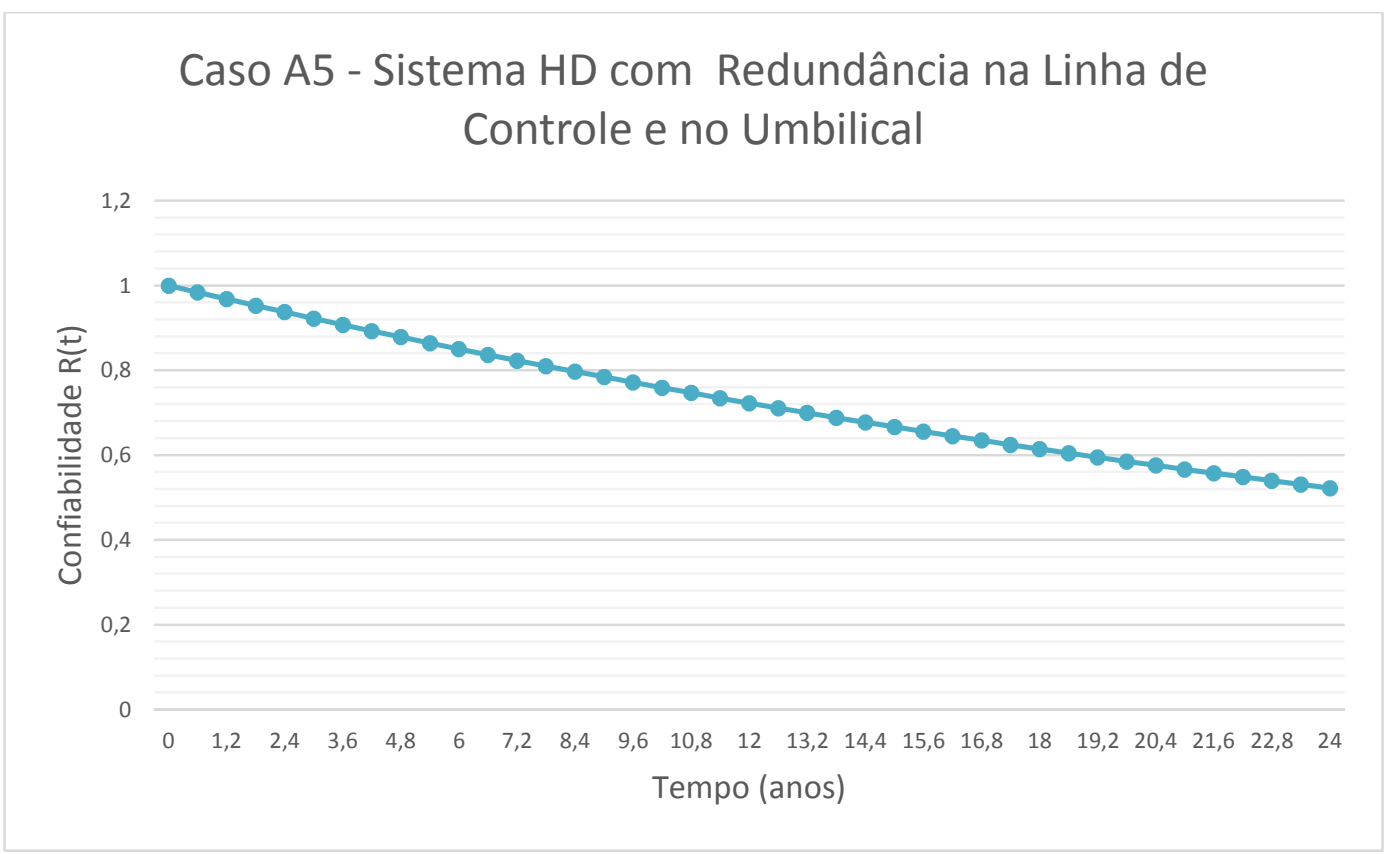

Figura 6-15 - Confiabilidade x Tempo - Sistema HD com redundância no UC e na LC

O tempo operacional médio é de $6.442,4$ dias (17,6 anos), a taxa de falha instantânea no final da missão é de $3,875 \times 10^{-5}$, a disponibilidade média do sistema é de 0,7354 e a disponibilidade instantânea do sistema no final da missão é de 0,5221 . 


\subsection{Caso A6 - Sistema HD com redundância na LC e no UC e falha no acionamento}

O caso 6 representa o sistema hidráulico direto com redundância na linha de controle e no umbilical, assumindo a possibilidade de falha no acionamento. Este sistema é diferente dos outros aqui apresentados até agora pois é um sistema paralelo em espera, enquanto os outros são paralelos ativos. Isto quer dizer que, enquanto nos outros casos não há necessidade de acionamento dos equipamentos em paralelo (pois já estão acionados), neste caso o acionamento do sistema em paralelo é necessário. Enquanto o sistema estiver funcionando através do "trem \#1" de acionamento (UC1/LC1, por exemplo), o "trem \#2" não está ativo (sem pressão hidráulica no caso de um sistema hidráulico direto, por exemplo). Nesta configuração, deve ser considerado que possa haver uma falha no equipamento de acionamento do "trem \#2", falhando assim todo o sistema.

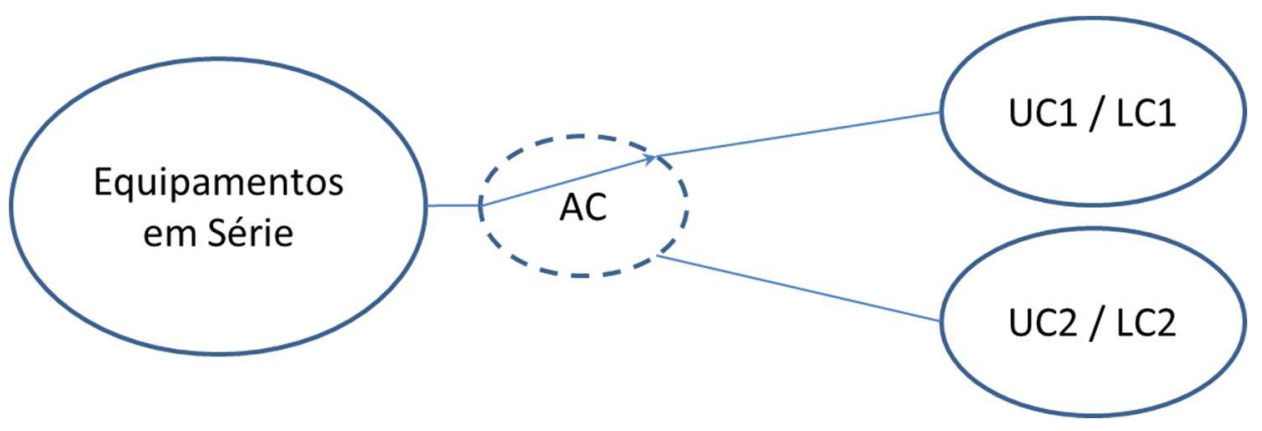

Figura 6-16 - Simplificação do sistema A6

A Tabela 6-17 contém a descrição dos estados do sistema A6:

Figura 6-17 - Descrição dos estados do sistema A6

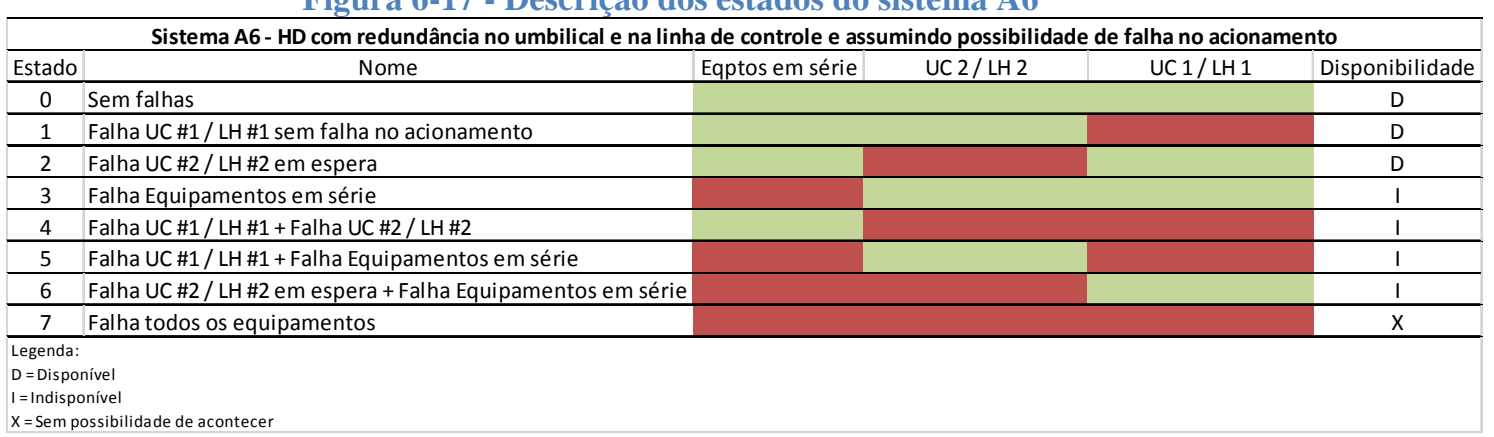

Pode-se agora mostrar o diagrama de transição de estados do sistema A6. Apesar de estarmos tratando de um sistema simplificado que contém 8 estados, neste caso as taxas de falha utilizadas são um pouco diferentes. A primeira diferença é que existem duas taxas de falha do sistema UC 2 / LH 2 (umbilical de 
controle \#2 e linha hidráulica \#2): Uma quando este "trem \#2" de acionamento estiver em estado de espera, isto é, sem pressão hidráulica; e outro quando este estiver em funcionamento, após a falha do "trem" \#1 (UC 1 / LH 1). Estas diferenças são refletidas nos valores na transição entre os estados "0" e 1 e entre os estados 2 e 4.

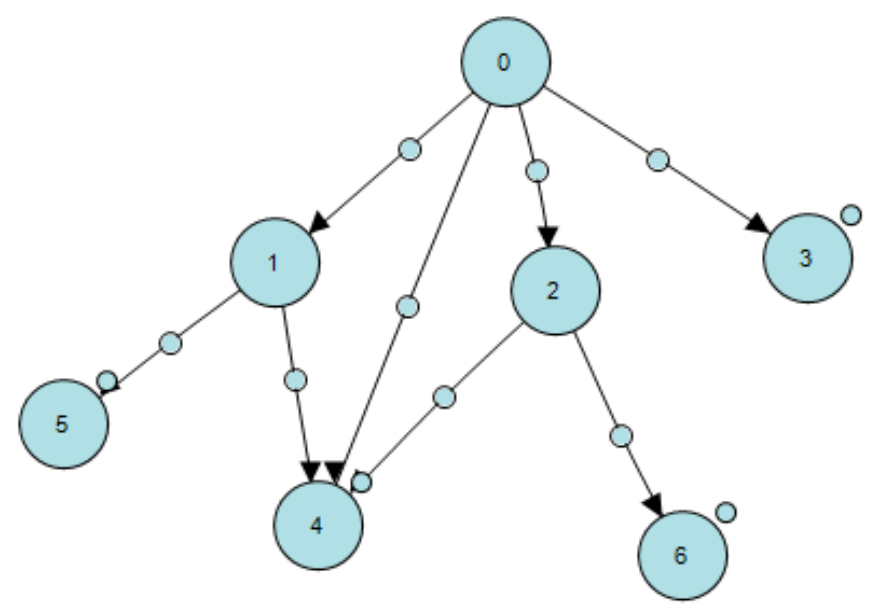

Figura 6-18 - Diagrama de transição de estados para sistema A6

A segunda diferença é que, agora, existe a possibilidade de uma transição do estado "0", isto é, sem falhas no sistema, para um estado indisponível 4 . Isto acontece quando o "trem" \#1 falha e há também uma falha no acionamento do "trem" \#2, impossibilitando assim do sistema de funcionar. Nova transição pode ser vista na figura 6-18 acima.

No sistema A6 serão utilizadas cinco taxas de falha para a solução do sistema, e as cinco taxas de falha estão em negrito na Tabela 6-11 abaixo: 
Tabela 6-11 - Taxas de fallha dos equipamentos - Sistema A6

\begin{tabular}{|l|c|}
\hline \multicolumn{1}{|c|}{ Equipamentos } & Lambda - $\boldsymbol{\lambda}$ (1/hora) \\
\hline HPU Hidáulico & $7,250 \mathrm{E}-05$ \\
\hline ANM/Tree cap & $1,140 \mathrm{E}-06$ \\
\hline Tubing Hanger - Acoplamento Hidráulico & $4,000 \mathrm{E}-08$ \\
\hline DHSV (PLC + FTO) & $4,620 \mathrm{E}-07$ \\
\hline Equipamentos em Série & $7,414 \mathrm{E}-05$ \\
\hline & \\
\hline Umbilical 2 em espera & $4,830 \mathrm{E}-07$ \\
\hline Linha Hidráulica 2 em espera & $7,200 \mathrm{E}-08$ \\
\hline UC 2 / LH 2 em espera & $5,550 \mathrm{E}-07$ \\
\hline & \\
\hline Umbilical - Parte Hidráulica & $1,610 \mathrm{E}-06$ \\
\hline Linha Hidráulica & $2,400 \mathrm{E}-07$ \\
\hline UC 2 / LH 2 & $1,850 \mathrm{E}-06$ \\
\hline & \\
\hline Acionamento - AC (p) & $1,712 \mathrm{E}-04$ \\
\hline & \\
\hline Umbilical - Parte Hidráulica 1 & $1,610 \mathrm{E}-06$ \\
\hline Linha Hidráulica 1 & $2,400 \mathrm{E}-07$ \\
\hline UC 1 / LH 1 & $1,850 \mathrm{E}-06$ \\
\hline UC \#1 / LH \#1 sem falha no acionamento & $1,849 \mathrm{E}-06$ \\
\hline UC \#1 / LH \#1 com falha no acionamento & $3,166 \mathrm{E}-10$ \\
\hline
\end{tabular}

A Figura 6-19 mostra o gráfico de confiabilidade ao longo da vida produtiva do poço para um sistema hidráulico direto com redundância no umbilical de controle e na linha de controle, assumindo a possibilidade de falha no acionamento do "trem" \#2 (UC 2 / LC 2): 


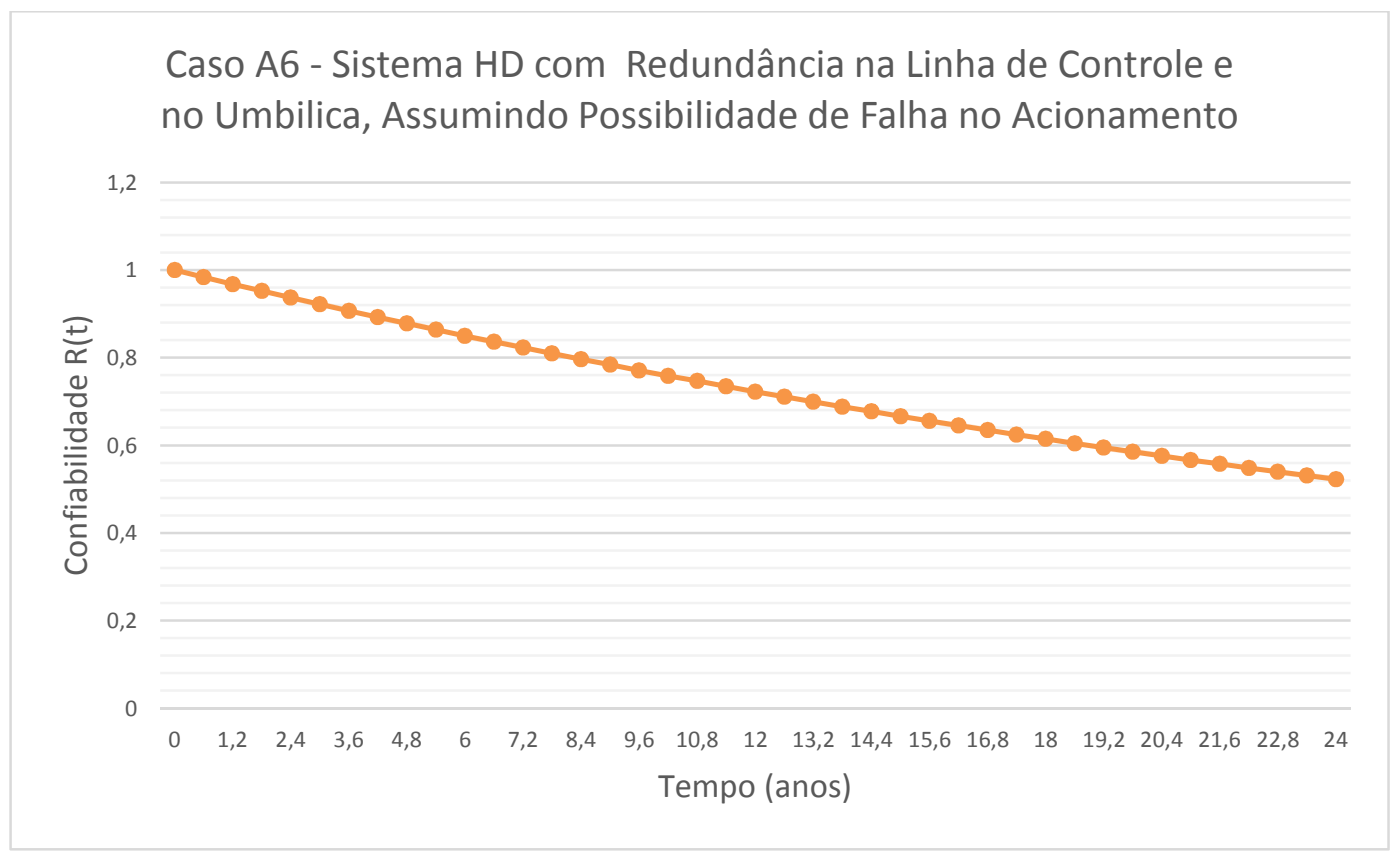

Figura 6-19 - R(t) x T - Sist HD redundância na LC e UC e falha no acionamento

O tempo operacional médio é de $6.442,6$ dias (17,6 anos), a taxa de falha instantânea no final da missão é de $3,874 \times 10^{-5}$, a disponibilidade média do sistema é de 0,7355 e a disponibilidade instantânea do sistema no final da missão é de 0,5222.

\subsection{Caso B1 - Sistema EH - ANM Multiplexada}

O caso B1 compreende o sistema hidráulico multiplexado, sem redundância na linha hidráulica de controle. Como já dito no capítulo 5, a principal característica do sistema eletro-hidráulico multiplexado é que o comando para acionamento de qualquer válvula pertencente ao sistema é feito eletricamente, sendo que o acionamento continua sendo hidráulico, além de possuir um acumulador de pressão na cabeça do poço (fundo do mar), mais precisamente no SCM.

A Figura 6-20 ilustra a simplificação do sistema B1. O esquema completo pode ser visto na Figura 5-7. Neste sistema, as duas linhas hidráulicas do Umbilical de controle, que até agora eram denominadas pelas iniciais do próprio umbilical (UC), agora passam a se chamar HP A e HP B (High Pressure), e no sistema multiplexado estas duas linhas sempre trabalham em hot stand by, ou seja, pressurizadas.

Outra característica da simplificação desta configuração é que, apesar de conter vários equipamentos em série (fora as duas linhas hidráulicas HP A e HP 
B), os equipamentos foram divididos em dois blocos de equipamentos em série: 0 primeiro contendo os equipamentos antes do SCM e o segundo com os equipamentos após o SCM. Esta divisão foi necessária porque o "estado" em que o sistema irá vai depender de qual equipamento falhe e o principal motivo desta diferença de estado é a presença do acumulador de pressão do SCM. Isto é, caso algum equipamento posicionado antes do SCM falhe, o acumulador permite que o sistema continue operacional e, portanto, o sistema passa para um estado "disponível". Caso algum equipamento posicionado depois do SCM (ou o próprio SCM) falhe, o sistema passa para um estado de indisponibilidade imediata.

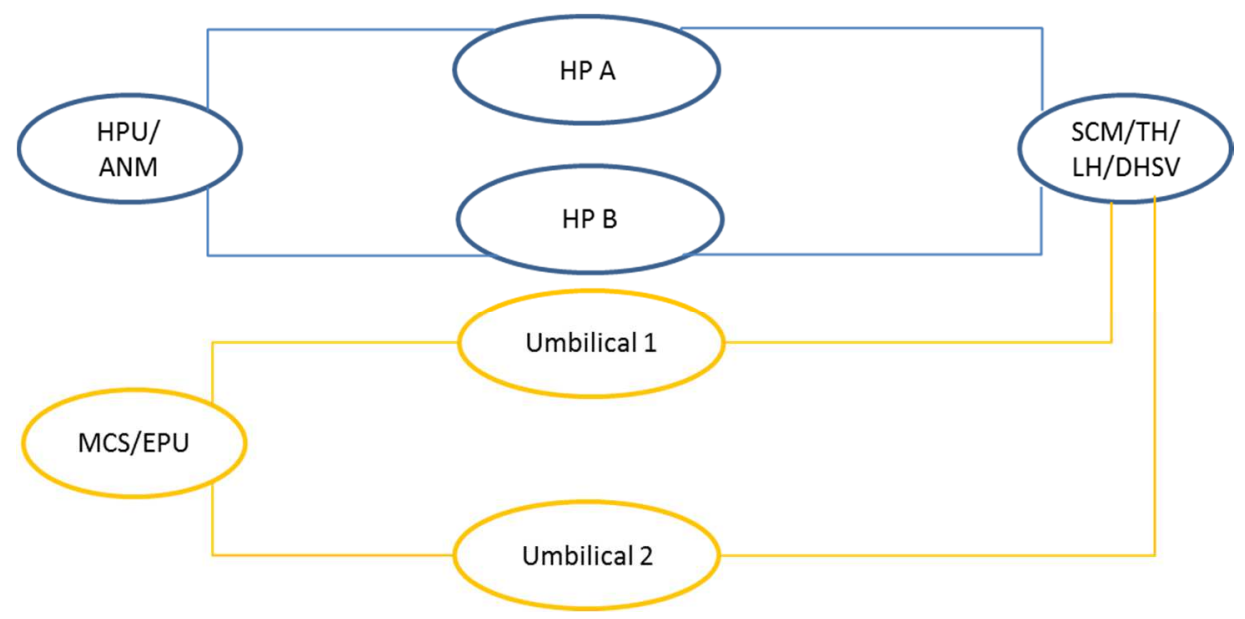

Figura 6-20 - Simplificação do sistema B1

A Tabela 6-12 contém a descrição dos estados do sistema B1. Com as simplificações realizadas, tem-se 16 estados a serem analisados. Como já foi descrito no capítulo 5 , as taxas de falha do sistema elétrico não que compõe o sistema eletro-hidráulico multiplexado não foram incluídos nos cálculos porque é programado como "fail as is", e não "fail safe close", como o sistema hidráulico. Isto quer dizer que, caso o sistema elétrico falhe durante a operação, o sistema não irá falhar, isto é, a válvula DSSS não irá fechar e não haverá perda de produção, pois todos os equipamentos permanecerão na mesma posição que se encontram no momento da falha. 
Tabela 6-12 - Descrição dos estados do sistema B1

\begin{tabular}{|c|c|c|c|c|c|}
\hline \multicolumn{6}{|c|}{ Sistema B1 - Sistema Multiplexado } \\
\hline Estado & Nome & Eqptos em série 2 Eqptos em série 1 & $\mathrm{HPB}$ & HPA & Disponibilidade \\
\hline 0 & Sem falhas & & & & $\mathrm{D}$ \\
\hline 1 & Falha HPA & & & & $\mathrm{D}$ \\
\hline 2 & Falha HP B & & & & $\mathrm{D}$ \\
\hline 3 & Falha Equipamentos em série 1 & & & & $\mathrm{D}$ \\
\hline 4 & Falha Equipamentos em série 2 & & & & $\mathrm{I}$ \\
\hline 5 & Falha HP A + Falha HP B & & & & $\mathrm{D}$ \\
\hline 6 & Falha HP A + Falha Equipamentos em série 1 & & & & $\mathrm{D}$ \\
\hline 7 & Falha HP A + Falha Equipamentos em série 2 & & & & 1 \\
\hline 8 & Falha HP B + Falha Equipamentos em série 1 & & & & $\mathrm{D}$ \\
\hline 9 & Falha HP B + Falha Equipamentos em série 2 & & & & 1 \\
\hline 10 & Falha Equipamentos em série 1 + Falha Equipamentos em série 2 & & & & 1 \\
\hline 11 & Falha HP A + Falha HP B + Falha Equipamentos em série 1 & & & & $\mathrm{D}$ \\
\hline 12 & Falha HP A + Falha HP B + Falha Equipamentos em série 2 & & & & 1 \\
\hline 13 & Falha HP A + Falha Equipamentos em série 1+ Falha Equipamentos em série 2 & & & & 1 \\
\hline 14 & Falha HP B + Falha Equipamentos em série 1+ Falha Equipamentos em série 2 & & & & 1 \\
\hline 15 & Falha todos os componentes & & & & 1 \\
\hline $\begin{array}{l}\text { Legenda: } \\
D=\text { Dispo } \\
I=\text { Indisp } \\
\text { Eqptos er } \\
\text { Eqptos er }\end{array}$ & $\begin{array}{l}\text { nivel } \\
\text { onivel } \\
\text { nsérie } 1 \text { = HPU e Conjunto ANM } \\
\text { nsérie } 2 \text { =SCM, TH, LH e DHSV }\end{array}$ & & & & \\
\hline
\end{tabular}

Assim, o diagrama de transição de estados do sistema B1 é mostrado abaixo

(Figura 6-21):

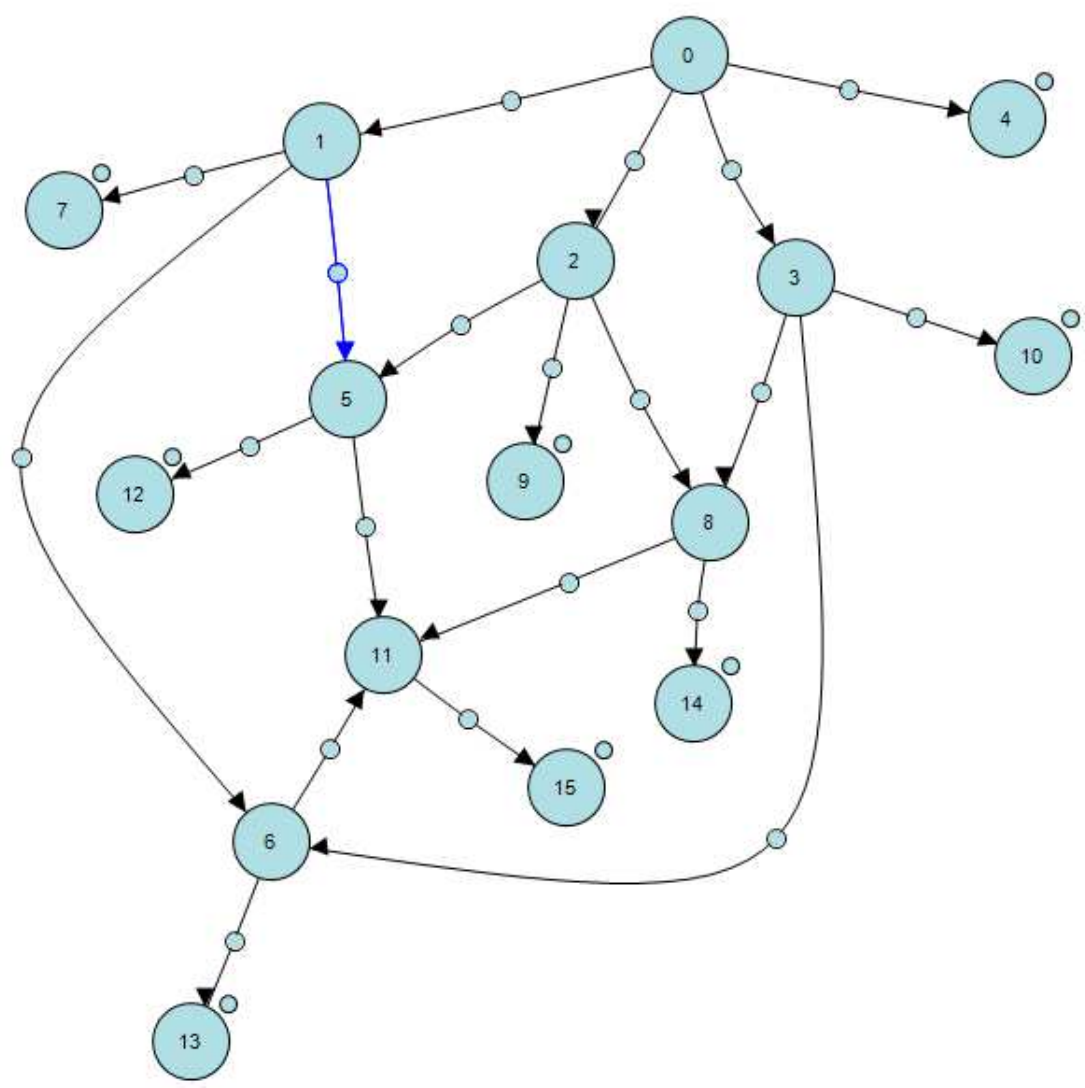

Figura 6-21 - Diagrama de transição de estados para sistema B1

No sistema B1 serão utilizadas quatro taxas de falha para a solução do sistema, que estão em negrito na tabela abaixo. A taxa de falha denominada 
"equipamentos de Série 1" corresponde à soma das taxas de falha do HPU e do conjunto ANM, enquanto a taxa de falha "equipamentos em série 2" corresponde à some das taxas de falha do SCM, do tubing hanger, da linha hidráulica e do DSSS.

Tabela 6-13 - Taxas de falha dos equipamentos - Sistema B1

\begin{tabular}{|l|c|}
\hline \multicolumn{1}{|c|}{ Equipamentos } & Lambda $-\boldsymbol{\lambda}$ (1/hora) \\
\hline HPU Hidáulico & $7,250 \mathrm{E}-05$ \\
\hline ANM/Tree cap & $1,140 \mathrm{E}-06$ \\
\hline Equipamentos em Série 1 & $7,364 \mathrm{E}-05$ \\
\hline & \\
\hline SCM & $2,383 \mathrm{E}-05$ \\
\hline Tubing Hanger - Acoplamento Hidráulico & $4,000 \mathrm{E}-08$ \\
\hline Linha Hidráulica & $2,400 \mathrm{E}-07$ \\
\hline DHSV (PLC+ FTO) & $4,620 \mathrm{E}-07$ \\
\hline Equipamentos em Série 2 & $2,457 \mathrm{E}-05$ \\
\hline & \\
\hline Umbilical - Parte Hidráulica - HP A & $1,610 \mathrm{E}-06$ \\
\hline & \\
\hline Umbilical - Parte Hidráulica - HP B & $1,610 \mathrm{E}-06$ \\
\hline
\end{tabular}

A Figura 6-22 mostra o gráfico de confiabilidade ao longo da vida produtiva do poço para um sistema multiplexado, com controle hidráulico do DSSS e sem redundância nas linhas hidráulicas de controle, dentro do poço.

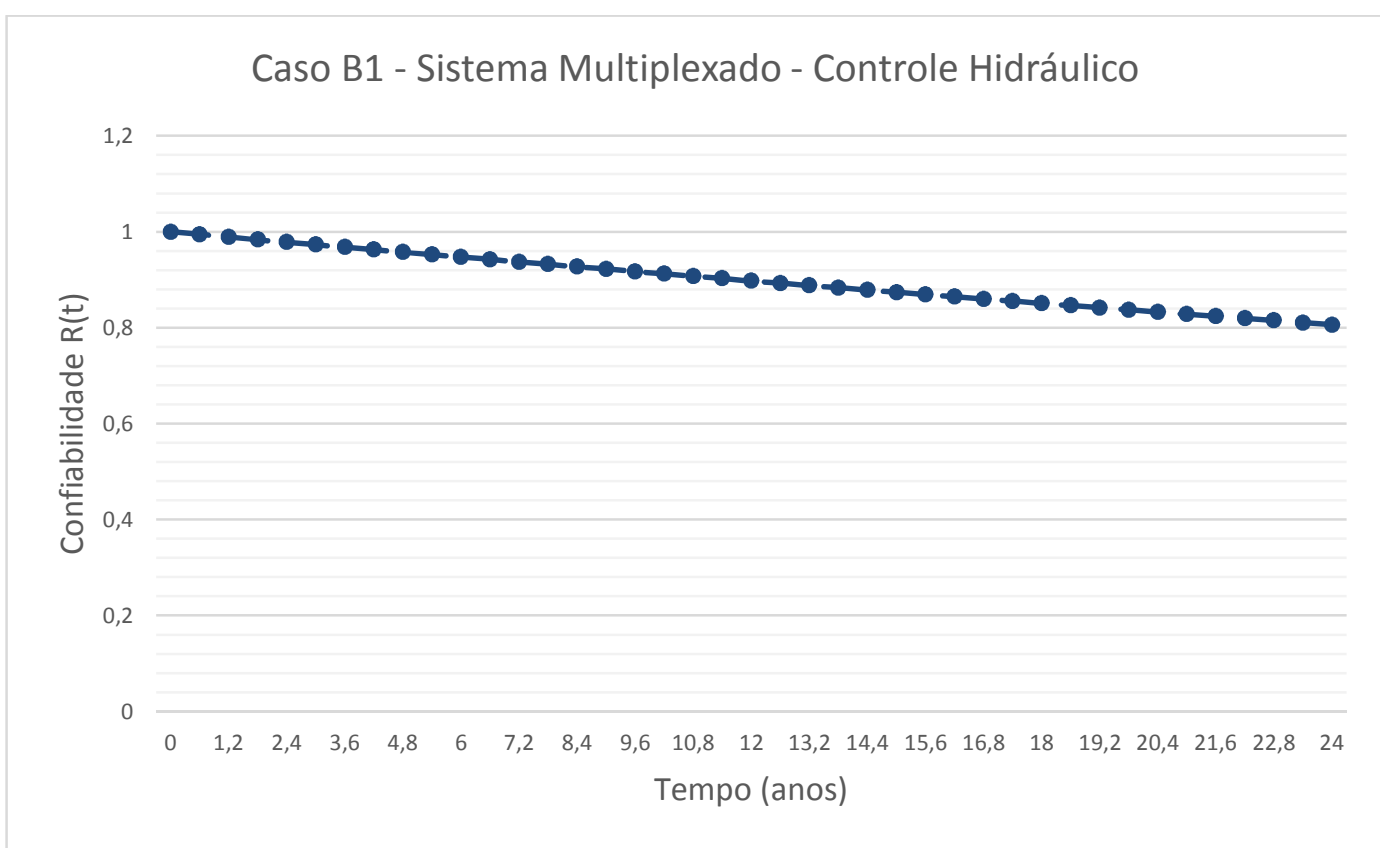

Figura 6-22 - Confiabilidade x Tempo - Sistema multiplexado 
O tempo operacional médio é de $7.881,3$ dias (21,6 anos), a taxa de falha insantânea no final da missão é de $1,981 \times 10^{-5}$, a disponibilidade média do sistema é de 0,8997 e a disponibilidade instantânea do sistema no final da missão é de 0,8063.

\subsection{Caso B2 - Sistema EH - ANM Multiplexada com redundância na LC}

O caso B2 também compreende um sistema hidráulico multiplexado, porém agora com redundância na linha hidráulica de controle. O esquema simplificado está abaixo (Figura 6-23):

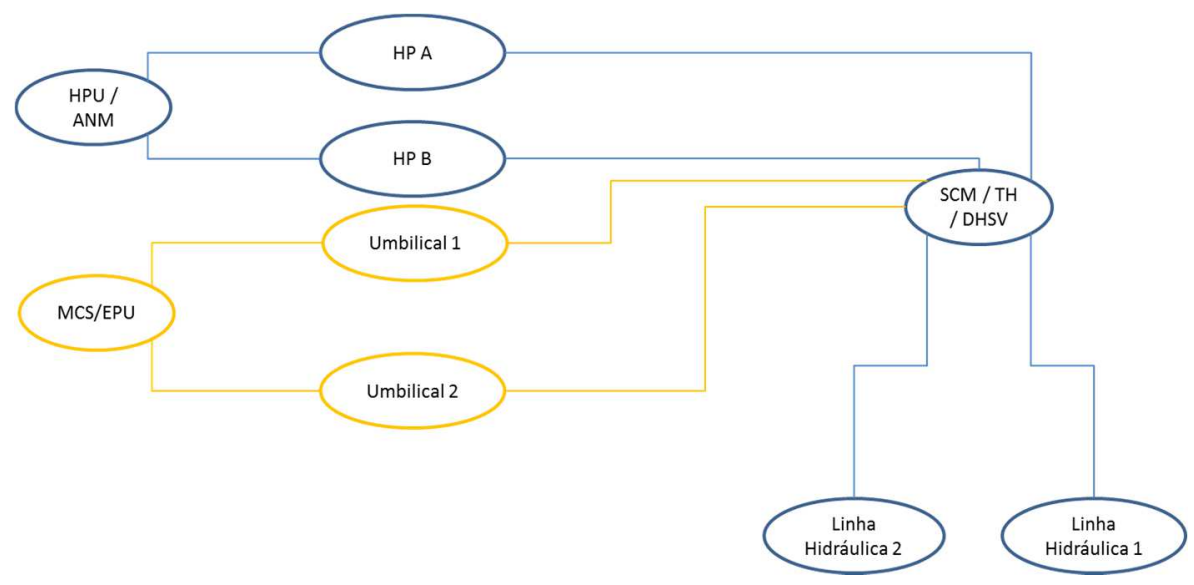

Figura 6-23 - Simplificação do sistema B2

Por possuir 6 equipamentos no sistema (excluindo-se os equipamentos elétricos pelo mesmo motivo já apresentado no caso $B 1$ ), tem-se um total de $2^{6}=$ 64 estados a serem analisados (Tabela 6-14): 
Tabela 6-14 - Descrição dos estados do sistema B2

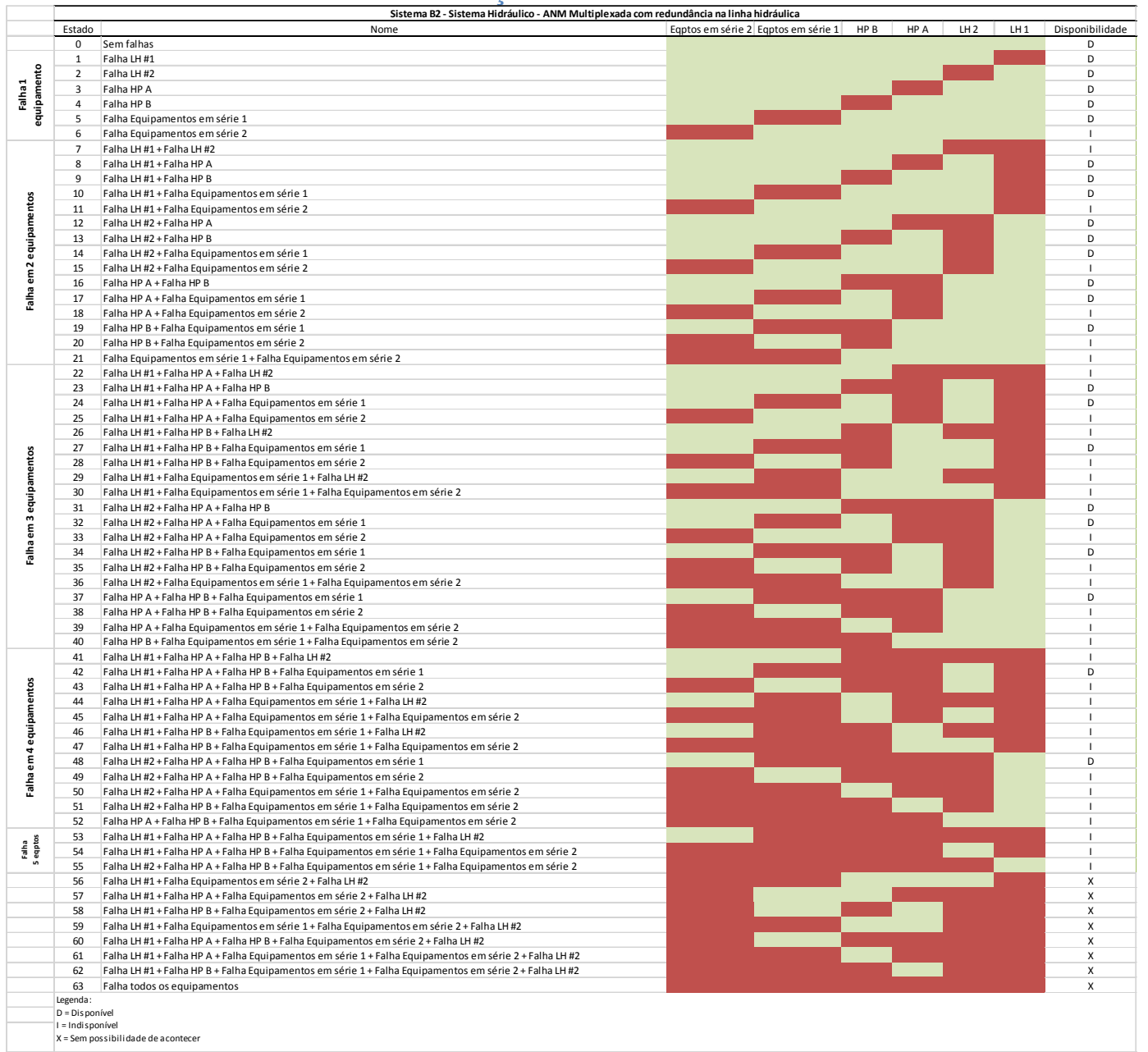

E o diagrama de transição de estados do sistema B2: 


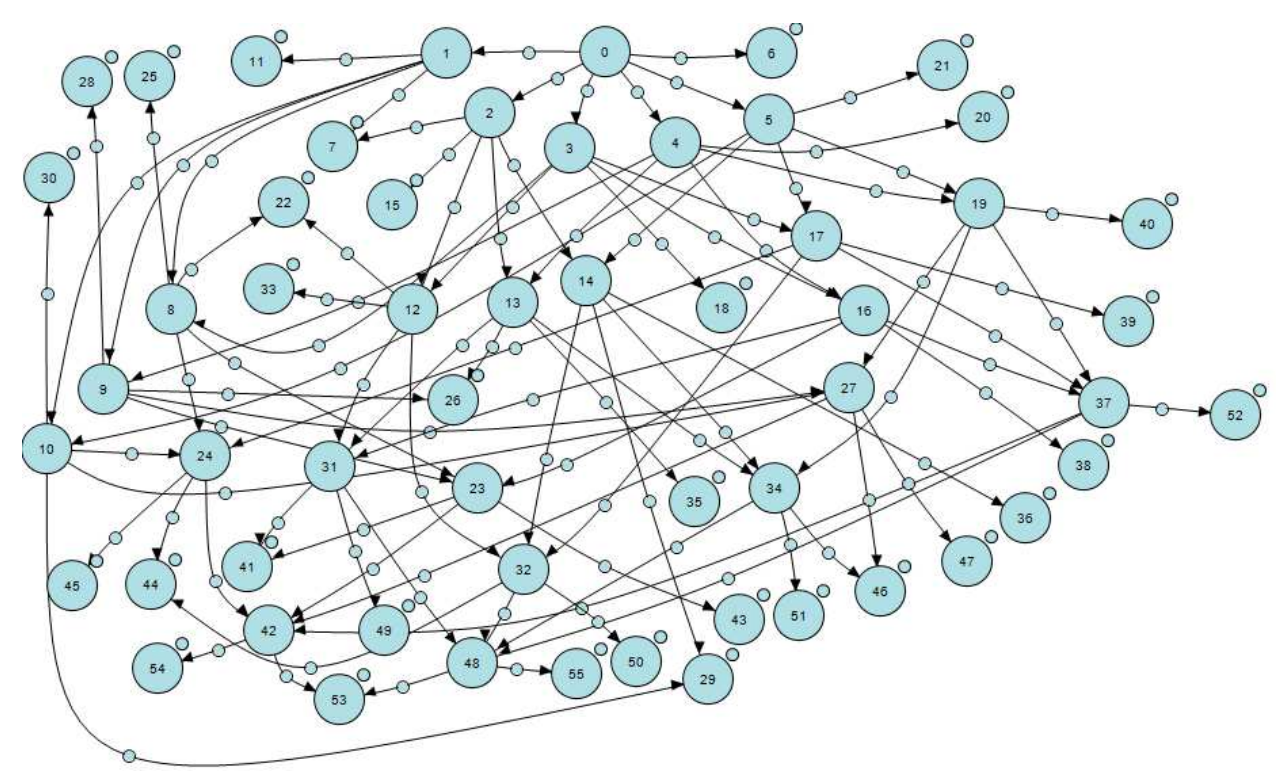

Figura 6-24 - Diagrama de transição de estados para sistema B2

Percebe-se que, quando aumentamos para 64 os estados a serem analisados, o estudo se torna mais complexo. Neste caso foram utilizadas seis taxas de falha:

Tabela 6-15 - - Taxas de falha dos equipamentos - Sistema B2

\begin{tabular}{|l|c|}
\hline \multicolumn{1}{|c|}{ Equipamentos } & Lambda - $\lambda$ (1/hora) \\
\hline HPU Hidáulico & $7,250 \mathrm{E}-05$ \\
\hline ANM/Tree cap & $1,140 \mathrm{E}-06$ \\
\hline Equipamentos em Série 1 & $7,364 \mathrm{E}-05$ \\
\hline & \\
\hline SCM & $2,383 \mathrm{E}-05$ \\
\hline Tubing Hanger - Acoplamento Hidráulico & $4,000 \mathrm{E}-08$ \\
\hline DHSV (PLC + FTO) & $4,620 \mathrm{E}-07$ \\
\hline Equipamentos em Série 2 & $2,433 \mathrm{E}-05$ \\
\hline & \\
\hline & \\
\hline Umbilical - Parte Hidráulica - HP A & $1,610 \mathrm{E}-06$ \\
\hline & \\
\hline Umbilical - Parte Hidráulica - HP B & $1,610 \mathrm{E}-06$ \\
\hline & \\
\hline Linha Hidráulica \#1 & $2,400 \mathrm{E}-07$ \\
\hline & $2,400 \mathrm{E}-07$ \\
\hline Linha Hidráulica \#2
\end{tabular}

E o gráfico de confiabilidade ao longo da vida produtiva do poço para um sistema multiplexado, com controle hidráulico do DSSS e com redundância nas linhas hidráulicas de controle, dentro do poço é: 


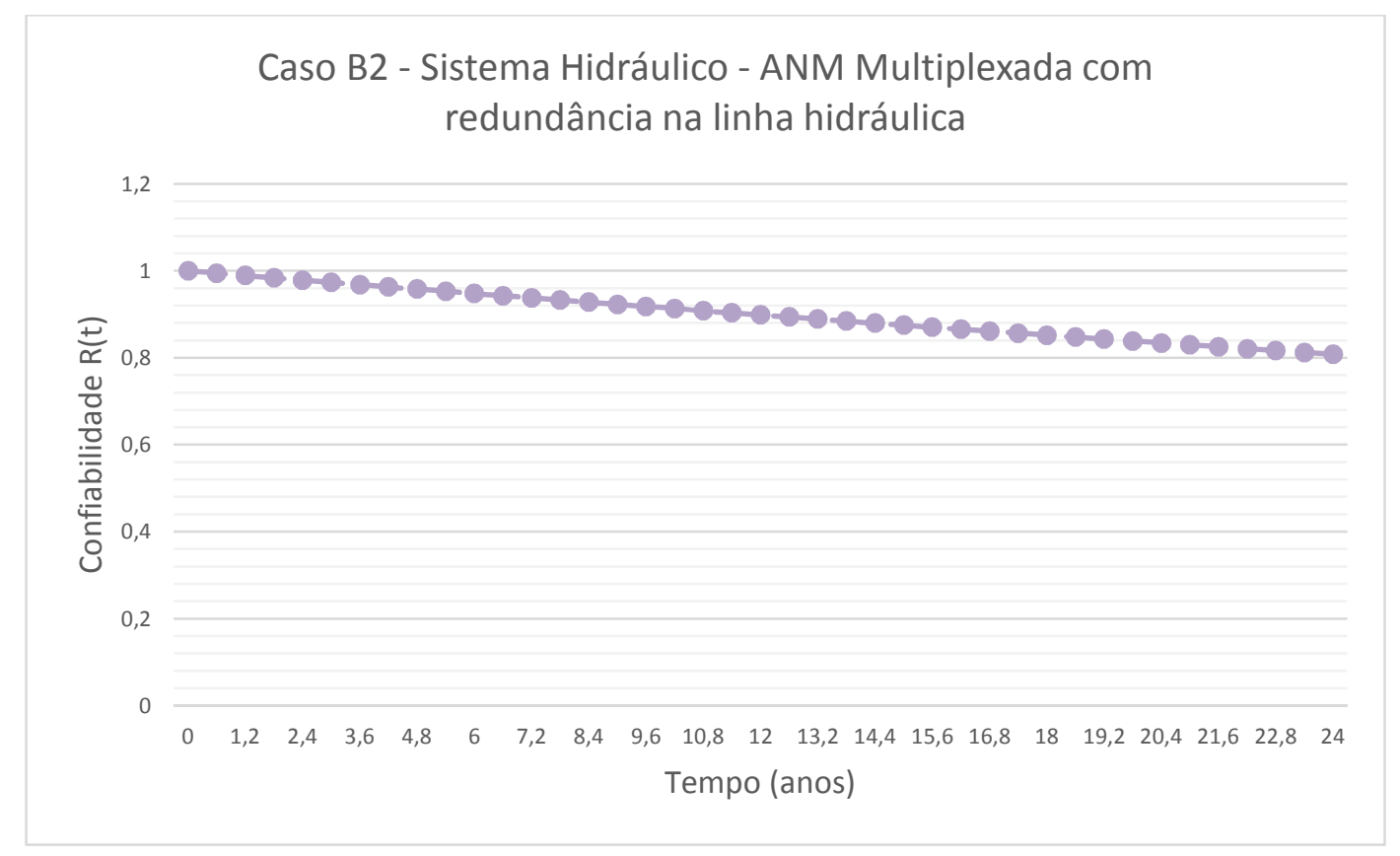

Figura 6-25 - Confiabilidade x Tempo - Sistema multiplex com redundância na LC

O tempo operacional médio é de $7.889,3$ dias (21,6 anos), a taxa de falha instantânea no final da missão é de $1,966 \times 10^{-5}$, a disponibilidade média do sistema é de 0,9006 e a disponibilidade instantânea do sistema no final da missão é de 0,8080 .

\subsection{Caso C1 - Sistema "elétrico direto" sem redundância}

Os sistemas tipo "C" são os sistemas de acionamento elétrico do DSSS, ao invés de acionamento hidráulico. O primeiro sistema elétrico não possui redundâncias, e é uma analogia ao sistema hidráulico direto. Este caso servirá como base de comparação, tanto para o próximo caso de válvula acionada eletricamente como para os outros sistemas acionados hidraulicamente. $O$ sistema C1 simplificado pode ser representado conforme a figura abaixo: 


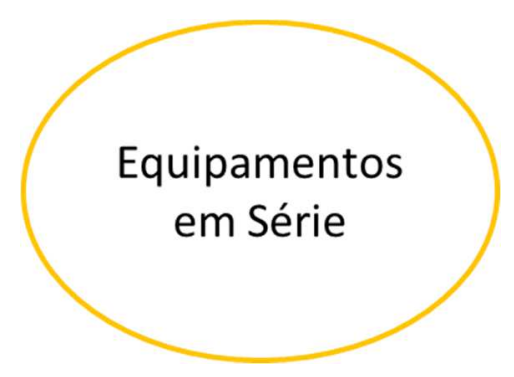

Figura 6-26 - Simplificação do sistema C1

Da mesma forma que o sistema hidráulico direto sem redundância (caso A1), - caso $\mathrm{C} 1$ possui apenas duas possibilidades de estado: disponível ou indisponível, já que em caso de falha de qualquer equipamento do sistema, todo o sistema falha (Tabela 6-16).

Tabela 6-16 - Descrição dos estados do sistema C1

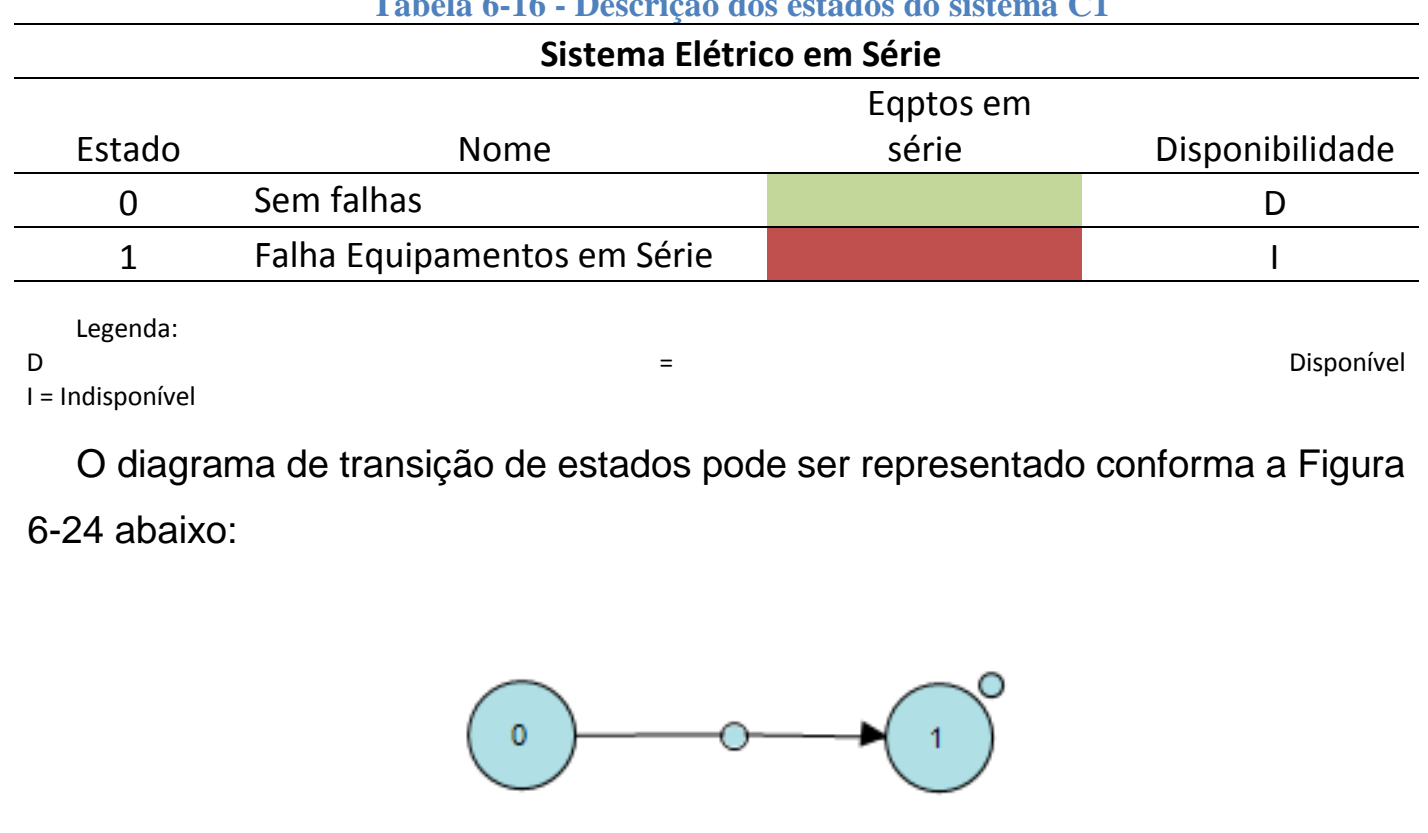

Figura 6-27 - Diagrama de transição de estados para sistema C1

Da mesma forma que o caso $A 1$, o sistema elétrico direto pode ser representado por uma única taxa de falha, que será a some de todas as taxas de falha dos equipamentos em série: 
Tabela 6-17 - Taxas de fallha dos equipamentos - Sistema C1

\begin{tabular}{|l|c|}
\hline \multicolumn{1}{|c|}{ Equipamentos } & Lambda $-\boldsymbol{\lambda}$ (1/hora) \\
\hline HPU Elétrico & $1,601 \mathrm{E}-05$ \\
\hline Umbilical - Parte elétrica & $2,700 \mathrm{E}-07$ \\
\hline SCM & $2,383 \mathrm{E}-05$ \\
\hline ANM/Tree cap & $1,080 \mathrm{E}-06$ \\
\hline Tubing Hanger - Acoplamento Elétrico & $1,300 \mathrm{E}-07$ \\
\hline Linha elétrica & $5,900 \mathrm{E}-07$ \\
\hline DHSV (PLC+FTO) & $4,620 \mathrm{E}-07$ \\
\hline Equipamentos em Série & $4,237 \mathrm{E}-05$ \\
\hline
\end{tabular}

Por falta de dados de taxa de falha para um DSSS acionado eletricamente, foi utilizado o mesmo valor de um DSSS acionado hidraulicamente

E, da mesma forma dos que foi realizado para os sistemas anteriores, abaixo o gráfico de confiabilidade do sistema elétrico direto sem redundâncias, ao longo da vida produtiva do poço.

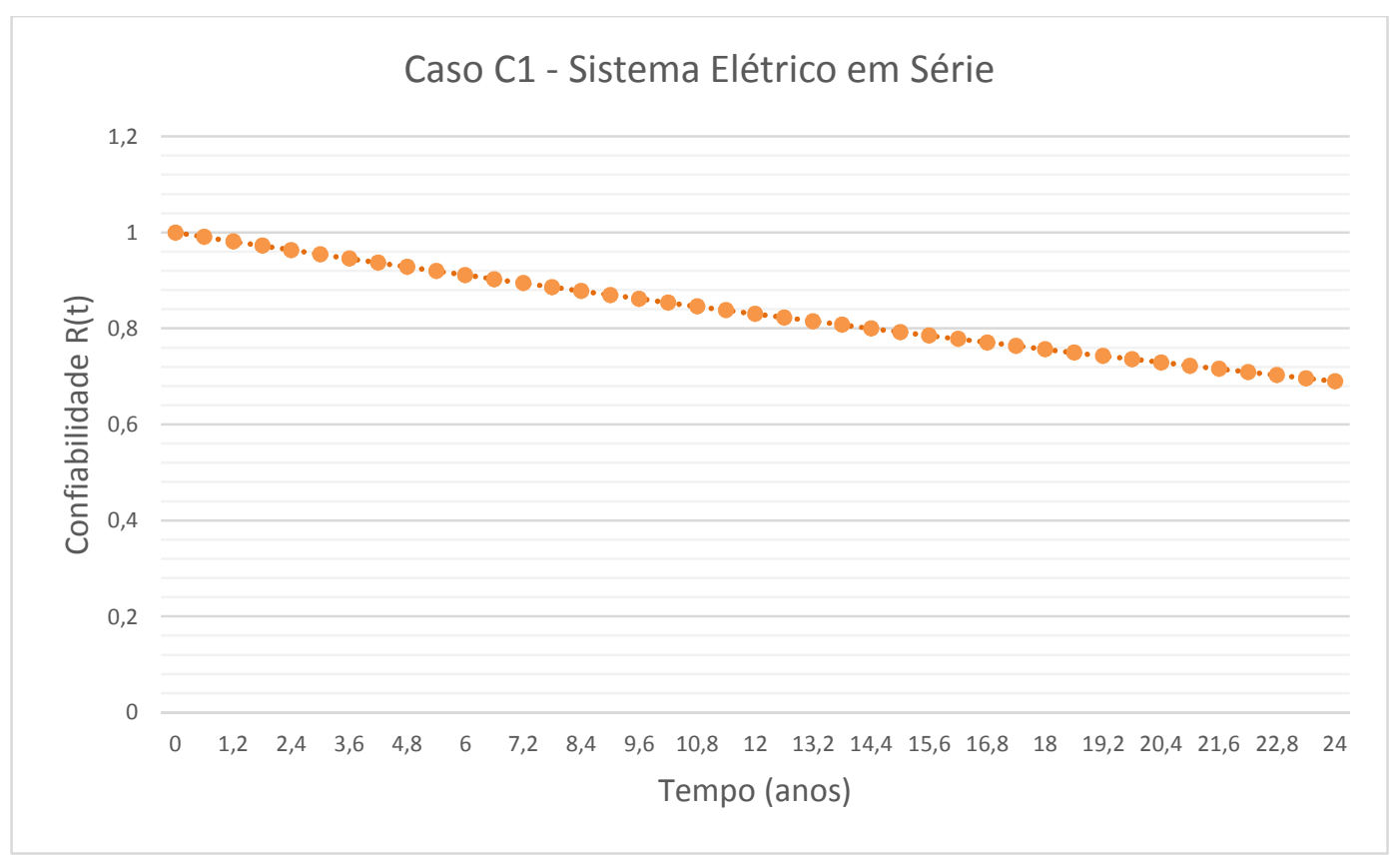

Figura 6-28 - Confiabilidade x Tempo - Sistema elétrico direto sem redundância

O tempo operacional médio é de $7.318,1$ dias (20 anos), a taxa de falha instantânea no final da missão é de $2,923 \times 10^{-5}$, a disponibilidade média do sistema é de 0,8354 e a disponibilidade instantânea do sistema no final da missão é de 0,6899. 


\subsection{Caso C2 - Sistema multiplexado com controle elétrico}

O caso C2 é referente ao sistema multiplexado com acionamento elétrico do DSSS. O sistema completo contém 8 equipamentos, o que ocasionaria em um estudo de 256 estados, porém com a simplificação já realizada nos casos anteriores, tem-se uma redução de estados para 16 estados a serem analisados (Figura 6-29).

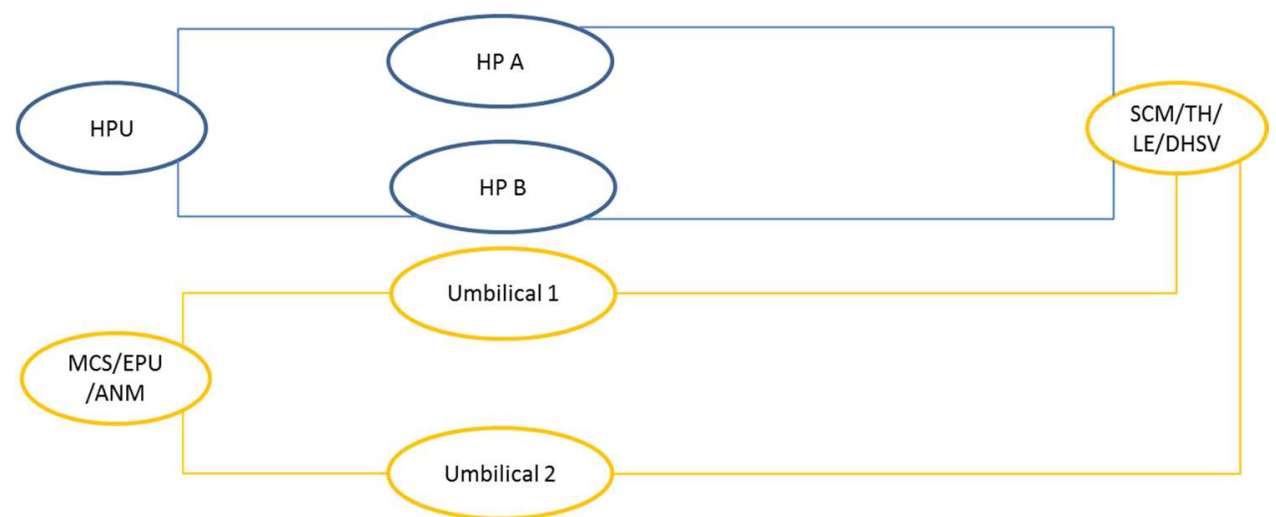

Figura 6-29 - Simplicação do sistema C2

Além disso, como pode ser visto na tabela de descrição dos estados, existem vários estados que não são possíveis de se concretizarem pois já haverá ocorrido a falha no sistema em alguma etapa anterior. Portanto, somente dez estados são passíveis de análise (Tabela 6-18):

Tabela 6-18 - Descrição dos estados do sistema C2

\begin{tabular}{|c|c|c|c|}
\hline & Sistema C2- & tiplexado - Acionamento Elétrico & \\
\hline Estado & Nome & \begin{tabular}{|l|l|l} 
Eqptos em série 2 & Eqptos em série 1 & Umbilical Elétrico 2 \\
\end{tabular} & $\begin{array}{l}\text { Umbilical Elétrico } 1 \text { Disponibilidade } \\
\end{array}$ \\
\hline 0 & $\begin{array}{ll}\text { Sem falhas } \\
\end{array}$ & & $D$ \\
\hline & Falha UE 1 & & D \\
\hline & Falha UE 2 & & $\mathrm{D}$ \\
\hline & Falha Equipamentos em série 1 & & 1 \\
\hline & Falha Equipamentos em série 2 & & 1 \\
\hline & Falha UE 1+ Falha UE 2 & & 1 \\
\hline 6 & Falha UE 1+Falha Equipamentos em série 1 & & 1 \\
\hline 7 & Falha UE 1+ Falha Equipamentos em série 2 & & 1 \\
\hline 8 & Falha UE 2+ Falha Equipamentos em série 1 & & 1 \\
\hline 9 & Falha UE 2+ Falha Equipamentos em série 2 & & 1 \\
\hline 10 & Falha Equipamentos em série 1+ Falha Equipamentos em série 2 & & $x$ \\
\hline 11 & Falha UE 1+ Falha UE 2+Falha Equipamentos em série 1 & & $x$ \\
\hline 12 & Falha UE 1+ Falha UE 2 + Falha Equipamentos em série 2 & & $x$ \\
\hline 13 & Falha UE 1+ Falha Equipamentos em série 1+ Falha Equipamentos em série 2 & & $x$ \\
\hline 14 & Falha UE 2+ Falha Equipamentos em série 1+Falha Equipamentos em série 2 & & $x$ \\
\hline & Falha todos os componentes & 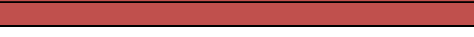 & $x$ \\
\hline
\end{tabular}

Assim, o diagrama de transição de estados pode ser estruturado conforme a Figura 6-30 abaixo: 


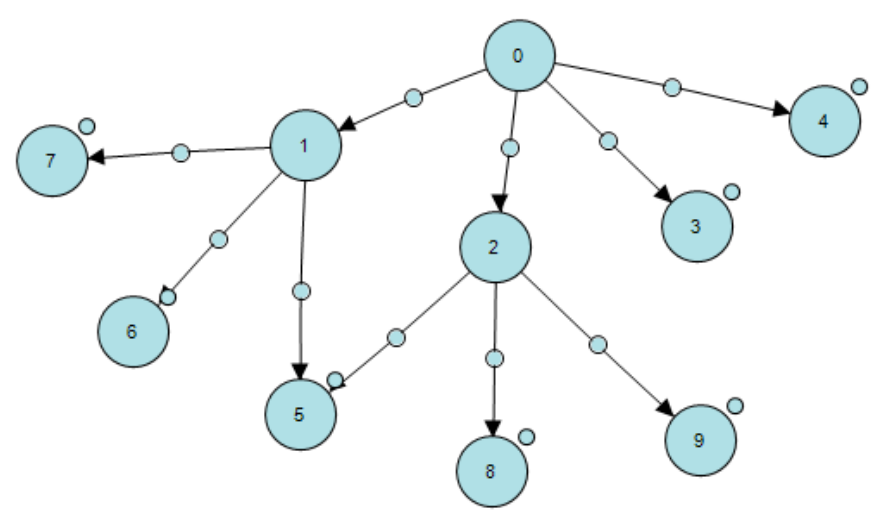

Figura 6-30 - Diagrama de transição de estados para sistema C2

Abaixo estão as taxas de falhas utilizadas no sistema C2. Conforme já mencionado, para este caso foram utilizadas quatro taxas de falha (Tabela 6-19):

Tabela 6-19 - Taxas de fallha dos equipamentos - Sistema C2

\begin{tabular}{|l|c|}
\hline \multicolumn{1}{|c|}{ Equipamentos } & Lambda $-\boldsymbol{\lambda}$ (1/hora) \\
\hline MCS/EPU & $1,601 \mathrm{E}-05$ \\
\hline ANM/Tree cap & $1,670 \mathrm{E}-06$ \\
\hline Equipamentos em Série 1 & $1,768 \mathrm{E}-05$ \\
\hline & \\
\hline SCM & $2,383 \mathrm{E}-05$ \\
\hline Tubing Hanger - Acoplamento Elétrico & $1,300 \mathrm{E}-07$ \\
\hline Linha Elétrica & $5,900 \mathrm{E}-07$ \\
\hline DHSV (PLC + FTO) & $4,620 \mathrm{E}-07$ \\
\hline Equipamentos em Série 2 & $2,501 \mathrm{E}-05$ \\
\hline & \\
\hline Umbilical - Parte Elétrica 1 & $2,700 \mathrm{E}-07$ \\
\hline & \\
\hline Umbilical - Parte Elétrica 2 & $2,700 \mathrm{E}-07$ \\
\hline
\end{tabular}

E abaixo o gráfico de confiabilidade do sistema multiplexado com acionamento elétrico (Figura 6-31): 


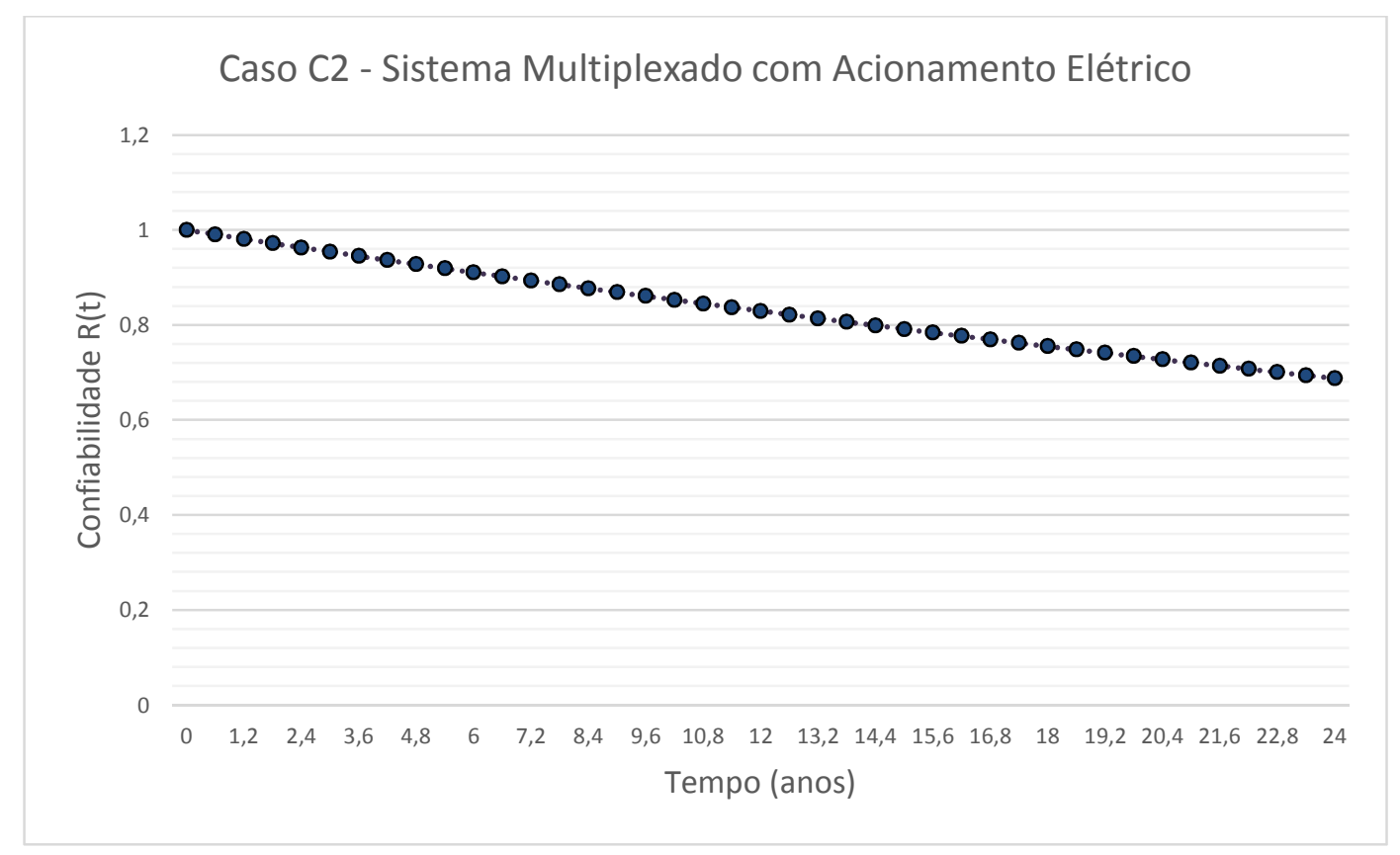

Figura 6-31 - Confiabilidade x Tempo - Sistema multiplex com acionamento elétrico

O tempo operacional médio é de $7.308,4$ dias (20 anos), a taxa de falha instantânea no final da missão é de $2,937 \times 10^{-5}$, a disponibilidade média do sistema é de 0,8343 e a disponibilidade instantânea do sistema no final da missão é de 0,6880 .

\subsection{Comparação dos Resultados}

Analisando os sistemas, podemos traçar a curva de disponibilidade de todos os sistemas estudados em um único gráfico (Figura 6-32): 


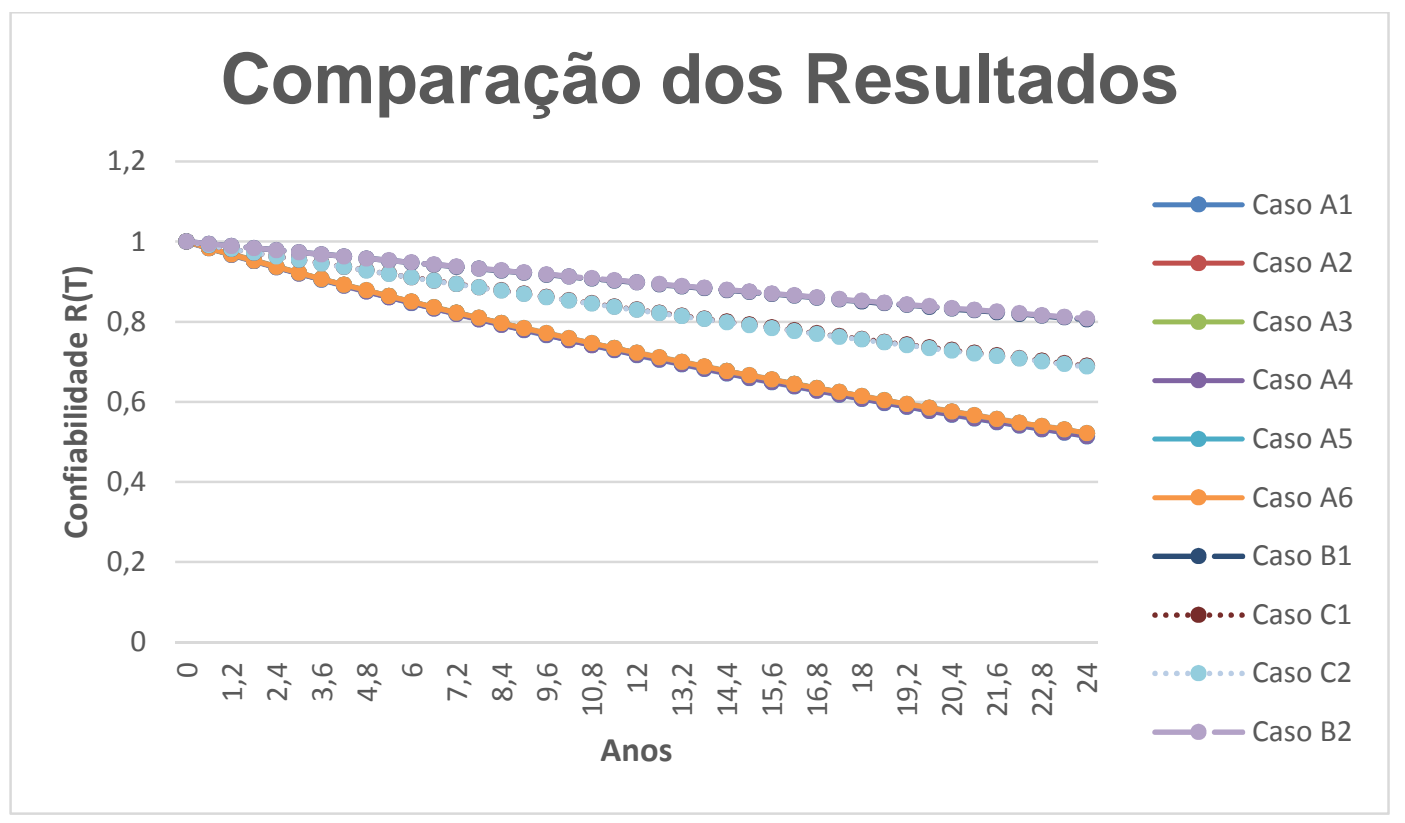

Figura 6-32 - Gráfico de comparação de Confiabilidade x Tempo - Todos os sistemas

Onde:

Tabela 6-20 - Descrição dos sistemas - Tabela resumo

\begin{tabular}{|l|l|}
\hline Caso & \multicolumn{1}{|c|}{ Descrição do Sistema } \\
\hline Caso A1 & Hidráulico direto sem redundância \\
\hline Caso A2 & Hidráulico direto com redundância do umbilical \\
\hline Caso A3 & Hidráulico direto com duas redundâncias do umbilical \\
\hline Caso A4 & Hidráulico direto com redundância na linha de controle \\
\hline Caso A5 & Hidráulico direto com redundância no umbilical e na linha de controle \\
\hline Caso A6 & $\begin{array}{l}\text { Hidráulico direto com redundância no umbilical e na linha de controle e assumindo } \\
\text { possibilidade de falha no acionamento }\end{array}$ \\
\hline Caso B1 & Sistema Eletro-Hidráulico - ANM Multiplexada sem redundância na linha de controle \\
\hline Caso B2 & Sistema Eletro-Hidráulico - ANM Multiplexada com redundância na linha de controle \\
\hline Caso C1 & Elétrico sem redundância \\
\hline Caso C2 & Elétrico - ANM Multiplexada com acionamento elétrico \\
\hline
\end{tabular}

Pelo gráfico acima, podemos perceber que não há muita diferença de confiabilidade ao longo da vida produtiva do poço entre os sistemas hidráulicosdireto (casos do tipo "A"), pois todas as curvas estão praticamente sobrepostas. O sistema multiplexado (caso do tipo "B") se mostrou mais confiável, e sua curva está destacada com relação ás outras. Este sistema termina com uma confiabilidade - após 24 anos de operação, da mesma ordem de 7 anos de 
operação dos sistemas hidráulicos-direto - mais de três vezes confiável. Os sistemas elétricos (casos do tipo "C") se mostraram com valores intermediários entre os sistemas hidráulicos direto e o sistema multiplexado, e após 24 anos de operação tem uma confiabilidade da mesma ordem de 14 anos de operação dos sistemas hidráulicos direto.

Percebe-se que a inclusão de redundâncias no sistema hidráulico direto não influencia de forma significativa na confiabilidade do sistema. Porém, quando se compara o sistema hidráulico direto com o sistema multiplexado, a confiabilidade aumenta consideravelmente, e o principal fator que influencia nestes resultados são os acumuladores hidráulicos que os SCMs possuem, possibilitando uma maior continuidade das operações com uma maior combinação de falhas de equipamentos do sistema.

Comparando algumas métricas já apresentadas nos tópicos anteriores, temse:

Tabela 6-21 - Comparação das métricas

\begin{tabular}{lcccc}
\hline & $\begin{array}{c}\text { Tempo } \\
\text { operacional } \\
\text { médio (anos) }\end{array}$ & $\begin{array}{c}\text { Taxa de falha } \\
\text { instantânea no } \\
\text { final da missão }\end{array}$ & $\begin{array}{c}\text { Disponibilidade } \\
\text { média do } \\
\text { sistema }\end{array}$ & $\begin{array}{c}\text { Disponibilidade } \\
\text { instantânea do } \\
\text { sistema no final } \\
\text { da missão }\end{array}$ \\
\hline Caso A1 & 17,5 & 3,905 & 0,7302 & 0,5139 \\
\hline Caso A2 & 17,6 & 3,878 & 0,7348 & 0,5211 \\
\hline Caso A3 & 17,6 & 3,877 & 0,7348 & 0,5212 \\
\hline Caso A4 & 17,5 & 3,901 & 0,7309 & 0,515 \\
\hline Caso A5 & 17,6 & 3,875 & 0,7354 & 0,5221 \\
\hline Caso A6 & 17,6 & 3,874 & 0,7355 & 0,5222 \\
\hline Caso B1 & 21,6 & 1,981 & 0,8997 & 0,8063 \\
\hline Caso B2 & 21,6 & 1,966 & 0,906 & 0,808 \\
\hline Caso C1 & 20 & 2,923 & 0,8354 & 0,6899 \\
\hline Caso C2 & 20 & 2,973 & 0,8343 & 0,688 \\
\hline
\end{tabular}

Os casos tipo "A", isto é, os hidráulicos-diretos, tem um tempo operacional médio em torno de 17,5 anos, enquanto os casos multiplexados possuem o tempo operacional médio de 21,6 anos, e os casos do tipo "C", isto é, de acionamento elétrico, 20 anos. 
A taxa de falha do DSSS utilizada para o cálculo dos casos tipo "C" foram os mesmos utilizados para os casos tipo "A" e "B", mesmo sendo uma outra válvula a ser utilizada. Porém, o estudo da NTNU (SEIME, 2012) apresentou um modelo para extrapolação de dados de uma tecnologia existente para o processo de qualificação de uma nova tecnologia. Estes passos seriam:

1. Listar todas os modos de falha da tecnologia existente;

2. Copiar esta lista para a nova tecnologia

3. Rever a lista, na perspectiva da nova tecnologia

4. Remover os modos de falha não relacionados à nova tecnologia e acrescentar novos modos de falha, caso necessário

5. Achar as correspondentes causas de falha para cada modo de falha

Como, para este estudo, os dois modos de falha utilizados nos casos onde a DSSS é acionado hidraulicamente foram PLC (falha de fechamento prematuro) e FTO (falha em abrir quando solicitada), estes também podem ser usados para o caso de acionamento elétrico e, por falta de histórico, utilizar o mesmo valor da taxa de falha. 


\section{CONCLUSÕES E RECOMENDAÇÕES}

\subsection{Conclusões}

Este trabalho teve como objetivo realizar a comparação de confiabilidades entre diferentes sistemas de dispositivos de segurança de sub-superfície, assim como diferentes configurações, com uma visão mais focada na perda de produção do que na segurança.

A metodologia utilizada foi o processo de Markov contínuo. A análise Markoviana constitui-se em uma técnica de modelagem e análise dinâmicas de confiabilidade e disponibilidade de sistemas. O comportamento da confiabilidade de um sistema é representado usando-se um diagrama de transições entre estados, o qual consiste em um conjunto de estados discretos nos quais o sistema pode se encontrar em um determinado momento, e define as taxas segundo as quais transições entre esses estados podem ocorrer. Desta forma, modelos Markovianos consistem em representações de cadeias de eventos, ou seja, transições dentro do sistema que, no contexto da análise de confiabilidade e disponibilidade, correspondem a sequências de falhas e reparos.

Para a realização das simulações, foi utilizado o software E\&P Office, um software desenvolvido em parceria entra a Petrobras e o departamento de engenharia de produção da Universidade Federal de Pernambuco - UFPE. O software permite a montagem dos diagramas de transição de estados, e a geração das curvas de confiabilidade a partir dos dados de entrada (estados possíveis, taxas de falha de transição de um estado para outro, situação do sistema em cada estado - disponível ou indisponível).

Além disso, também houve um levantamento do que seria uma boa definição para o conceito de falha. Foi visto quem a definição de falha como "uma condição insatisfatória é válida", porém insuficiente para a maioria dos casos apresentados. Pela complexidade do assunto, a premissa escolhida para a realização do estudo foi que considerar o sistema em paralelo se encontre ativo para quase todos os casos (somente o caso A6 foi diferente), e assim pode-se assumir todo o sistema como foi projetado para a efetividade dos equipamentos em paralelo serem notadas e levadas em consideração na solução dos problemas. Além disso, foram utilizados os conceitos de falha da ISO 14224 "PLC" - falha de fechamento 
prematuro - e "FTO" - falha em abrir quando solicitada - como sendo as falhas relevantes da DSSS para este estudo.

Analisando somente os sistemas hidráulicos diretos, não se percebe muita vantagem (aumento da confiabilidade) nos sistemas redundantes, quando comparado ao sistema sem redundância. Este fato acorre basicamente porque nos sistemas apresentados, a taxa de falha que se apresentou dominante foi a dos equipamentos em série, principalmente por causa do valor da taxa de falha obtido para o equipamento HPU, que está uma ordem de grandeza maior do que os outros equipamentos. Esta característica também foi verificada tanto para os sistemas multiplexados como para os sistemas elétricos.

O valor da taxa de falha para as linhas de controle, instaladas dentro do poço, no anular coluna de produção - revestimento de produção, é consideravelmente baixo, quando comparado aos outros equipamentos do sistema. Esta informação pode afetar diretamente os resultados do trabalho, pois a linha de controle é um equipamento que permite a possibilidade de se ter em paralelo, com a perspectiva de um aumento da confiabilidade do sistema. Porém, como a taxa de falha é baixa, outros equipamentos se sobressaem e a inclusão de uma linha de controle em paralelo não aumenta os valores de confiabilidade como esperado. Para a utilização destes estudos é importante realizar uma verificação dos valores para representar mais fielmente os dados do operador em questão, já que cada empresa tem suas peculiaridades, seus sistemas, seus históricos e, consequentemente, suas taxas de falha.

Por outro lado, a taxa de falha da HPU utilizada com base no OREDA se mostrou bem relevante quando comparado com todos os outros equipamentos dos sistemas, e como este equipamento se encontra sempre em série, qualquer aumento da confiabilidade deste equipamento tem bastante relevância no aumento da confiabilidade do sistema como um todo. Da mesma forma, é importante a verificação destes valores no caso de utilização destes números na vida real pois, da mesma forma, cada operador tem suas taxas de falha mais coerentes com seus sistemas utilizados.

O sistema multiplexado apresentou uma confiabilidade bem maior do que os sistemas hidráulicos diretos durante toda a vida produtiva do poço. Esta característica se deve principalmente pela presença de acumuladores hidráulicos no SCM, o que possibilita uma maior continuidade das operações com uma maior 
combinação de falhas de equipamentos do sistema. Atualmente os SCMs são projetados para serem trocados no caso de falha, porém esta possibilidade não foi contemplada neste estudo (assim como nenhuma outra manutenção corretiva e troca de equipamentos de nenhum sistema proposto).

Os sistemas elétricos também se mostraram mais confiáveis do que os sistemas hidráulicos-diretos, porém menos confiáveis do que os sistemas multiplexados com acionamento hidráulico.

O sistema multiplexado apresentou uma confiabilidade, após 24 anos de operação, da mesma ordem de 7 anos de operação dos sistemas hidráulicosdireto, enquanto o sistema elétrico direto apresentou uma confiabilidade, após 24 anos de operação, da mesma ordem de 14 anos de operação dos sistemas hidráulicos-direto.

\subsection{Recomendações para Próximos Trabalhos}

Todas as análises foram realizadas com base nos dados do OREDA, que contém dados até 2009. Uma recomendação seria realizar uma coleta das informações mais recentes para atualizar os resultados.

Os equipamentos HPU e as linhas hidráulicas se mostraram bastante relevantes para a confiabilidade do sistema, levando em consideração os dados obtidos através do OREDA. Foram utilizados, para estes dois equipamentos, taxas de falha de ordem de grandeza diferentes, e uma análise mais detalhada destas taxas de falha, visando obter um maior refinamento dos dados e dos resultados, será uma importante continuidade deste trabalho.

Muitos dos sistemas de acionamento das válvulas de segurança de subsuperfície, atualmente utilizados na indústria, contém manifolds submarinos como parte do sistema. Neste estudo, não levamos em consideração nenhum manifold em nenhum modelo apresentado, o que poderá ser uma frente de estudo.

Uma ferramenta interessante do estudo de confiabilidade de sistemas através de processos de Markov é a possibilidade de inclusão de manutenção de partes do sistema, estando ele em operação (e, consequentemente, causando a parada do sistema) ou estando em stand by (o que não ocasionaria a interrupção da operação do sistema). Apesar de, em um poço de petróleo, a manutenção corretiva ser muito custosa, principalmente quando estamos falando de poços 
offshore de completação molhada, existem equipamentos em esta manutenção é possível. Estas operações de manutenção não foram foco de estudo deste trabalho, porém sua continuidade com a inclusão de reparos em parte do sistema, seja em stand by, seja em operação, é uma possibilidade e uma contribuição para a comunidade.

Outro ponto que não foi levado em consideração neste trabalho foi a realização de testes do sistema, uma vez que quando estes testes existem, a confiabilidade do sistema pode ser afetada e, uma vez o sistema testado, poderíamos até considerarmos uma "mudança de estado" do sistema. Atualmente os testes do sistema de controle do DSSS são voltados para a segurança, isto é, são realizados com o intuito de avaliar se há algum vazamento no sistema na necessidade de fechamento da válvula. 


\section{REFERÊNCIAS BIBLIOGRÁFICAS}

ACCIOLY, R. M. S. Análise da duração do tempo de vida de bombas centrífugas submersas. 1995. Dissertação (Mestrado em Engenharia de Produção)-COPPE, UFRJ, Rio de Janeiro, 1995.

ALVES, A. L. Disponibilidade instantânea de poços submarinos durante a fase de produção: visão de segurança operacional. 2012. Dissertação (Mestrado em Engenharia Oceânica)-COPPE, UFRJ, Rio de Janeiro, 2012.

AMERICAN PETROLEUM INSTITUTE. API RP 14B: design, installation, repair and operation of subsurface safety valve systems. Washington, 2012.

AMERICAN PETROLEUM INSTITUTE. API Specification 14A: specification for subsurface safety valve equipment. Washington, 2005.

BANE, D. E.; PEOPLES, Brock. OTC 19870: subsurface safety valve control system for ultradeepwater applications. In: OFFSHORE TECHNOLOGY CONFERENCE, 2009, Houston. Papers... Houston: OTC, 2009.

CABRAL, P. Erros e incertezas nas medições. IEP: Senhora da Hora; ISEP: Porto, 2004. Disponível em: 〈http://www.peb.ufrj.br/cursos/ErrosIncertezas.pdf〉. Acesso em: dez. 2015.

CARVALHO, M. H. Simulação do impacto da disponibilidade de sistemas no retorno economico e produção de petróleo. 2011. Dissertação (Mestrado em Ciências e Engenharia de Petróleo)-Universidade Estadual de Campinas, Campinas, 2011.

EXPROSOFT. Risk analysis of subsea wells completed with or without a surface controlled subsurface safety valve (SCSSV): study update and revision 1. Trondheim, 2012.

FERNÁNDEZ Y FERNÁNDEZ, Eloi; PEDROSA JUNIOR, Oswaldo A.; PINHO, António Correia de. Dicionário do petróleo em lingua portuguesa: exploração e produção de petróleo e gás. Rio de Janeiro: PUC-Rio: Lexikon, 2009.

FONSECA, T. C. Metodologia de análise de integridade para projetos de poços de desenvolvimento da produção. 2012. Dissertação (Mestrado em Engenharia Mecânica)-Universidade Estadual de Campinas, Campinas, 2012.

FROTA, H. M. Desenvolvimento de método para planejamento da manutenção de poços petrolíferos em águas profundas. 2003. Dissertação (Mestrado em Engenharia de Reservatório e de Exploração)-Universidade Estadual do Norte Fluminense, Macaé, 2003.

GARCIA, P. et al. Optimizing downhole safety valve test scheduling using a multiobjective generic algorithm: (PSAM-0174). In: INTERNATIONAL CONFERENCE ON PROBABILISTIC SAFETY ASSESSMENT \& 
MANAGEMENT (PSAM), 8., 2006, New Orleans. Proceedings... New York: ASME, 2006.

IBE, O. C. Markov processes for stochastic modeling. Londres: Elsevier, 2013.

INTERNATIONAL ORGANIZATION FOR STANDARDIZATION. ISO 14224:2006: petroleum, petrochemical and natural gas industries: collection and exchange of reliability and maintenance data for equipment. Geneva, 2006.

LAFRAIA, J. R. Manual de confiabilidade, mantenabilidade e disponibilidade. Rio de Janeiro: Qualitymark, 2001.

LEWIS, E. E. Introduction to reliability engineering. New York: John Wiley \& Sons, 1996.

MEDLEY, E. L. Experience with surface controlled sub-surface safety valves. In: SPE EUROPEAN PETROLEUM CONFERENCE, 1978, London. Papers... London: SPE, 1978.

MEYER, P. L. Probabilidade: aplicações à Estatística. Rio de Janeiro: LTC, 1984.

MOLNES, E. et al. Reliability of surface controlled subsurface safety valves, phase III - main report. Trondheim: SINTEF, 1989.

MOLNES, E. Risk analysis of subsea wells completed with or without a surface controlled subsurface safety valve (SCSSV). Trondheim: Exprosoft, 2004.

MOREIRA, J. R. F. Reliability of subsea completion systems. 1993. Tese (Doutorado em )-Cranfield Institute of Technology, Cranfield, 1993.

MOREIRA, J. R. F.; JORGE, N. M. O estudo de confiabilidade e análise de risco de completação submarina, enfoque poço isolado e uso de DHSV. Rio de Janeiro: PETROBRAS, 2004.

MOUBRAY, J. Reliability-centered maintenance. New York: Industrial Press, 1997.

NORSOK D-10: well integrity in drilling and well operations. Lysaker: Standards Norway, 2013.

NOWLAN, F.; HEAP, H. Reliability-centered maintenance. Washington: Dolby Access, 1978.

SEIME, O. J. Reliability assessment of an electrical downhole safety valve. 2012. Project Thesis (Master Programme in Subsea Technology)-Norwegian University of Science and Technology, Trondheim, 2012. 
SIMÕES FILHO, S. Análise de confiabilidade e custo do ciclo de vida como critério para decisão do sistema de segurança. 1996. Dissertação (Mestrado em Engenharia de Produção)-COPPE, UFRJ, Rio de Janeiro, 1996.

SINTEF. OREDA (Offshore Reliability Data): handbook 2009. 5th ed. Norway: OREDA, 2009.

TAKASHINA, N. T. O conceito de barreira de segurança e sua confiabilidade em um poço de petróleo. São Paulo: IBP, 1987. 